\title{
Identifying HIV-1 RNA splice variant protein interactomes using HyPR-MSsv
}

2

Rachel A. Knoener ${ }^{1,2}$, Edward L. Evans III², Jordan T. Becker², Mark Scalf ${ }^{1}$, Bayleigh E. Benner ${ }^{2}$, Nathan M. Sherer 2,4 , Lloyd M. Smith ${ }^{1,3,4}$

${ }^{1}$ Department of Chemistry, University of Wisconsin, Madison, Wisconsin, United States

${ }^{2}$ McArdle Laboratory for Cancer Research and Institute for Molecular Virology, University of Wisconsin, Madison, Wisconsin, United States

${ }^{3}$ Lead Contact

${ }^{4}$ Senior Author

${ }^{*}$ Correspondence: smith@chem.wisc.edu

\section{ABSTRACT}

HIV-1 generates unspliced (US), partially spliced (PS), and completely spliced (CS) classes of RNAs; each playing distinct roles in viral replication. Elucidating their host protein "interactomes" is crucial to understanding virus-host interplay. Here, we present HyPR-MS sv for isolation of US, PS, and CS transcripts from a single population of infected CD4+ T-cells and mass spectrometric identification of their in vivo protein interactomes. Analysis revealed 212 proteins differentially associated with the unique RNA classes; including, preferential association of regulators of RNA stability with US- and PS-transcripts and, unexpectedly, mitochondria-linked proteins with UStranscripts. Remarkably, $>80$ of these factors screened by siRNA knock-down impacted HIV-1 gene expression. Fluorescence microscopy confirmed several to co-localize with HIV-1 US RNA and exhibit changes in abundance and/or localization over the course of infection. This study validates HyPRMSsv for discovery of viral splice variant protein interactomes and provides an unprecedented resource of factors and pathways likely important to HIV-1 replication. 


\section{KEYWORDS}

28 HIV, splicing, proteomics, interactome, mass spectrometry, hybridization, viral, RNA binding proteins, 29 RNA metabolism, RNA imaging

\section{INTRODUCTION:}

32 The human immunodeficiency virus type 1 (HIV-1) uses the alternative splicing of a single primary RNA

33 transcript to produce three major classes of viral RNA variants: unspliced (US), partially spliced (PS),

34 and completely spliced (CS). The individual variants perform distinct roles during HIV-1 replication

35 through dynamic interactions with specific viral and host proteins (Coffin et al., 1997). These protein

36 "interactomes" guide the RNA through required cellular pathways encompassing splicing, RNA nuclear

37 export, mRNA translation, and packaging of full-length, US RNA genomes into progeny virions that

assemble at the plasma membrane. Each HIV-1 splice variant performs a distinct function and is thus

predicted to interface with a unique protein interactome.

41 HIV gene expression is traditionally divided into two phases referred to as "early" and "late". Early gene expression involves translation of auxiliary proteins Tat and Rev as well as the accessory protein Nef

43 from CS transcripts. Tat and Rev localize to the nucleus where Tat facilitates viral transcription and Rev

44 mediates nuclear export of intron-retaining US and PS transcripts. Late gene expression is marked by

45 translation of the US transcript to synthesize Gag and Gag-Pol capsid proteins and translation of PS

46 transcripts to generate Envelope glycoproteins as well as the Vpu, Vpr, and Vif immunomodulatory

47 factors.

49 HIV splicing generates vast numbers of splice variants, with over 50 proposed to be physiologically 50 significant (Emery et al., 2017; Ocwieja et al., 2012; Purcell and Martin, 1993; Vega et al., 2016). The 51 locations of splice donor and acceptor sites (Sertznig et al., 2018; Vega et al., 2016), the identities of 52 several cis- and trans- regulatory elements (Mahiet and Swanson, 2016; Sertznig et al., 2018; Stoltzfus, 
53 2009), and the transcript and protein product abundances needed for efficient viral replication (Cullen,

54 1991; Karn and Stoltzfus, 2012; Weinberger et al., 2005) are still topics of intensive investigation toward

55 the development of antiviral therapies.

57 Previous works have shown that the HIV splice variant classes interact differentially with both viral and

58 host proteins. For example, HIV-1 US and PS transcripts hijack the cellular CRM1-mediated nuclear

59 export pathway through the activities of Rev and a cis-acting RNA structure known as the Rev-

60 response element (RRE) (Pollard and Malim, 1998). Rev multimerizes on the RRE and recruits CRM1

61 to form a functional RNA export complex (Bai et al., 2014; Daugherty et al., 2008; Daugherty et al.,

62 2010; DiMattia et al., 2016; DiMattia et al., 2010; Fang et al., 2013). This is in contrast to CS transcripts that do not require Rev and recruit components of the NXF1/NXT1 export machinery, similar to the bulk of cellular fully-spliced mRNAs. A second example is HIV genome packaging wherein US transcripts are packaged into virions due to favored interactions between the Gag polyprotein and a structured RNA packaging signal known as "psi" in the 5' untranslated region of the US transcript (Berkowitz et al.,

67 1993; Lever et al., 1989; Luban and Goff, 1994). These binding sites are lost in PS and CS transcripts due to splicing (Purcell and Martin, 1993). Additional host factors are implicated as interactors in differential regulation of US, PS, and CS RNA transcripts (Bolinger and Boris-Lawrie, 2009; Freed and Mouland, 2006; Jin and Musier-Forsyth, 2019; Mbonye and Karn, 2014; McLaren et al., 2008; Meng

71 and Lever, 2013; Swanson and Malim, 2006). However, the list is far from complete.

In the current study, we describe successful isolation of the three major HIV-1 splice variant classes

74 from a single population of natively infected CD4+ T cells and define their distinct in vivo RNA-protein 75 interactomes using mass spectrometry. We identify over 200 proteins differentially associated with the 76 US, PS, and CS HIV splice variant pools, 116 of which are new virus-host interactors. Of these 77 proteins, gene-specific siRNA knockdown indicated $>80$ new effectors of HIV-1 RNA regulation. We 78 further demonstrate several instances of identified host protein co-localization with HIV RNA, and 
changes to the single-cell abundance and/or subcellular distribution of several identified host proteins over the course of HIV-1 infection. Collectively, we detail a powerful new approach for probing virushost interactions and use it to expose many new host factors with potential roles in the HIV-1 replication cycle.

\section{RESULTS:}

Purification of HIV-1 splice variant classes. We recently described HyPR-MS (Hybridization Purification of RNA-Protein Complexes Followed by Mass Spectrometry); a strategy to identify the in vivo protein interactomes of specific viral RNAs, IncRNAs, and mRNAs (Knoener et al., 2017; Spiniello

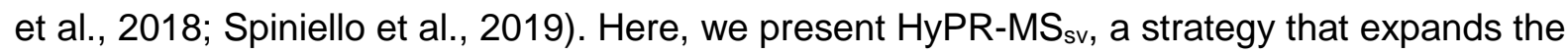
capabilities of HyPR-MS to differentiate in vivo protein interactomes for multiple splice variants (SV) derived from a single primary transcript and isolated from a single cell population. Applied here, we purified the three major classes of HIV-1 splice variants (unspliced (US), partially spliced (PS), and completely spliced (CS)) from a single population of infected Jurkat CD4+ T cells, then identified and characterized their protein interactomes using mass spectrometry.

To preserve in vivo viral RNA-protein complexes prior to cell lysis, Jurkat cultures were treated with formaldehyde at 48-hours post-infection (Multiplicity of Infection (MOI) of $\sim 1$ infectious units per cell). To isolate the US, PS, and CS RNA pools, three biotinylated capture oligonucleotides (CO's) were designed complementary to three distinct regions of the HIV RNA genome: intron-1 (unique to US), intron-2 (present in both US and PS), and the 3'-exon (present in US, PS, and CS) (Figure 1A, Table S1). Cell lysates were first depleted of the US HIV RNA through hybridization to the intron-1 CO, followed by its capture with streptavidin-coated magnetic beads, and subsequent release using toeholdmediated oligonucleotide displacement. Additional hybridization, capture and release steps were 


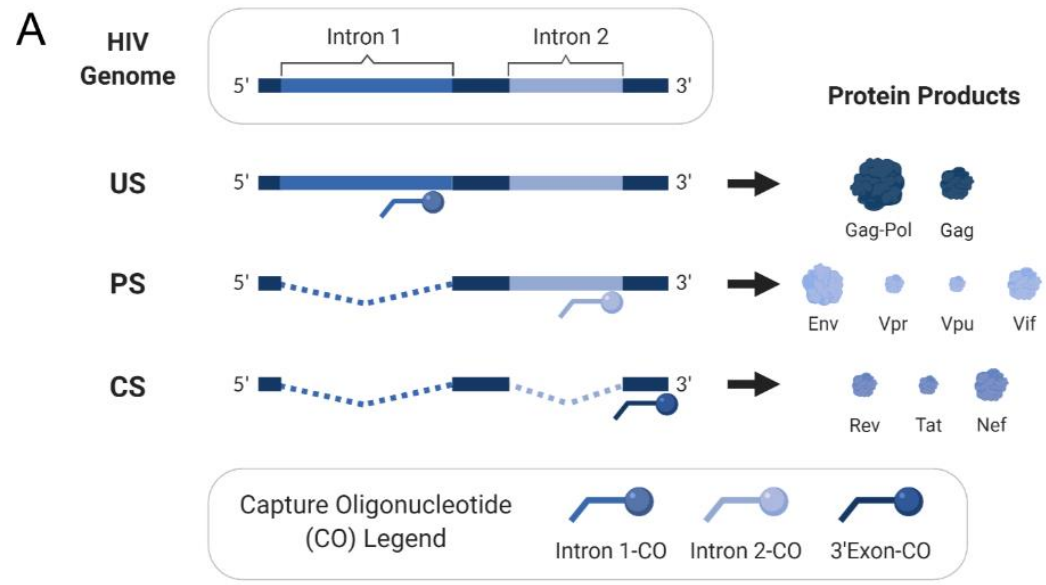

B

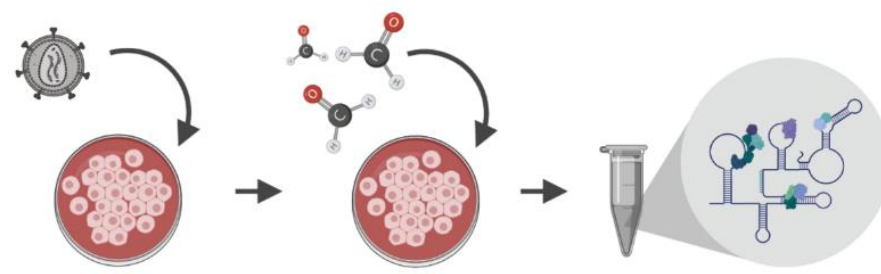

HIV Infect

Formaldehyde Crosslink
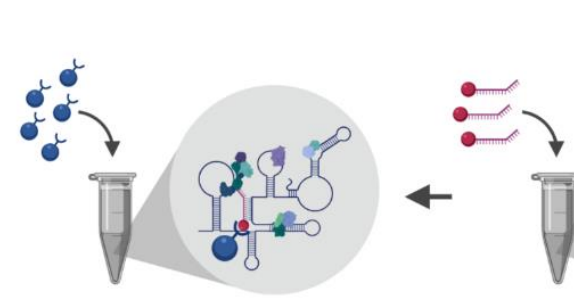

Capture with Streptavidin-Coated Magnetic Beads

Hybridization of $\mathrm{CO}$ to HIV RNA

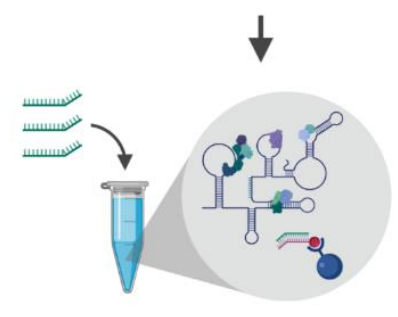

Toe-hold Mediated Release

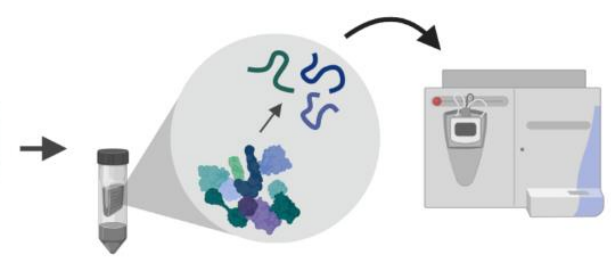

Trypsin Digestion of Proteins

Mass Spectrometry

C

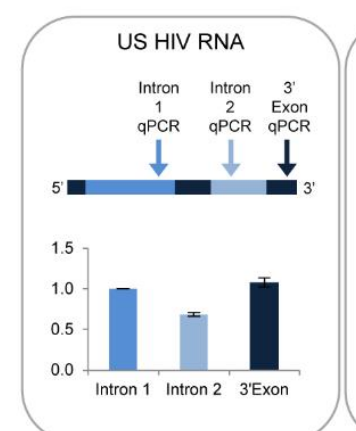

Lyse and Solubilize
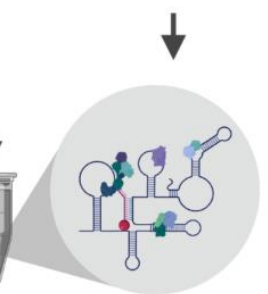

(n)

\begin{abstract}
.
\end{abstract}

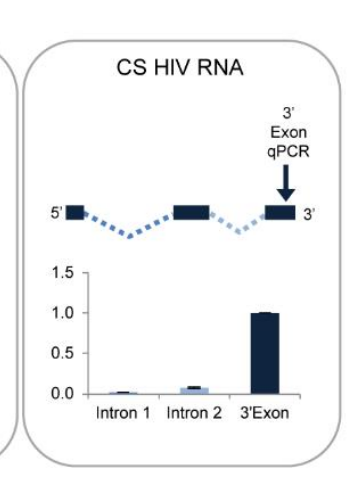


subsequently repeated iteratively using first the intron-2 $\mathrm{CO}$ and then the 3'-exon $\mathrm{CO}$ for isolation of

the PS and CS RNA pools, respectively. Once purified, proteins cross-linked to each isolated HIV RNA class were identified by mass spectrometry (Figure 1B).

RT-qPCR assays specific to intron 1, intron 2, and the 3'-exon (Table S1) were used to test RNA

capture specificity and efficiency. For three biological replicates of the US, PS, and CS captures, the

magnitude of amplification using each qPCR assay confirmed strong capture specificity for the desired splice variant class over the other two classes (Figure 1C, Table S2). Enrichment of HIV transcripts over a cellular control transcript $(G A P D H)$ was $>100$-fold (Figure S1A, Table S2). Capture efficiency

115 (the amount of each transcript depleted from the lysate after capture) was $>70 \%$ for each variant 116 (Figure S1B, Table S2).

Elucidation of unique protein interactomes for each HIV-1 splice variant class. To identify host proteins differentially interacting with the US, PS, and CS RNA pools, we isolated the in vivo crosslinked HIV RNA variants from three biological replicate experiments of $5 \times 10^{7}$ infected Jurkat cells;

121 with each replicate generated from a separate set of cultured cells and virus preparations. Interacting 122 proteins from the US, PS, and CS capture samples were purified, analyzed by bottom-up mass 123 spectrometry, then identified and quantified using search and label-free quantitation algorithms (Cox 124 and Mann, 2008; Tyanova et al., 2016). We determined which proteins preferentially associated with 125 each splice variant class by conducting three pairwise comparisons: US vs PS, US vs CS, and PS vs 126 CS. Using the Student's t-test and a permutation-based false discovery rate (FDR) of 5\%, we identified 127212 proteins that differentially interacted with one or more of the HIV splice variant classes; 101, 93, 128 and 68 proteins in the US, PS, and CS captures, respectively (Table S3). Hierarchical clustering was 129 used to organize the 212 proteins into a heat map for visualization. The associated dendrogram shows 130 the extent of similarity among the "interaction profiles" for each protein. This analysis revealed clusters 131 of proteins elevated for each individual class as well as proteins common to members of the three HIV 
splice variant classes. The most abundant of these were proteins preferentially associated with both the US and PS HIV transcripts but not the CS pool (45 proteins) (Figure 2A).

We used these interactome data to infer biological pathways potentially relevant to the regulation of each splice variant class. Using gene ontology (GO) term enrichment algorithms (Mi et al., 2017), we evaluated each interactome for enrichment of proteins involved in specific biological processes. This analysis revealed over-representation of several GO terms in the interactome of each splice variant class; some common to more than one class (Table S4, Figure 2B). Notable amongst these were nine 140 proteins known to regulate RNA stability, associated with both the US and PS, but not CS, transcripts 141 (FXR1, YBX1, YBX3, IGF2BP1, IGF2BP3, SYNCRIP, HNRNPR, YTHDF2, and UPF1). Proteins involved in mRNA splicing, and the regulation thereof, were also elevated in the US and PS relative to the CS capture samples (YBX1, SYNCRIP, HNRNPR, HNRNPL, BCAS2, RBMX, and MBNL1) but with less congruence. A subset of these proteins were elevated only in the US capture samples (HNRNPA2B1 and HNRNPK; negative regulators of splicing) or PS capture samples (DAZAP1 and enriched in both the US (12 proteins) and CS (18 proteins) interactomes. Interestingly, however, while the CS interactome included translation initiation proteins (as may be expected), the US interactome was enriched for proteins linked to mRNA translation in the mitochondria, with cellular component GO

151 term enrichment analysis further revealing 45 mitochondrion proteins enriched in the US RNA 152 interactome, 8 of which are mitochondrial nucleoid proteins (Figure 2C, Table S4). 
A

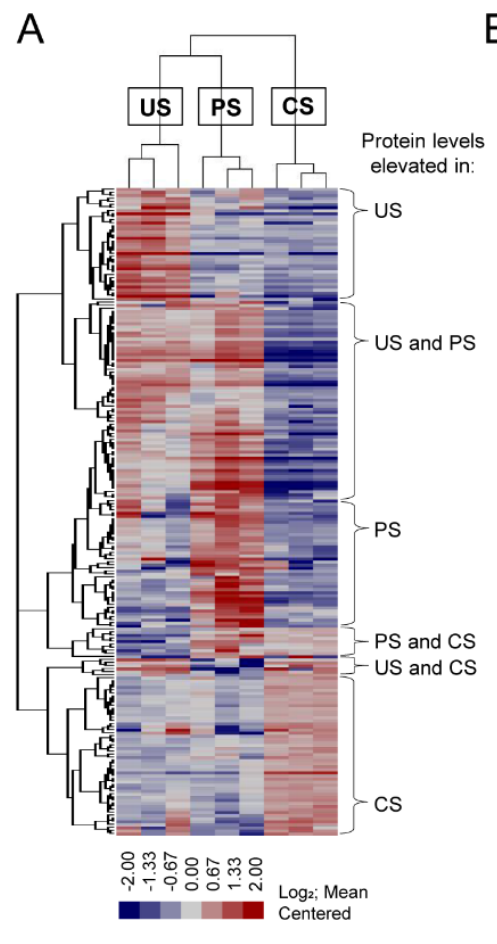

B

\begin{tabular}{|l|c|c|c|c|c|c|}
\hline \multirow{2}{*}{$\begin{array}{l}\text { Biological Process or Cellular } \\
\text { Component }\end{array}$} & \multicolumn{2}{|c|}{ US } & \multicolumn{2}{|c|}{ PS } & \multicolumn{2}{c|}{ CS } \\
\hline Crotein & p-value & $\begin{array}{c}\text { protein } \\
\#\end{array}$ & p-value & $\begin{array}{c}\text { protein } \\
\#\end{array}$ & p-value \\
\hline Coenzyyme metabolic process & 26 & $1 \times 10^{-13}$ & $\mathrm{NE}$ & $\mathrm{NE}$ & $\mathrm{NE}$ & $\mathrm{NE}$ \\
\hline Mitochondrial nucleiod & 14 & $4 \times 10^{-10}$ & $\mathrm{NE}$ & $\mathrm{NE}$ & $\mathrm{NE}$ & $\mathrm{NE}$ \\
\hline Regulation of mRNA stability & 8 & $1 \times 10^{-10}$ & $\mathrm{NE}$ & $\mathrm{NE}$ & $\mathrm{NE}$ & $\mathrm{NE}$ \\
\hline mRNA splicing; via spliceosome & 9 & $9 \times 10^{-9}$ & 9 & $7 \times 10^{-9}$ & $\mathrm{NE}$ & $\mathrm{NE}$ \\
\hline Regulation of mRNA splicing & 9 & $1 \times 10^{-5}$ & 9 & $9 \times 10^{-6}$ & $\mathrm{NE}$ & $\mathrm{NE}$ \\
\hline \multicolumn{1}{|c|}{ Positive regulation of mRNA splicing } & 5 & $1 \times 10^{-4}$ & 7 & $5 \times 10^{-7}$ & $\mathrm{NE}$ & $\mathrm{NE}$ \\
\hline Negative regulation of mRNA splicing & $\mathrm{NE}$ & $\mathrm{NE}$ & 3 & $2 \times 10^{-4}$ & $\mathrm{NE}$ & $\mathrm{NE}$ \\
\hline Chromosome condensation & 3 & $2 \times 10^{-4}$ & $\mathrm{NE}$ & $\mathrm{NE}$ & $\mathrm{NE}$ & $\mathrm{NE}$ \\
\hline Histone trimethylation & $\mathrm{NE}$ & $\mathrm{NE}$ & 6 & $6 \times 10^{-8}$ & $\mathrm{NE}$ & $\mathrm{NE}$ \\
\hline Nuclear Body & $\mathrm{NE}$ & $\mathrm{NE}$ & 3 & $8 \times 10^{-6}$ & $\mathrm{NE}$ & $\mathrm{NE}$ \\
\hline Post-transcriptional regulation of gene expression & 15 & $7 \times 10^{-9}$ & 14 & $4 \times 10^{-8}$ & 8 & $2 \times 10^{-4}$ \\
\hline Regulation of translation & 12 & $1 \times 10^{-7}$ & 12 & $7 \times 10^{-8}$ & 7 & $2 \times 10^{-4}$ \\
\hline Negative regulation of translation & 9 & $2 \times 10^{-8}$ & 9 & $1 \times 10^{-8}$ & $\mathrm{NE}$ & $\mathrm{NE}$ \\
\hline Translation & 12 & $4 \times 10^{-7}$ & $\mathrm{NE}$ & $\mathrm{NE}$ & 18 & $1 \times 10^{-15}$ \\
\hline Translation initiation & $\mathrm{NE}$ & $\mathrm{NE}$ & $\mathrm{NE}$ & $\mathrm{NE}$ & 12 & $2 \times 10^{-13}$ \\
\hline Mitochondrial translation & 7 & $2 \times 10^{-6}$ & $\mathrm{NE}$ & $\mathrm{NE}$ & $\mathrm{NE}$ & $\mathrm{NE}$ \\
\hline Cotranslational protein targeting to membrane & $\mathrm{NE}$ & $\mathrm{NE}$ & $\mathrm{NE}$ & $\mathrm{NE}$ & 10 & $4 \times 10^{-12}$ \\
\hline tRNA aminoacylation for protein translation & $\mathrm{NE}$ & $\mathrm{NE}$ & $\mathrm{NE}$ & $\mathrm{NE}$ & 4 & $3 \times 10^{-5}$ \\
\hline
\end{tabular}

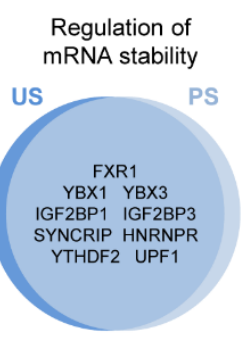

Regulation of translation

Nuclear Bodies

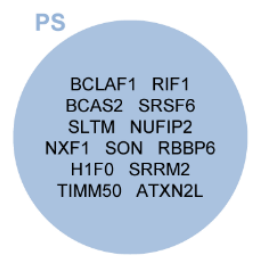

Thers

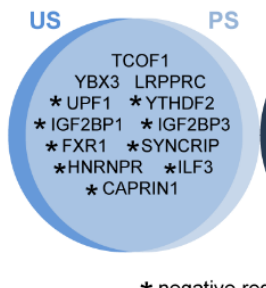

* negative regulation
mRNA splicing; via spliceosome

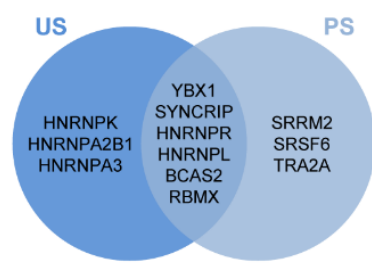

Regulation of mRNA splicing

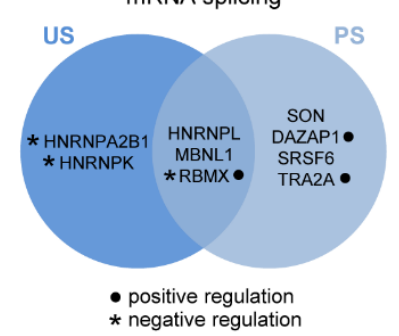

Translation

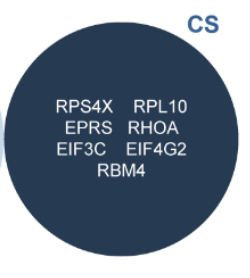

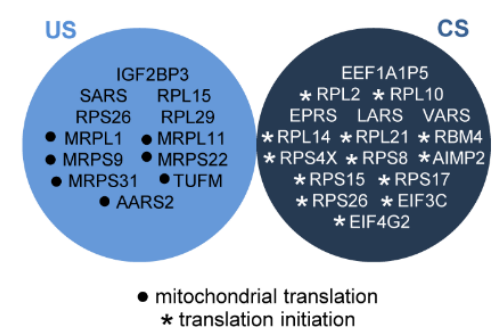

Figure 2: Determination and analysis of HIV splice variant protein interactomes. A. Heat map depicts relative intensities for each of the 212 proteins (rows) in each of the three biological replicates of the US, PS, and CS (columns) differential interactomes. B. Condensed list of gene ontology biological process or cellular component terms enriched in each of the HIV splice variant interactomes. The "protein \#" column indicates the number of proteins in the interactome that are annotated with the biological process indicated. The " $p$-value" column indicates the likelihood that the proteins of the biological process are present in each interactome by random chance and were provided by GO term enrichment software (Mi et al., 2017). A lower p-value suggests non-random over-representation of a biological process. "NE"= Not Enriched. C. Venn Diagrams of proteins annotated for biological processes or cellular components enriched in the splice variant differential interactomes. 
of viral US (Gag-CFP) and CS (mCherry) gene expression (Figures 3A and 3B) (Knoener et al., 2017).

Relative to a scrambled siRNA control, statistically significant changes ( $p$-value $<0.05$ ) to early $(C S)$ and/or late (US) gene expression were observed for a remarkable $69 \%$ (84 total) of the targeted host genes (Figure 3C; Table S7). The KD of 33 host proteins affected the expression of US and CS protein products in the same direction (either both increased or both decreased) and with approximately the same magnitude. By comparing mCherry:CFP fluorescence ratios for each protein KD to the negative control, we determined that CS and US protein expression were differentially affected by KD of 51 host proteins; for 26 of the proteins the expression changes were in the same direction but with different magnitudes; for 18 only the expression of the US RNA protein product was affected; and for 7 only the expression of the CS RNA protein product was affected (Figure 3C, Table S7). Based on the direction of the changes in HIV-1 gene expression (increased or decreased), we categorized 71 host genes as putative "negative" effectors and 15 as putative "positive" effectors (Figure 3C, Table S7). Interestingly,

171 of the 16 negative effectors, 10 were implicated in mitochondria-associated pathways based on GO analysis; of those ten, nine were identified by HyPR-MS sv $_{\text {to }}$ to prefentially interact with the US HIV RNA

173 (Tables S4 and S7).

HyPR-MS sv candidates co-localize with US HIV RNA at distinct subcellular locations.

176 We selected a subset of 20 HyPR-MS sv identified host proteins for further validation studies. This

177 subset was, in part, chosen based on the commercial availability of antibodies that allowed for

178 immunoblot- and/or immunofluorescence-based detection of the host proteins (Table S8), and included

179 five proteins linked to mitochondria (LRPPRC, DHX30, MBOAT7, GSDMA, and DLD; all negative 180 effectors of US RNA gene expression); ten genes encoding proteins with functions related to mRNA 181 processing, localization and stability (FAM120A, HNRNPR, IGF2BP3, G3BP1, RBMX, CSDE1, SRSF6, 182 SRRM2, RBM4, and RPL15; the majority of which were positive effectors of either US or CS gene 183 expression); and five additional proteins that had not previously been linked to RNA regulation 184 (TRIM56, BUB3, DNM2, DYNC1H1 and NCLN) (Figure 3D, Table S7). Fifteen of the 20 proteins were 
A

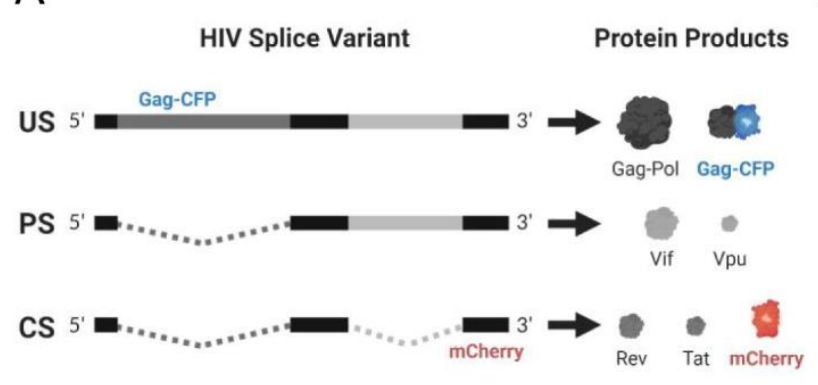

C

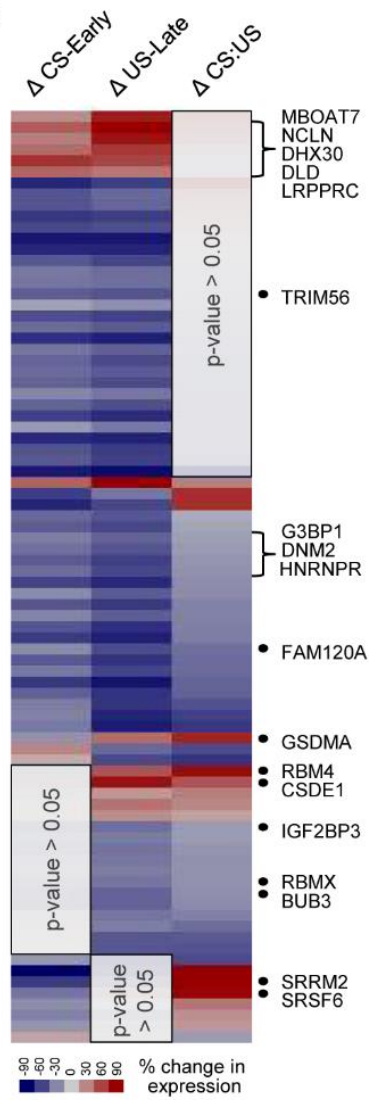

$\mathrm{D}$
B

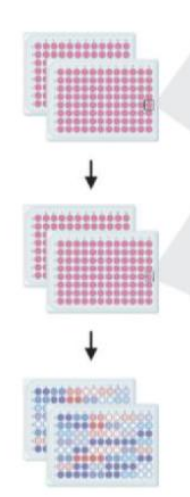

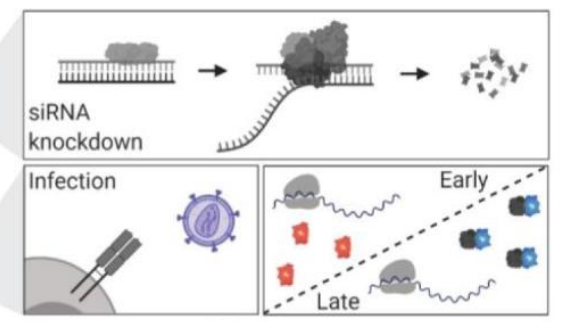

Fluorescence detection

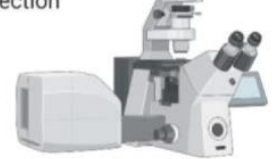

\begin{tabular}{|c|c|c|c|c|c|}
\hline \multirow{2}{*}{\multicolumn{2}{|c|}{ Protein }} & \multirow[b]{2}{*}{$\begin{array}{l}\text { HIV splice } \\
\text { variant }\end{array}$} & \multicolumn{2}{|c|}{$\begin{array}{c}\text { Effect of siRNA } \\
\text { knockdown }\end{array}$} & \multirow[b]{2}{*}{ General protein function } \\
\hline & & & $\begin{array}{l}\text { Early } \\
\text { (CS) }\end{array}$ & $\begin{array}{l}\text { Late } \\
\text { (US) }\end{array}$ & \\
\hline \multirow{5}{*}{$\begin{array}{l}\frac{\pi}{\frac{\pi}{5}} \\
\frac{0}{0} \\
0 \\
\frac{1}{0} \\
\frac{0}{2} \\
\frac{1}{\Sigma}\end{array}$} & LRPPRC & US, PS & Inc & Inc & Mitochondrial and nuclear; potential role in mRNA nuclear export \\
\hline & $\mathrm{DH} \times 30$ & US, PS & Inc & Inc & Mitochondrial; RNA helicase \\
\hline & MBOAT7 & US, PS & Inc & Inc & Localizes to ER and mitochondrial associated membranes (MAMs) \\
\hline & GSDMA & us & Dec & Inc & Mitochondrial lipid binding; apoptotic process \\
\hline & DLD & cs & Inc & Inc & Mitochondrial and nuclear; lipoamide dehydrogenase \\
\hline \multirow{3}{*}{ 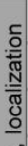 } & FAM120A & US, PS & Dec & Dec & mRNA transport \\
\hline & HNRNPR & US, PS & Dec & Dec & mRNA processing \\
\hline & IGF2BP3 & US, PS & NC & Dec & Regulation of mRNA stability and translation \\
\hline \multirow{2}{*}{$\frac{3}{\frac{\pi}{\pi}}$} & G3BP1 & US, PS & Dec & Dec & Helicase; stress granule assembly \\
\hline & RBMX & US, PS & NC & Dec & mRNA splicing \\
\hline \multirow{4}{*}{$\begin{array}{l}\frac{0}{0} \\
\frac{c}{0} \\
\frac{0}{0} \\
0 \\
\frac{5}{2} \\
\frac{r}{\varepsilon}\end{array}$} & CSDE1 & US, PS & NC & Inc & Regulation of mRNA stability \\
\hline & SRSF6 & PS & Dec & NC & mRNA splicing \\
\hline & SRRM2 & PS & Dec & NC & mRNA splicing \\
\hline & RBM4 & cs & NC & Inc & Regulation of mRNA splicing and translation \\
\hline \multirow{4}{*}{ 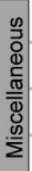 } & TRIM56 & us & Dec & Dec & E3 ubiquitin - protein ligase; innate antiviral immunity \\
\hline & BUB3 & PS & NC & Dec & Mitotic spindle assembly checkpoint \\
\hline & DNM2 & cs & Dec & Dec & Microtubule - associated; vesicular trafficking \\
\hline & NCLN & cs & Inc & Inc & Protein stabilization \\
\hline
\end{tabular}

Figure 3: Screen for host protein effects on early and late HIV gene expression. A. The HIV-1 reporter virus used contains a Gag open-reading frame (ORF) with three copies, in tandem, of a cyan fluorescent protein (CFP) reporter and an mCherry reporter in the Nef ORF. B. In 96-well plates, 293TACT-YFP cells were transfected with gene-specific siRNAs for 4 hours, 48-hours later they were transfected again for 4 hours followed by incubation with the HIV reporter virus. The cells were then fixed at 48-hours post incubation. Fluorescence microscopy was used to quantify CFP and mCherry. C. Heatmap of HIV gene expression changes after siRNA knockdown of host proteins. Eighty-four of 121 proteins showed statistically significant changes in early and/or late HIV gene expression ( $p$-value $<0.05$ ). D. Twenty proteins were selected for confirmation of KD efficacy using western blot. The table summarizes the HyPR-MS and KD results for the proteins for which the WB or IF showed significant KD of the targeted host protein (18 proteins). Note: KDs detection for proteins IGF2BP3, SRRM2, and DNM2 were unsuccessful by WB but were later shown to be effective using the same antibodies in fixed cell immunofluorescence (Tables S9 and S11). 
detected by immunoblot and siRNA KD was confirmed (31 to $95 \%$ relative to negative control siRNA)

(Figure S2). IGF2BP3, SRRM2, DNM2, RPL15, and DYNC1H1 KDs were not confirmed by immunoblot (Tables S9).

US HIV RNA-protein interactions may commence as early as production of the nascent HIV transcript in the nucleus or as late as virus particle formation at the plasma membrane. To determine potential

192 sites of interaction, we used 3-color combined fluorescence in situ hybridization / immunofluorescence 193 (FISH/IF) single-cell imaging to show host factor subcellular localization relative to US RNA and viral 194 Gag proteins (Figures 4A and S3). Cells were infected with an HIV-1 reporter virus (HIV-1 E-R-CFP) 195 allowing for identification of infected cells and confirmation of specificity of the US RNA FISH probes 196 (Stellaris FISH probe set specific to intron-1 (Table S10)) and Gag antibody (anti-p24Gag (Table S8)). 197 Host proteins were detected using the primary antibodies employed for our immunoblot analysis (Table 198 S8); with 17 of the 18 host proteins (all but DLD) detected by IF and showing greater than $40 \%$ 199 decreases in IF signal after host protein siRNA KD. This imaging-based analysis also allowed 200 verification of the efficacy of siRNA KD for three of the host proteins (IGF2BP3, SRRM2, and DNM2) 201 that we had been unable to detect using immunoblot (Table S11).

FISH/IF was performed on HeLa cells 48-hours post-infection to localize US RNA, Gag, and each of the $17 \mathrm{HyPR}_{\mathrm{MS}}$ identified host proteins. Analysis by single-cell fluorescence microscopy showed consistent co-localization of US HIV-1 RNA with 11 of the proteins (Figures 4A and S3), with four (HNRNPR, RBMX, RBM4, MBOAT7) predominantly localized to the nucleus or near the nuclear membrane and seven (FAM120A, IGF2BP3, MOV10, TRIM56, DNM2, LRPPRC, CSDE1)

208 predominantly localized to the cytoplasm in uninfected cells (Figure S4). In infected cells, we observed 209 five recurrent US RNA-host protein co-localization phenotypes: (1) at nuclear puncta; (2) at puncta 210 proximal to the nuclear membrane; (3) at cytoplasmic puncta; (4) at large, cytoplasmic complexes 211 reminiscent of stress granules, and; (5) at the plasma membrane (Figures 4A and S3). In the nucleus, 
A
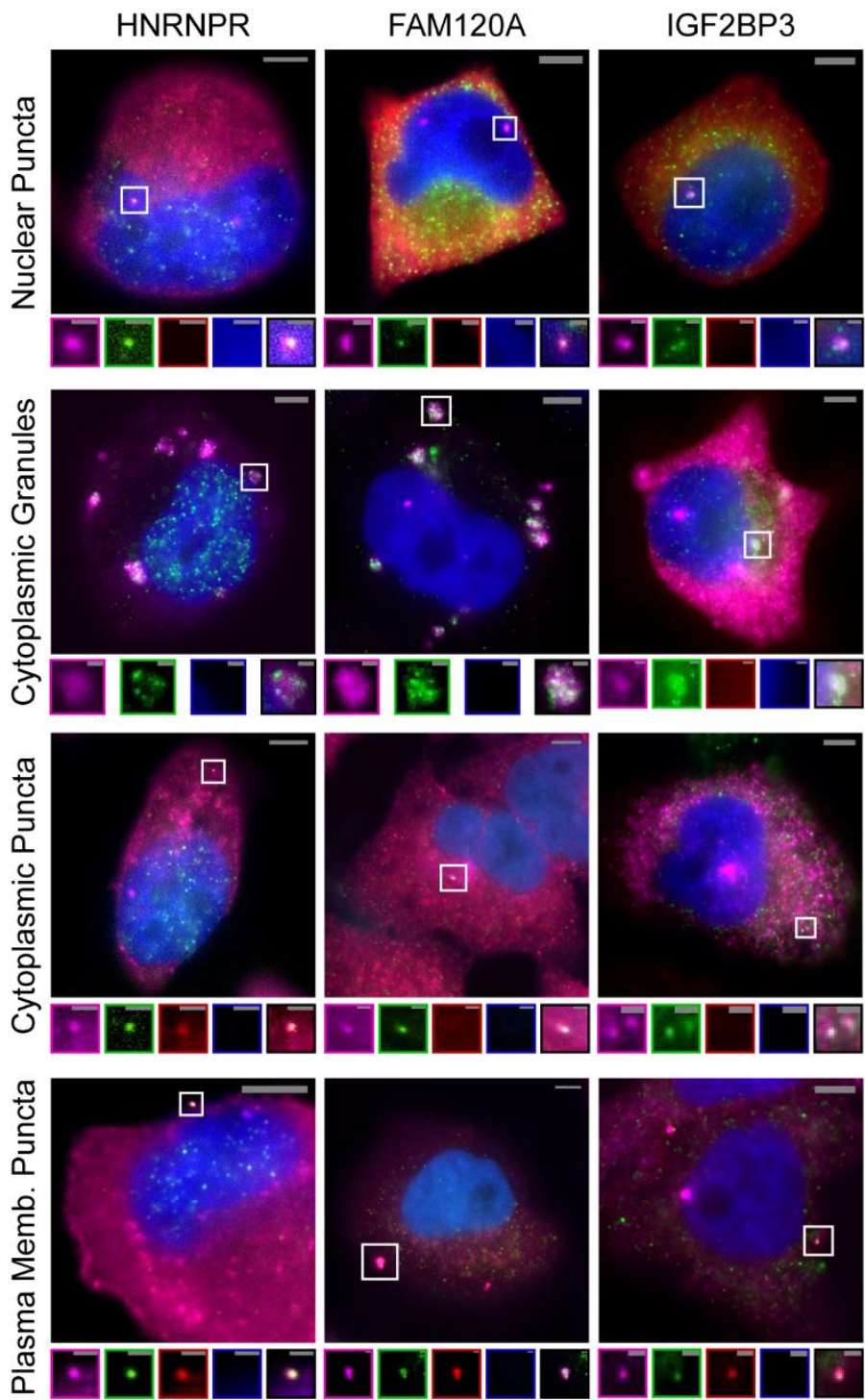

$\mathrm{B}$

\begin{tabular}{|c|c|c|c|c|c|c|}
\hline \multicolumn{2}{|c|}{ Host Protein } & $\begin{array}{l}\text { \# Cells } \\
\text { Evaluated }\end{array}$ & $\begin{array}{l}\text { Nuclear } \\
\text { Puncta }\end{array}$ & $\begin{array}{l}\text { Peri nuclear } \\
\text { Puncta }\end{array}$ & $\begin{array}{l}\text { Cyto plasmic } \\
\text { Puncta }\end{array}$ & $\begin{array}{l}\text { Plasma } \\
\text { Membrane }\end{array}$ \\
\hline \multirow{7}{*}{ 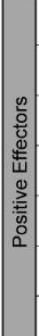 } & HNRNPR & 41 & $80 \%$ & $41 \%$ & $90 \%$ & $68 \%$ \\
\hline & FAM120A & 38 & $8 \%$ & $5 \%$ & $97 \%$ & $83 \%$ \\
\hline & IGF2BP3 & 45 & $4 \%$ & $0 \%$ & $98 \%$ & $68 \%$ \\
\hline & MOV10 & 45 & $0 \%$ & $20 \%$ & $84 \%$ & $83 \%$ \\
\hline & RBMX & 17 & $82 \%$ & $41 \%$ & $76 \%$ & $50 \%$ \\
\hline & DNM2 & 29 & $7 \%$ & $0 \%$ & $100 \%$ & $100 \%$ \\
\hline & TRIM56 & 49 & $0 \%$ & $8 \%$ & $71 \%$ & $31 \%$ \\
\hline \multirow{4}{*}{ 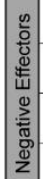 } & MBOAT7 & 47 & $57 \%$ & $91 \%$ & $91 \%$ & $0 \%$ \\
\hline & LRPPRC & 39 & $28 \%$ & $54 \%$ & $79 \%$ & $0 \%$ \\
\hline & RBM4 & 23 & $96 \%$ & $0 \%$ & $74 \%$ & $100 \%$ \\
\hline & CSDE1 & 41 & $7 \%$ & $29 \%$ & $93 \%$ & $80 \%$ \\
\hline
\end{tabular}
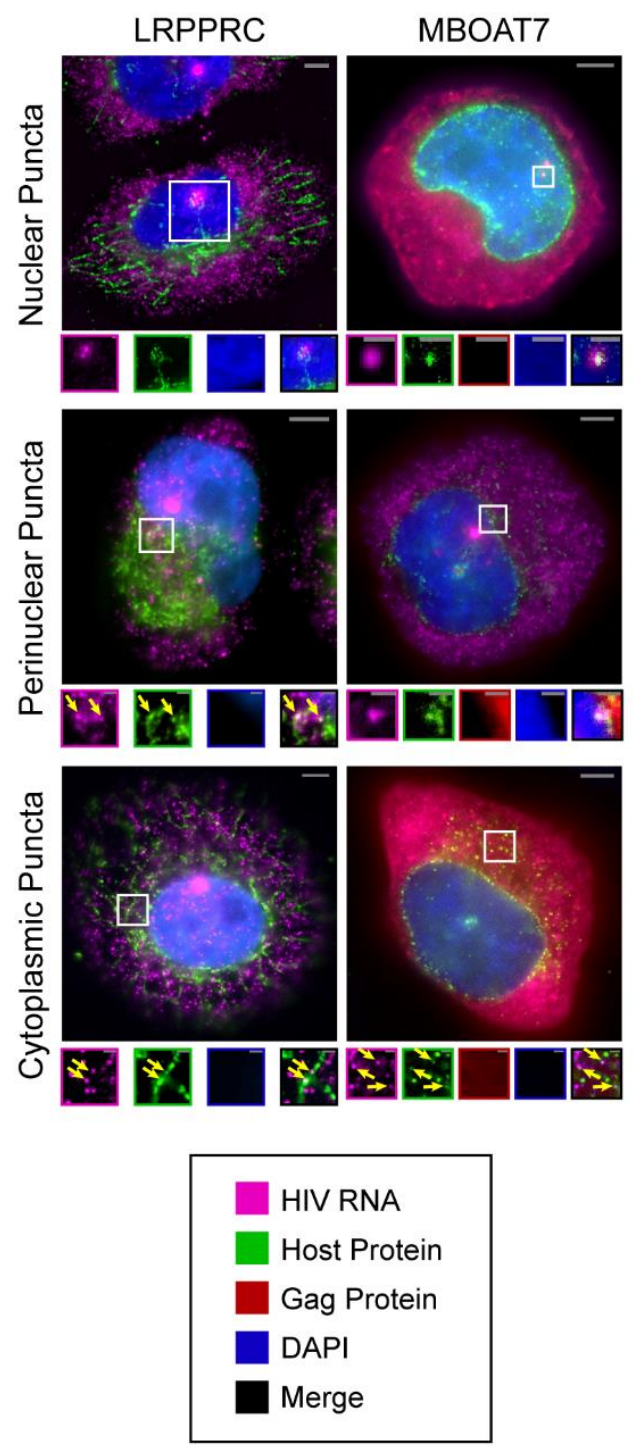

C

HyPR-MS $_{\text {SV }}$

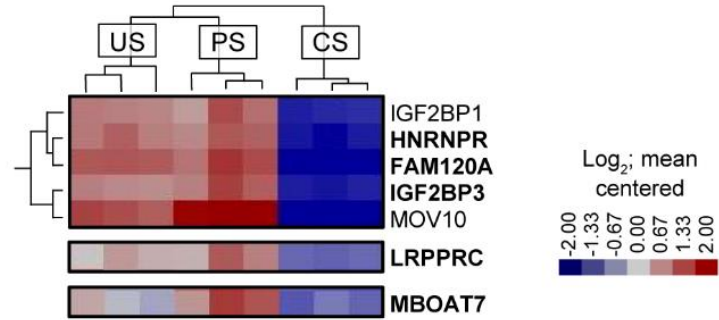

$\mathrm{D}$

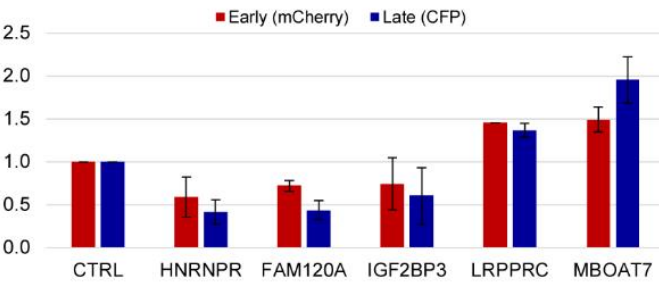


Figure 4: US HIV RNA co-localizes with positive and negative effectors at multiple sites within the cell. A. Representative images of co-localization phenotypes observed using FISH/IF. For each, a merged image of a cell highlighting a site of co-localization (white square) is shown. Enlarged regions of interest (ROI) of each fluorescence channel are displayed in the associated small panels to separate overlapping US HIV RNA, host protein, HIV Gag polyprotein, and DAPI signals. Some images were obtained from experimental replicates that did not include Gag IF and therefore do not include images from the corresponding channel. Note: Brightness and contrast settings were adjusted individually for each color channel of the images to effectively show co-localization. These settings may be different for the ROls. B. Table showing the frequency of observing a particular co-localization phenotype of US HIV RNA with each of 11 host proteins. Frequencies are displayed as the percentage of cells observed with each co-localization phenotype. C. Regions-of-interest from the HyPR-MS, hierarchically clustered heatmap (Fig. 2A) showing the close relation of HNRNPR, FAM120A and IGF2BP3 interaction profiles; each preferentially interacted with US and PS HIV RNA. D. Data for proteins of interest from the siRNA KD screen. HIV gene expression decreases for HNRNPR, FAM120A, and IGF2BP3 upon KD with a greater decrease in late gene expression than in early. For mitochondria-related proteins LRPPRC and MBOAT7, HIV gene expression increases upon KD of the host protein.

213 we typically observed one or two bright US RNA puncta per cell, consistent with prior reports describing 214 sites of active HIV-1 transcription (Puray-Chavez et al., 2017). Puncta proximal to the nuclear

215 membrane and cytoplasmic puncta were smaller, more numerous, and of lower intensity. Cytoplasmic 216 granules were large with moderate intensity accumulations of US HIV RNA surrounded by or spotted 217 with host protein. Plasma membrane puncta were variable in size and intensity and often co-localized 218 with Gag, thus likely represent virion assembly sites (Figures 4A and S3).

We quantified the frequency of each co-localization phenotype for 17-52 cells per antibody (Figure 4B,

221 Table S12), excluding cytoplasmic granules that were only rarely observed. The data revealed that 222 proteins that predominantly localize to the nucleus or proximal to the nuclear membrane (HNRNPR, 223 RBMX, RBM4, MBOAT7) had a higher frequency of co-localization with HIV RNA at nuclear puncta 224 (57-96\%) relative to proteins that were predominantly localized to the cytoplasm (FAM120A, IGF2BP3, 225 MOV10, DNM2, TRIM56, LRPPRC, CSDE1; 0-8\%). Two proteins (HNRNPR and RBMX) co-localized 226 frequently with HIV-1 US RNA at all four quantified sites (41-90\%). All 11 host proteins co-localized with 227 US RNA at small cytoplasmic puncta in a high percentage of cells $(71-100 \%)$ with most (all but 228 LRPPRC and MBOAT7) co-localizing with US RNA at the plasma membrane (31-100\% of cells), 229 generally with Gag also present (Figure 4B, Table S12). 


\section{A subset of HyPR-MS $S_{\text {sv }}$ candidates likely co-traffic with US RNAs from sites of transcription to}

the cytoplasm. Several HyPR-MS candidates (HNRNPR, FAM120A, IGF2BP3, RBMX, RBM4,

CSDE1, DNM2, LRPPRC, MBOAT7) were observed to accumulate at bright US RNA nuclear puncta, suggesting that they associate with US RNA at or near sites of de novo transcription (Figure S3). Of these, HNRNPR, FAM120A, and IGF2BP3 were of particular interest because all three exhibited four US HIV RNA co-localization phenotypes (nuclear puncta, cytoplasmic granules, cytoplasmic puncta, and plasma membrane puncta) (Figure 4B); preferentially interacted with US and PS, but not CS, HIV RNA as determined by HyPR-MS sv (Figure 4C, Table S7), and positively affected US but not CS gene expression upon siRNA KD (Figure 4D, Tables S7). By contrast, LRPPRC, a protein shown to localize to the mitochondria as well as the nucleus (Mili and Pinol-Roma, 2003; Ruzzenente et al., 2012), and MBOAT7, a protein shown to localize to mitochondria-associated membranes (Hirata et al., 2013), localized to US HIV RNA nuclear puncta, at perinuclear puncta, and at cytoplasmic puncta but were not observed to co-localize with US RNA and Gag at the plasma membrane. Similar to the HNRNPR,

244 FAM120A, and IGF2BP3, both LRPPRC and MBOAT7 were preferentially associated with US and PS

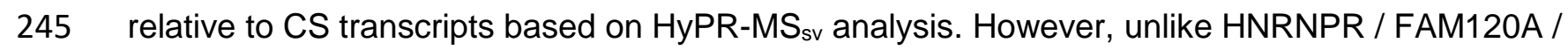
246 IGF2BP3, each of these proteins were negative effectors of both US and CS HIV-1 gene expression

247 (Figure 4D, Table S7). Interestingly, LRPPRC was detected not only near transcription sites but also in 248 a trail-like pattern that extended to the periphery of the nucleus (Figures 4A and S3) and MBOAT7 was 249 observed at transcription sites, at smaller subnuclear US HIV RNA puncta, and with high frequency and 250 abundance at US RNA puncta at or near the nuclear membrane (Figures 4A and S3).

HIV-1 infection alters the abundance and localization of several HyPR-MSsv identified proteins.

253 The FISH/IF single cell analyses of US HIV RNA, Gag, and host proteins also allowed for tracking of 254 host factor responses to infection (Figure 5). For example, HNRNPR, generally a nuclear protein, was 
255 primarily localized to the nucleus of cells expressing no, or low amounts of, Gag and US RNA, but 256 exhibited marked shifts from the nucleus to the cytoplasm in cells with high levels of Gag and US RNA 257 expression (Figure 5A). Changes to MBOAT7 were also striking, with much higher levels of expression 258 in cells with abundant Gag and US RNA than in uninfected or early infected cells (Figure 5B).

259 To further track HyPR-MS sv host factor changes, we plotted single-cell measurements of total Gag and 260 total US HIV RNA and used the resulting inflection point to discriminate cells in "early" and "late" stages 261 of HIV gene expression (Figures 5C and 5D; Table S13). We measured relative host protein 262 abundances for twelve of these factors at these stages (HNRNPR, FAM120A, IGRF2BP3, LRPPRC, 263 MBOAT7, CSDE1, DNM2, MOV10, RBM4, RBMX, SRRM2, TRIM56 (Figure 5E and 5F, Table S13)). In 264 general, each host protein exhibited non-random, bimodal expression changes from "early" and "late" 265 HIV gene expression (Figure S5, Table S13). For example, in early/uninfected cells we observed linear 266 increases in HNRNPR and MBOAT7 expression, positively correlating with the subtle increases in US 267 HIV RNA expression (Figure 5E and 5F; slope $\mathrm{m}=1.7,0.9$ respectively). However, in late cells, HNRNPR expression rose then fell again as per-cell US RNA increased, fitting a polynomial rather than

271 A similar analysis was performed after image-based segmentation of cells into nuclear and cytoplasmic 272 compartments to better discriminate the subcellular location in which host protein changes occurred 273 (Figure S5, Table S13). For HNRNPR, the same trends were observed in the nucleus and cytoplasm as 274 were seen for the total cell (Figure S5). For MBOAT7, nuclear expression plateaued as it did for total 275 cell expression, but the cytoplasmic expression increased slightly as US RNA and Gag abundance 276 increased (Figure S5). In all, the expression of each of the 12 host proteins showed significant 277 correlation with the expression of US HIV RNA in at least one of the following sub-groups: early278 nuclear, late-nuclear, early-cytoplasmic, late-cytoplasmic (Figure S6, Table S13). 

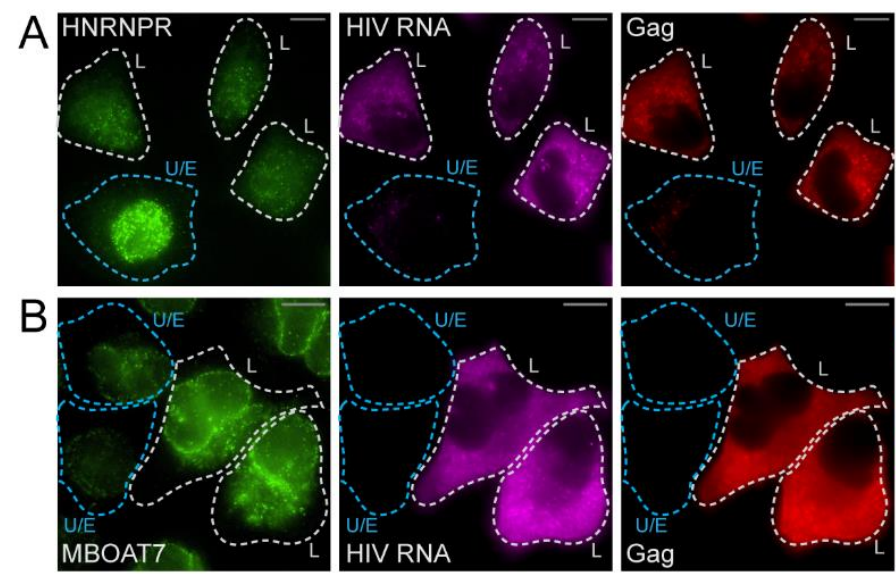

\section{Expression Changes}

E
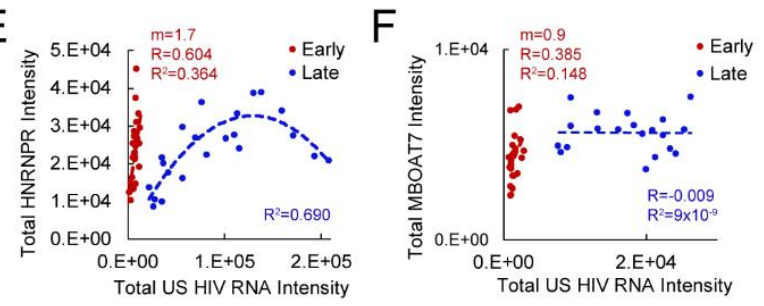

G
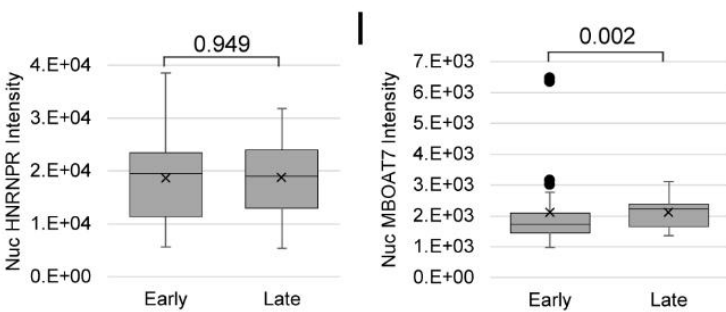

$\mathrm{H}$
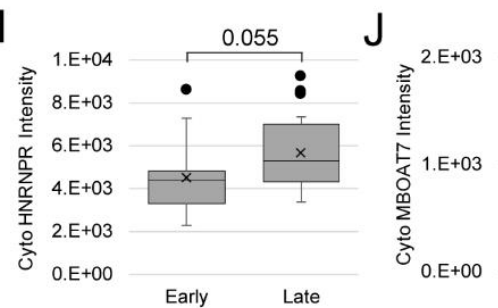

$\mathrm{K}$

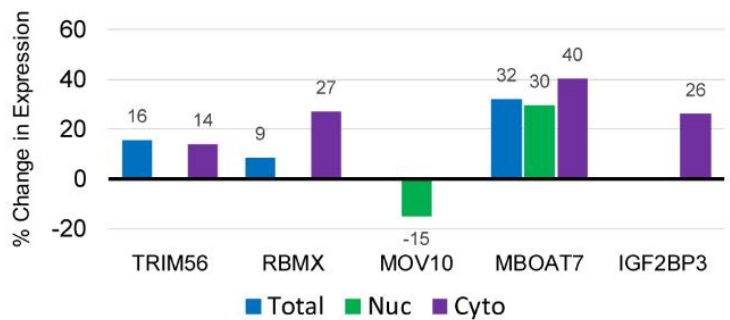

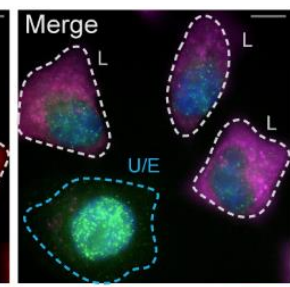
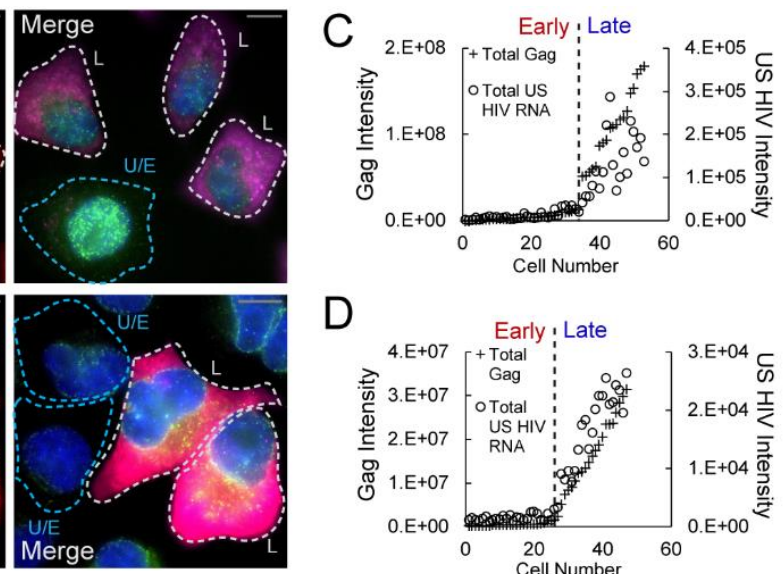

\section{Subcellular Distribution Changes}

L
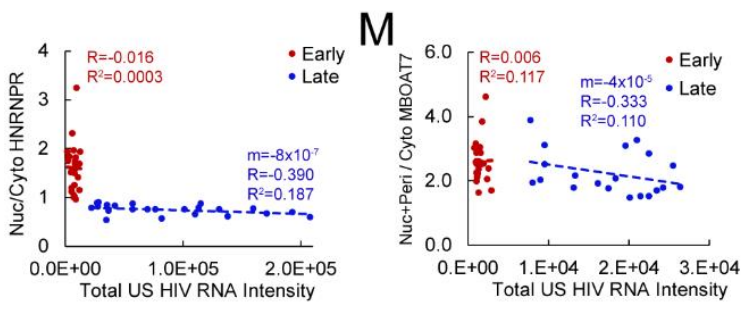

$\mathrm{N}$

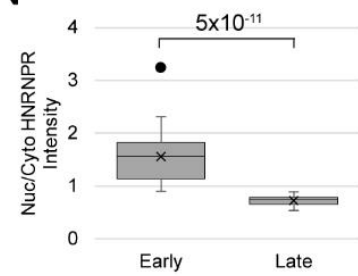

$\mathrm{O}$

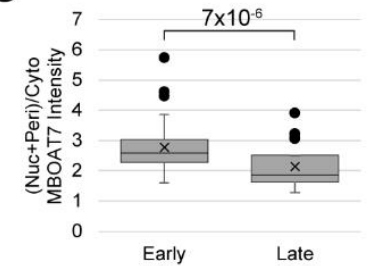

$\mathrm{P}$

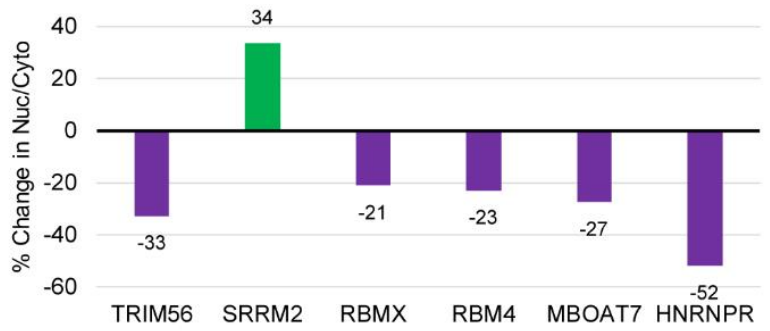


Figure 5: Host protein expression and cellular distribution. A. HNRNPR cellular distribution appears to be different in uninfected/early stage infected cells (U/E; blue outlines) than in late stage infected cells (L; white outlines). B. MBOAT7 expression appears greater in late stage infected cells than in uninfected/early stage infected cells. C-D. Plots of cellular Gag-IF and US HIV RNA-FISH intensities for cells analyzed for HNRNPR (C) and MBOAT7 (D). Cells prior to the inflection points in each plot are termed "early cells" as they are either uninfected or at stages of HIV replication prior to late gene expression (i.e. high amounts of Gag in the cytoplasm). Cells after the inflection point are termed "late cells" as they express high, IF-detectable levels of Gag in the cytoplasm. E-F. For each cell in the early and late cell sub-groups, the intensity of US HIV RNA versus the intensity of HNRNPR $(E)$ and MBOAT7 $(F)$ is plotted. Linear or polynomial regressions $\left(R^{2}\right)$ are fit to each early and late sub-group and the Pearson's correlation coefficient $(R)$ calculated for linear regressions. This demonstrates the extent of correlation between US HIV RNA expression and the expression of each host protein. G-J. A student's t-test is applied to determine if the host protein intensities in early cells are significantly different from those in late cells in the nucleus and the cytoplasm. K. \% change in the median expression for all host proteins with early vs late $p$-values $<0.05$. Calculations were made for total cell, nuclear, and cytoplasmic differences. L-M. Total cellular US HIV RNA intensities versus host protein nuc/cyto or nuc+peri/cyto ratios. Demonstrates extent of correlation of host protein cellular distribution with US HIV RNA expression. N-O. A student's t-test measures significant differences in the cellular distribution between the early and late cells for HNRNPR and MBOAT7. P. \% change in the median nuc/cyto or nuc+peri/cyto ratio for all host proteins with $p$-values $<0.05$. Purple indicates the late cells have a higher proportion of the host protein in the cytoplasm than do the early cells. Green indicates the late cells have a higher proportion in the nucleus.

281 For HNRNPR and MBOAT7, the most evident differences were in cytoplasmic expression (cyto

282 HNRNPR, median increase $=21 \%, p=0.055$; cyto MBOAT7, median increase $\left.=41 \%, p=3 \times 10^{-5}\right)($ Figure

283 5G-5J, Figure S5, Table S13). In all, changes to nuclear or cytoplasmic abundance were observed for

284 five host proteins ( $\mathrm{p}$-values < 0.05; MBOAT7, TRIM56, RBMX, MOV10, and IGF2BP3) (Figures 5K, S5,

285 Table S13). Three of these proteins showed differences to total cellular expression (MBOAT7, RBMX,

286 and TRIM56), with RBMX and TRIM56 only increasing in the cytoplasm. Two proteins did not show net

287 differences in overall expression, but exhibited statistically significant differences (p-value $<0.05)$ in

288 expression in the nucleus (MOV10) or the cytoplasm (IGF2BP3).

289 To identify potential host protein translocation events, we evaluated single cell nuclear-to-cytoplasmic

290 (nuc/cyto) ratios relative to US RNA abundance and looked for statistically significant differences in

291 early and late cells (Figure S5, Table S13). HNRNPR nuc/cyto ratios ranged from 1 to 3 in

292 early/uninfected cells but only ranged from 0.6 to 0.9 in late infected cells; exhibiting a negative

293 correlation with US HIV RNA expression (Figure 5L). For MBOAT7, the nuc/cyto ratio ranged from 1.7

294 to 3.9 in early cells and 1.5 to 3.9 in late cells; with no significant correlation with US RNA expression 
295 for either phase (Figure 5M). However, overall nuc/cyto ratios were significantly lower for late cells 296 relative to early cells for both proteins (median decrease $=-52 \% ; p=5 \times 10^{-11}$ and median decrease $=-27 \%$; $297 \mathrm{p}=7 \times 10^{-6}$, respectively) (Figure 5N and 50). In all, the nuc/cyto ratios of six HyPR-MS candidate 298 proteins showed notable changes to nuc/cyto ratio (HNRNPR, MBOAT7, TRIM56, SRRM2, RBMX, and 299 RBM4); all, with the exception of SRRM2, exhibiting relative increases to cytoplasmic abundance 300 (Figure 5P, Table S13).

302 Taken together, these analyses demonstrated that many of the host factors identified by HyPR-MSsv 303 not only modulate HIV-1 gene expression (Figure 3) but co-localize with HIV-1 US RNA (Figure 4) and 304 respond to infection by increasing in abundance and/or undergoing alterations to subcellular distribution 305 (Figure 5).

\section{DISCUSSION:}

308 The variation in gene products encoded by the HIV-1 genome is largely achieved through regulated 309 synthesis of a diverse RNA transcriptome. Deciphering the distinct cellular processes each splice 310 variant undergoes and the host proteins involved is critical to understanding HIV-1 replication. Here, 311 using HIV-1 as a relevant model system, we describe HyPR-MS sv $_{\text {as }}$ a new tool that can be applied to 312 elucidate distinct protein interactomes for distinct splice variant classes.

314 Isolation of the multiple HIV splice variant classes and comparative analysis of their differential protein 315 interactors yielded a rich interactome resource valuable for studies of HIV-1 RNA metabolism. Notably, 316 the protein interactomes of the three splice variant classes differ markedly from one another,

317 presumably reflecting functional differerences (Figure 2). We uncovered over fifty proteins that 318 differentially impacted early and late HIV gene expression based on siRNA KD (Figure 3), mapped the 319 cellular locations where several of the host proteins co-localized with US HIV RNA (Figure 4), and 320 established a correlation between infection and altered levels of expression or subcellular localization 
321 for several host proteins (Figure 5). Combined, these results provide a road-map for RNA-protein

322 interactions potentially central to HIV replication (Figure 6).

324 In developing the HyPR-MS sv approach, we aimed to (1) ensure the relevance of protein interactors by 325 only pursuing interactions that occur in cells (i.e., in vivo) (2) ensure versatility of the technique for 326 broad applications wherein it is useful to differentiate between one or more RNA splice variants for 327 comparative RNA-capture proteomics and (3) determine, for the first time, the protein interactomes for 328 the three major HIV splice variant classes. The first two goals were achieved by configuring HyPR329 MS sv to sequentially deplete specific classes of HIV RNA from the same pool of natively infected cell 330 lysates using three independently-targeted sets of short ( 30 nt) biotinylated capture oligos (Figure 1).

331 To our knowledge, all previous studies for discovery of HIV RNA protein interactors, with the exception 332 of our prior study (Knoener et al., 2017), utilized synthetic viral RNAs as bait added to cellular lysates 333 (Marchand et al., 2011; Singh et al., 2016) or viral constructs engineered to encode artificial RNA 334 sequences for the purpose of RNA "tagging" (e.g., MS2 loops) (Kula et al., 2011). While effective at identifying protein interactors, both of these strategies may complicate interpretation of results either by

336 eliminating the cellular context of interactions (e.g., some interactions occur in the nucleus and some in 337 the cytoplasm) or by introducing non-native components that can interfere with native interactions. 338 Additional strengths of the HyPR-MS sv approach are that it can be used to extract native RNA 339 transcripts produced from any strain or infected cell type and can easily be adapted to study other 340 viruses or cellular RNA splice variants.

342 By isolating the HIV-1 splice variant classes, we were able to compare RNAs with both shared and 343 distinct sequences, and likely corresponding secondary, tertiary, and quaternary structures, to decipher 344 how their protein interactors may consequently differ. We validated the sequential capture of US, PS, 345 and CS HIV RNAs using RT-qPCR and showed at least 200-fold specificity relative to cellular RNAs 346 and at least 10-fold specificity for the splice variant class of interest in each capture. We determined 
using statistical analysis that over 200 proteins interact preferentially with any one subset of the HIV splice variant classes at $48 \mathrm{~h}$ post-infection. Among these are proteins specific to the US, PS, or CS

HIV RNAs as well as a large number of proteins preferentially associated with both the US and PS HIV RNAs, which are Rev-dependent, intron-retaining transcripts responsible for late HIV gene expression

(Figure 2A and Table S7). Of the 210 host proteins identified as HIV-1 RNA interactors, 25 had been

previously shown to associate with US HIV RNA (Knoener et al., 2017) and 51 with viral proteins (Gag,

353 Gag-Pol, Tat, Rev) that are known to be involved in HIV-1 RNA regulation (Oughtred et al., 2019)

354 (Table S7). Based on siRNA knockdown, at least 48 represent potential new host regulatory factors

355 (Table S7). Using Gene Ontology (GO) term enrichment analysis we showed that several biological

356 processes and cellular components are over-represented in each splice variant subgroup (Figure 2B,

357 Table S4), suggesting cellular pathways that may be uniquely involved in the processing of a subset of

358 HIV splice variants. Notable was enrichment of proteins related to the regulation of mRNA stability and

359 splicing in the US and PS interactomes and proteins related to mitochondrial gene expression and 360 organization in the US interactome.

362 With a focus on late-stage Rev-dependent US and PS RNA nuclear export, we examined a large 363 cluster of 16 proteins with closely related HIV splice variant interaction profiles which preferentially 364 associated with US and PS, but not CS, transcripts (Figure S7, Table S7). Eleven of these host proteins 365 were known stress granule components and/or had functions in splicing. Ten were determined to be 366 positive effectors of late gene expression, six of which affected late gene expression significantly more 367 than early. Within this group, a subcluster of three proteins (HNRNPR, FAM120A, and IGF2BP3) 368 exhibited markedly similar HyPR-MS RNA interaction profiles (Figure 4C), siRNA KD effects (Figure 369 4D), and subcellular localization patterns (Figure 4A). HNRNPR and IGF2BP3, as well as IGF2BP1 and 370 YBX1 which also cluster with this group (Figure S7), were previously identified as components of 371 IGF2BP1-ribonucleoprotein granules (IMP1-granules); cytoplasmic granules that contain and confer 372 stability to mRNAs that have not yet been translated (Jonson et al., 2007). HNRNPR was also shown to 
373 stabilize and facilitate subcellular localization of RNA (Briese et al., 2018; Reches et al., 2016).

374 Intriguingly, YBX1, IGF2BP1, and HNRNPR have previously been suggested to have roles in HIV

375 replication: YBX1 was shown to stabilize HIV US RNA and enhance virus production (Jung et al., 2018;

376 Mu et al., 2013), overexpression of IGF2BP1 was shown to reduce HIV infectivity through its interaction

377 with Gag (Zhou et al., 2008), and HNRNPR was shown to interact with HIV Rev (Hadian et al., 2009).

378 By contrast, FAM120A has not previously been linked to viruses but has been shown to protect RNAs

379 from Ago2-mediated degradation through the RNA-induced silencing complex (RISC) (Kelly et al., 380 2019), which frequently serves in an antiviral role (Eckenfelder et al., 2017; Harvey et al., 2011). Our

381 functional analysis showed a decrease in late HIV gene expression upon knockdown of all five of these 382 proteins (IGF2BP1, YBX1, HNRNPR, IGF2BP3, and FAM120A; Table S7), consistent with shared roles 383 for these clustered host proteins as positive regulators of US HIV RNA transport and/or stability.

Analysis of the HyPR-MS and siRNA knockdown screen data also revealed a trend for mitochondrialinked proteins that interacted with US and/or PS HIV RNA and served as negative effectors of HIV gene expression. Of particular interest were LRPPRC and MBOAT7 because they both preferentially interacted with US and PS HIV RNA; were categorized as negative effectors of late gene expression, and could be detected co-localizing with US RNA both in the nucleus and the cytoplasm. LRPPRC was previously shown to localize to the nucleus and to mitochondria as a putative effector of RNA metabolism in both locations (Mili and Pinol-Roma, 2003; Ruzzenente et al., 2012). One study showed that nuclear LRPPRC directly interacted with CRM1, elF4E, and a signature RNA secondary structure found in a subset of cellular RNAs (Volpon et al., 2017); features similar to how Rev and the RRE are known to drive US and PS RNA export. Interestingly, another study implicated LRPPRC in HIV-1 replication but as affecting the pre-integration stages (Schweitzer et al., 2012). By contast, MBOAT7 is 397 phosphatidylinositol (Lee et al., 2008; Lee et al., 2012); and has not previously been implicated in viral 398 or cellular RNA metabolism. However, in addition to perinuclear and ER localization, MBOAT7 has 
A

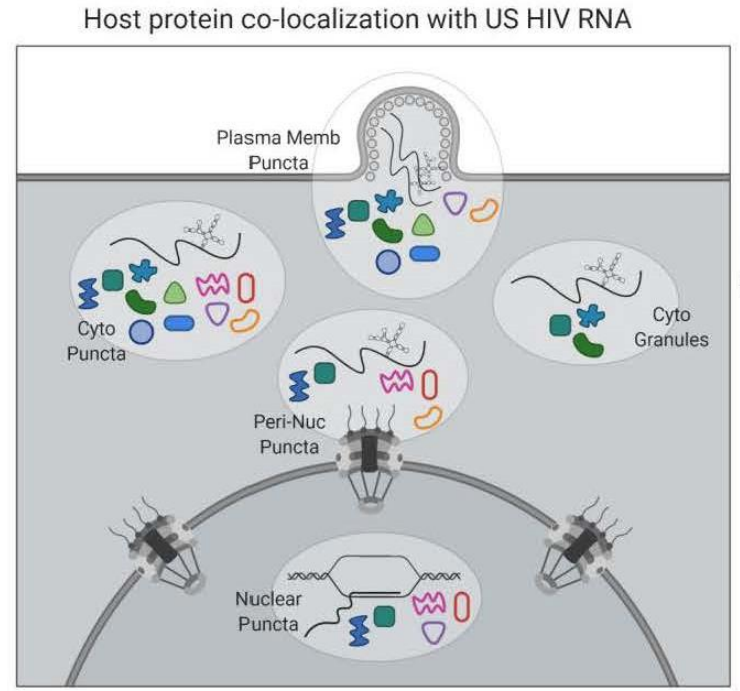
gene expression ( ) थी DNM2 FAM120A HNRNPR IGF2BP3 \& $\bigcirc \square$ RBMX TRIM56 MOV10 Negative Effectors of HIV gene expression

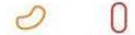
CSDE1 LRPPRC N $O$ MBOAT7 RBM4 Viral Components rum HIV Transcription No US HIV RNA
B

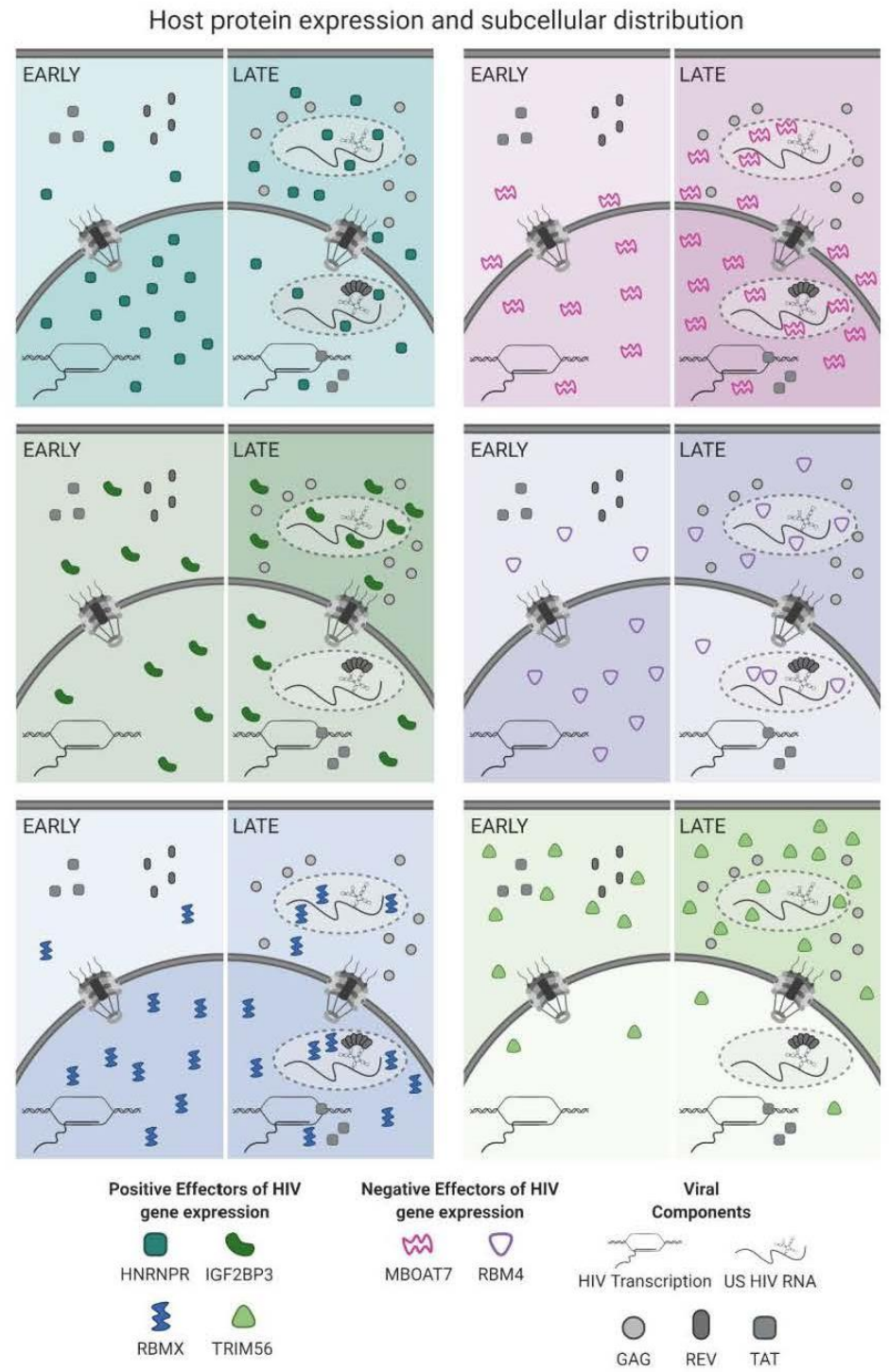

Figure 6: Models for subcellular co-localization, expression, and distribution of host proteins. A. Summary of cellular co-localization phenotypes observed by FISH/IF analysis of HIV US RNA and select host proteins. Host proteins represented include both positive and negative effectors of HIV gene expression as was determined by siRNA knockdown. B. Models of host protein changes in expression and cellular distribution from early to late HIV gene expression. Host protein quantities represented here show the general, but not exact, scale of changes in host protein abundance in the nucleus and cytoplasm over the course of HIV replication. The extent of shading in the nucleus or cytoplasm correlates with that same change in abundance. 
400 been reported to localize to mitochondrial associated ER membranes (MAMs) which bridge the ER to

401 the mitochondria to regulate antiviral signaling through the mitochondrial antiviral-signaling (MAVS) viral

402 RNA sensor (Hirata et al., 2013). Based on our combined results, we hypothesize that both LRPPRC 403 and MBOAT7 link US RNA transport to mitochondrial signaling pathways capable of dampening HIV-1 404 late stage gene expression.

406 This study describes and validates a powerful new biochemical approach for deep interrogation of the 407 complex interplay of viral and cellular RNA and protein factors during viral infection (Figure 6). Using 408 siRNA KD and single cell imaging experiments we also generated a catalog of host protein candidates 409 for positive and negative regulation of HIV-1 gene expression. Interestingly, a subset of proteins 410 (HNRNPR, RBM4, and RBMX) were frequently observed both at US RNA transcription sites as well as 411 at putative sites of virus particle assembly, suggesting that these factors may be capable of strong, 412 persistent association with viral RNA throughout the entire productive phase (Figure 6A). The changes 413 seen in subcellular distribution of HNRNPR are consistent with a role in stability and nuclear export of 414 intron-retaining HIV-1 transcripts while the expression changes and localization of IGF2BP3 support a 415 role in cytoplasmic US RNA transport and stability (Figure 6B). Finally, we identified a set of host 416 factors linked to mitochondria (including LRPPRC and MBOAT7) that may represent new effectors of 417 HIV-1 antiviral surveillance.

\section{MATERIALS and METHODS}

\section{Cell Lines}

421 Jurkat cells are T lymphocytes established from the peripheral blood of a 14-year-old male with acute T 422 cell leukemia and were obtained from ATCC (TIB-152). The cells were cultured in RPMI media 423 supplemented with $10 \%$ fetal bovine serum and $1 \%$ L-glutamine-penicillin-streptomycin in roller bottles 
424 rotated at 3 rotations per minute $(\mathrm{rpm})$ at $37^{\circ} \mathrm{C}$ in $5 \% \mathrm{CO}_{2}$. A cell density of $1 \times 10^{6}$ cells per $\mathrm{mL}$ of media 425 was maintained by regular quantification. This cell line was authenticated by karyotyping.

426 HEK293T cells are human embryonic kidney cells and were obtained from ATCC (CRL-11268). The

427 cells were cultured in DMEM media supplemented with $10 \%$ fetal bovine serum and $1 \%$ L-glutamine-

428 penicillin-streptomycin at $37^{\circ} \mathrm{C}$ in $5 \% \mathrm{CO}_{2}$. This cell line was authenticated by morphology and are

429 G418 resistant.

430 Human 293T cells stably-expressing YFP-ACT were cultured in Dulbecco's modified Eagle's medium

431 (DMEM) supplemented with 10\% fetal bovine serum, 1\% L-glutamine, and 1\% penicillin-streptomycin.

432 HeLa cells were cultured in DMEM media supplemented with $10 \%$ fetal bovine serum and $1 \%$ L-

433 glutamine-penicillin-streptomycin at $37^{\circ} \mathrm{C}$ in $5 \% \mathrm{CO}_{2}$.

\section{HIV-1 Virion Production}

$4352.5 \times 10^{6} \mathrm{HEK} 293 \mathrm{~T}$ cells were plated in $10 \mathrm{~cm}$ tissue-culture treated dishes in $10 \mathrm{~mL}$ media then

436 transfected using polyethylenimine with $1 \mu \mathrm{g}$ of DNA plasmid expressing the $\mathrm{G}$ envelope glycoprotein

437 from vesicular stomatitis virus (VSV-G) and $9 \mu \mathrm{g}$ of plasmid DNA encoding the full-length NL4-3

438 molecular clone of HIV-1 bearing inactivating mutations in env, vpr, and either a.) expressing a Cyan

439 Fluorescent Protein (CFP) reporter from the nef reading frame (HIV-1 E-R-CFP) (Adachi et al., 1986;

440 Becker and Sherer, 2017) or b.) expressing mCherry in the nef ORF and three copies of CFP, in

441 tandem, between the matrix and capsid ORFs of Gag (E-R- Gag-3xCFP mCherry/nef) (Hendrix et al.,

442 2015; Holmes et al., 2015; Mergener et al., 1992). At 24-hours post-transfection, media was replaced

443 with $4 \mathrm{~mL}$ fresh media. At 48-hours post-transfection, culture supernatants were harvested, filtered

444 through a sterile $0.45 \mu \mathrm{m}$ syringe filter and frozen at $-80^{\circ} \mathrm{C}$. Dose of HIV-1 E-R-CFP viral inoculum

445 required for effective infection was determine in small-scale infection titrations in Jurkat cells.

\section{HyPR-MS Analysis}


Jurkat Cell Infections. $1 \times 10^{8}$ Jurkat cells in 25mL RPMI, 25mL viral inoculum (HIV-1 E-R-CFP) in

DMEM, and polybrene (concentration $10 \mathrm{ug} / \mathrm{mL}$ ) were combined and incubated in a rotating roller bottle. After three hours, culture volume was increased to $300 \mathrm{~mL}$ using RPMI media and incubated at $3 \mathrm{rpm}$ for 45 hours. Infection was confirmed to be $>90 \%$ by visualizing CFP expression via epifluorescence 451 microscopy. Cells were centrifuged at 1500rpm for 10 minutes, washed three times with PBS, then 452 cross-linked by resuspending in $0.25 \%$ formaldehyde and incubated at room temperature for 10 453 minutes. Cross-linked cells were washed once with PBS then resuspended in 100mM Tris- $\mathrm{HCl}$ and 454 incubated at room temperature for 10 minutes to quench formaldehyde. Cells were washed twice more 455 in $1 \times P B S$, pelleted by centrifugation, and frozen at $-80^{\circ} \mathrm{C}$.

456 Cell Lysis. Jurkat cells pellets were resuspended on ice in lysis buffer (469mM LiCl, $62.5 \mathrm{mM} \mathrm{Tris} \mathrm{HCl}$, $457 \mathrm{pH}$ 7.5, 1.25\% LiDS, 1.25\% Triton X-100, 12.5mM Ribonucleoside Vanadyl Complex, 12.5mM DTT, $458125 \mathrm{U} / \mathrm{mL}$ RNasin Plus, 1.25X Halt Protease Inhibitors) to a final cell concentration of $5 \mathrm{X} 10^{6} \mathrm{cells} / \mathrm{mL}$. 459 Cells were lysed by frequent vortexing for 10 minutes, keeping the cells on ice between vortexes.

460 HIV-1 RNA Splice Variant Hybridization and Capture. Each capture replicate used $5 \times 10^{7}$ cells.

461 Three biological replicates of each splice variant capture was conducted for this analysis. The HIV-1

462 US, PS, and CS RNAs were each purified from the Jurkat cell lysate by three sequential and separate 463 hybridization and capture events; US followed by PS followed by CS HIV RNA. The amounts of 464 biotinylated capture oligonucleotides and streptavidin coated magnetic beads for each hybridization and 465 capture are listed in Table S1. The appropriate concentrations of biotinylated capture oligonucleotides 466 were added to the Jurkat cell lysates and the final concentration of lysis buffer ( $375 \mathrm{mM} \mathrm{LiCl,} 50 \mathrm{mM}$ 467 Tris, $1 \%$ LiDS, $1 \%$ Triton X-100, 10mM RVC, 10mM DTT, 100U/mL RNasin Plus, 1X Halt Protease 468 Inhibitors) was obtained by addition of nuclease free water. The samples were then incubated at $37^{\circ} \mathrm{C}$ 469 for three hours with gentle nutation. Streptavidin coated magnetic Speedbeads were washed 3 times 470 with wash buffer (375mM LiCl, 50mM Tris, 0.2\% LiDS, 0.2\% Triton X-100) prior to addition and nutation 471 for one hour at $37^{\circ} \mathrm{C}$ with the hybridization samples. Using a magnet, the beads were collected to the 
472 side of each tube, and the lysate was removed and transferred to a clean tube for the next hybridization

473 and capture. The beads were then washed 2 times, for 15 minutes each, at $37^{\circ} \mathrm{C}$ with a volume of wash

474 buffer 5-times the volume of the original aliquot of beads used for capture (i.e. $5 \mathrm{X}$ bead volume) then

475 one time for 5 minutes at room temperature with a $5 \mathrm{X}$ bead volume of release buffer $(100 \mathrm{mM} \mathrm{LiCl}$,

$47650 \mathrm{mM}$ Tris, $0.1 \%$ LiDS, $0.1 \%$ Triton X-100).

477 Release of HIV RNA from Beads. The beads for the US, PS, and CS RNA captures were individually 478 resuspended in a $3 X$ bead volume of release buffer. The appropriate amount of release oligonucleotide 479 (Table S1) was added and the bead mixture was nutated at room temperature for 30 minutes. Using a 480 magnet to collect the beads to the side of the tube, the supernatant containing the released RNA-

481 protein complexes was transferred to a clean tube. The resulting sample was divided into two aliquots;

$4822 \%$ for RT-qPCR analysis and $98 \%$ for mass spectrometric analysis.

483 RNA Extraction and Reverse Transcription. 2\% by volume of each release sample was incubated 484 overnight at $37^{\circ} \mathrm{C}$ with $1 \mathrm{mg} / \mathrm{mL}$ proteinase $\mathrm{K}, 4 \mathrm{mM} \mathrm{CaCl}_{2}$, and $0.2 \% \mathrm{LiDS}$ to remove the proteins. The 485 RNA was then extracted from the samples using TriReagent per manufacturer's protocol and 486 precipitated in $75 \%$ ethanol, with $2 \mathrm{uL}$ of GlycoBlue, at $-20^{\circ} \mathrm{C}$ for at least 2 hours. The RNA was pelleted 487 by centrifugation at $20,800 \mathrm{~g}$ and $4^{\circ} \mathrm{C}$ for 15 minutes, the pellet was washed with $75 \%$ ethanol, 488 centrifuged at $20,800 \mathrm{~g}$ and $20^{\circ} \mathrm{C}$ for 15 minutes, then resuspended in $15 \mathrm{uL}$ of nuclease free water.

489 10uL of the purified RNA was used for reverse transcription (High Capacity cDNA Reverse 490 Transcription Kit, Applied Biosystems) per the manufacturer's protocol. The procedures described here 491 were also performed on HIV-1 E-R-CFP virus inoculum for isolation and analysis of a semi-purified 492 standard of the US HIV RNA. The isolated RNA was quantified by NanoDrop analysis, serially diluted, 493 reverse transcribed and then used for a standard calibration curve for qPCR analysis.

494 qPCR Analysis. The 20uL reverse transcription product was diluted with $20 \mathrm{uL}$ of nuclease free water 495 and analyzed using sequence-specific qPCR primers and probes (Table S1) and Roche 496 LightCycler 480 Probes Master Mix for relative quantitation of the US, PS, and CS HIV transcripts and 
human GAPDH. Purified HIV-1 E-R-CFP plasmid was quantified by NanoDrop analysis, serially diluted, then used as a standard calibration curve for qPCR analysis.

499 Protein Purification and Trypsin Digestion. 98\% by volume of each capture sample was processed 500 using an adapted version of eFASP (Erde et al., 2014) for purification of proteins. Amicon 50kDa 501 MWCO filters and collection tubes were passivated by incubating overnight in 1\% CHAPS and then 502 rinsed thoroughly with mass spectrometry grade water. Each release sample was brought to a final 503 concentration of $8 \mathrm{M}$ Urea and $0.1 \%$ deoxycholic acid (DCA) then passed through the filter in 500uL 504 increments by centrifugation for 10 minutes at $14,000 \mathrm{~g}$. RNA-protein complexes were trapped in the 505 filter and the eluent passed through to a collection tube for discarding. In the same manner (addition of 506 solution followed by centrifugation), the following passages were conducted: 1.) Three passages of $507400 \mathrm{uL}$ of exchange buffer (8M urea, $0.1 \% \mathrm{DCA}, 50 \mathrm{mM}$ Tris $\mathrm{pH} 7.5)$, 2.) Incubation for 30 minutes with 508 200uL of reducing buffer (8M urea, 20mM DTT), 3.) Incubation for 30 minutes, in the dark, with 509 alkylation buffer (8M urea, 50mM iodoacetamide, 50mM ammonium bicarbonate), 4.) Three passages 510 of $400 \mathrm{uL}$ of digestion buffer ( $1 \mathrm{M}$ urea, $50 \mathrm{mM}$ ammonium bicarbonate, $0.1 \% \mathrm{DCA})$. Finally, the sample 511 remaining in the filter was brought to $100 \mathrm{uL}$ with digestion buffer, the filter was transferred to a clean, 512 passivated collection tube and 1ug of trypsin added to the filter for digestion. The filter-collection tube 513 containing the sample was sealed with parafilm to prevent evaporation during incubation overnight at $51437^{\circ} \mathrm{C}$. Following digestion, the filter-collection tube was centrifuged for 10 minutes at $14,000 \mathrm{~g}$. $50 \mathrm{uL}$ of $51550 \mathrm{mM}$ ammonium bicarbonate was added to the filter followed by centrifugation at $14,000 \mathrm{~g}$ for 10 516 minutes. This step was repeated once to ensure the collection of the entire peptide sample. The 200uL 517 peptide sample was then brought to $1 \%$ TFA followed by addition of $200 \mathrm{uL}$ of ethyl acetate. The sample 518 was vortexed for 1 minute then centrifuged at 15,800 $\mathrm{g}$ for 2 minutes. The top layer was aspirated and 519 discarded and extraction with $200 \mathrm{uL}$ ethyl acetate was repeated 2 times. The aqueous layer was then 520 dried using a Savant SVC-100H SpeedVac Concentrator and the sample resuspended in 150uL $0.1 \%$ 521 TFA. For removal of salts from the sample a C18 solid-phase extraction pipette tip was first conditioned 
522 with $70 \%$ ACN, $0.1 \%$ TFA, and then equilibrated with $0.1 \%$ TFA. The peptide sample was then loaded

523 onto the $\mathrm{C} 18$ solid phase by repeated passing of the $150 \mathrm{uL}$ sample over the cartridge. The C18

524 extraction pipette tip was then rinsed with $0.1 \%$ TFA 10 times followed by peptide elution in $150 \mu \mathrm{L} 70 \%$

525 ACN, 0.1\% TFA. The samples were then dried using the SpeedVac Concentrator and reconstituted in

526 95:5 H2O:ACN, 0.1\% formic acid.

527 Mass Spectrometry of Peptides. The samples were analyzed using an HPLC-ESI-MS/MS system

528 consisting of a high performance liquid chromatograph (nanoAcquity, Waters) set in line with an

529 electrospray ionization (ESI) Orbitrap mass spectrometer (LTQ Velos, ThermoFisher Scientific). A 100

$530 \mu \mathrm{m}$ id X $365 \mu \mathrm{m}$ od fused silica capillary micro-column packed with $20 \mathrm{~cm}$ of $1.7 \mu \mathrm{m}$-diameter, 130

531 Angstrom pore size, C18 beads (Waters BEH) and an emitter tip pulled to approximately $1 \mu \mathrm{m}$ using a

532 laser puller (Sutter Instruments) was used for HPLC separation of peptides. Peptides were loaded on-

533 column with $2 \%$ acetonitrile in $0.1 \%$ formic acid at a flow-rate of $400 \mathrm{~nL} /$ minute for 30 minutes. Peptides

534 were then eluted at a flow-rate of $300 \mathrm{~nL} /$ minute over 120 min with a gradient from $2 \%$ to $30 \%$

535 acetonitrile, in $0.1 \%$ formic acid. Full-mass profile scans were performed in the FT orbitrap between

$536375-1500 \mathrm{~m} / \mathrm{z}$ at a resolution of 120,000 , followed by MS/MS HCD scans of the ten highest intensity

537 parent ions at $30 \%$ relative collision energy and 15,000 resolution, with a mass range starting at 100

$538 \mathrm{~m} / \mathrm{z}$. Dynamic exclusion was enabled with a repeat count of one over a duration of 30 seconds. The

539 Orbitrap raw files were analyzed using MaxQuant (version 1.5.3.30) (Cox and Mann, 2008) and

540 searched with Andromeda (Cox et al., 2011) using the combined Uniprot (Breuza et al., 2016)

541 canonical protein databases for human and HIV-1 and supplemented with common contaminants

542 (downloaded June 8, 2016). Samples were searched allowing for a fragment ion mass tolerance of 20

543 ppm and cysteine carbamidomethylation (static) and methionine oxidation (variable). A $1 \%$ false

544 discovery rate for both peptides and proteins was applied. Up to two missed cleavages per peptide

545 were allowed and at least two peptides were required for protein identification and quantitation. Protein

546 quantitation was achieved using the sum of the peptide peak intensities for each protein of each 
547 biological replicate and capture sample type. The peak intensities of HIV capture samples were

548 normalized by the total peak intensity of all HIV capture samples and the same was done for scrambled 549 capture samples.

550 MS Data Analysis. To determine the differential interactomes of the HIV-1 splice variants pairwise 551 comparisons (US vs PS, US vs CS, PS vs CS) were statistically analyzed with the student's T-test and 552 a permutation based FDR (5\% threshold) using Perseus software (Tyanova et al., 2016) (Table S3). 553 Proteins that met this threshold in at least one pairwise comparison were then hierarchically clustered 554 using Cluster software (de Hoon et al., 2004) and TreeView (Saldanha, 2004) was used to facilitate 555 visualization of the differential interactomes. Gene Ontology analysis, using PANTHER (Mi et al., 2017), 556 of the proteins statistically elevated in each individual splice variant capture were evaluated for 557 enrichment of terms in the categories of Biological Processes and Cellular Component (Table S4)

\section{siRNA Knockdown Screen}

559 Cell Culture, $K D$, and Infection. The virus used for determining the effect of gene specific siRNA 560 knockdown on early and late HIV-1 gene expression was a two-color fluorescent HIV-1 reporter virus 561 (E-R-Gag-3xCFP mCherry/nef). This virus expresses mCherry in the nef ORF and three copies of 562 CFP, in tandem, between the matrix and capsid ORFs of Gag, in a similar but expanded manner as 563 previously done (Hendrix et al., 2015; Holmes et al., 2015; Mergener et al., 1992). This virus allows 564 screening for early (mCherry; completely-spliced gene products) and late (CFP; unspliced gene 565 products). Stocks of viral inoculum were produced in 293T cells by transfecting the E-R- Gag-3xCFP 566 mCherry/nef with psPAX2 and VSV-G. Human 293T cells stably-expressing YFP-ACT were cultured in 567 DMEM supplemented with 10\% fetal bovine serum, 1\% L-glutamine, and 1\% penicillin-streptomycin. All 568 cell incubations during the siRNA KD process were done at $37^{\circ} \mathrm{C}$ and $5 \% \mathrm{CO}_{2}$ in a humidified 569 incubator. Approximately $5 \times 10^{3}$ cells were plated in 24 wells of a 96 -well culture plate and incubated 24 570 hours; then the media was replaced with 125uL of anti-biotic free DMEM. 0.875uL of DarmaFECT 571 transfection reagent in 25uL of Opti-MEM was mixed with $25 \mathrm{uL}$ of Opti-MEM containing 4.4 pmol of 
572 gene specific siRNA (Table S5), incubated at room temperature for 20 minutes, then added to the

573 appropriate well of the 96-well plate. The final, in-well concentration of each siRNA was 25nM. After

574 four hours of incubation, the media was replaced with fresh DMEM media and the cells were incubated

575 overnight. 24-hours post transfection the cells were lifted from the bottom of the well by gentle pipetting,

576 divided equally into two wells, incubated for another 24-hours, then again each well containing cells

577 was divided equally into two wells (now a total of four wells for each gene specific siRNA KD). The cells

578 were allowed to adhere for 2-4 hours then a second siRNA transfection as described above was

579 conducted in all four wells. Four hours post transfection the siRNA containing media was replaced with

580 fresh media. Additionally, in two of the four wells, polybrene was added to the media (final

581 concentration of $2 \mathrm{ug} / \mathrm{mL}$ ) followed by the HIV-1 reporter virus (E-R- Gag-3xCFP mCherry/nef) inoculum

582 in DMEM. After 24 hours the media was exchanged for fresh media and 48-hours post infection the

583 cells were washed with PBS and fixed for 12 minutes using 4\% paraformaldehyde (PFA) in PBS then

584 stored at 4C in PBS until imaged. Two biological replicates, each consisting of two technical replicates

585 of infected and two technical replicates of uninfected cells, were obtained for each siRNA targeted

586 gene. Biological replicates are defined as full siRNA knockdown procedures, from cell plating to cell

587 fixation, performed on different days.

588 Imaging. Imaging experiments were performed on a Nikon Ti-Eclipse inverted wide-field

589 epifluorescence deconvolution microscope (Nikon Corporation). Images were collected using an Orca-

590 Flash 4.0 C11440 (Hamamatsu Photonics) camera and Nikon NIS Elements software (v 4.20.03) using

591 Nikon 4x/0.13 (Plan Apo) objective lense and the following excitation/emission filter set ranges

592 (wavelengths in nanometers): 418 to $442 / 458$ to 482 (CFP), 490 to 510/520 to 550 (YFP), 555 to

$593589 / 602$ to 662 (mCherry).

594 Image Processing and HIV Gene Expression Quantitation. Images were processed and analyzed

595 using FIJI/ImageJ2 (Rueden et al., 2017). For each well, only cell monolayers were used for

596 quantitation of fluorescence. Cell viability for each gene specific siRNA knockdown was assessed using 
597 the ACT-YFP marker. Wells that had YFP fluorescence detected within $+/-1.5$ standard deviations of

598 the plate mean were considered acceptable for further analysis. CFP and mCherry fluorescence for

599 each well was normalized to the YFP fluorescence for the gene specific siRNA and negative control

600 siRNA (included in each 96-well plate). The Student's t-test calculation was performed to determine if a

601 statistically significant change in CFP or mCherry expression was detected between each gene specific

602 siRNA KD and the negative control siRNA KD (Table S6; p-value < 0.05).

603 Western Blot Validation. 293T cells, with and without gene specific siRNA knockdown, were lysed in

$6041 \mathrm{x}$ radioimmunoprecipitation assay (RIPA) buffer (10 mM Tris- $\mathrm{HCl}$ [pH 7.5], $150 \mathrm{mM} \mathrm{NaCl}, 1 \mathrm{mM}$

605 EDTA, $0.1 \%$ SDS, $1 \%$ Triton X-100, 1\% sodium deoxycholate) and sonicated. Samples were then

606 boiled for 10 minutes in 2x dissociation buffer (62.5 mM Tris-HCl [pH 6.8], 10\% glycerol, $2 \%$ sodium

607 dodecyl sulfate [SDS], 10\% $\beta$-mercaptoethanol), run on SDS-PAGE 10\% polyacrylamide gels, and

608 transfered to nitrocellulose membranes $(0.2 \mu \mathrm{M}$ pore size $)$. Immunoblotting was performed as

609 previously described (Becker and Sherer, 2017; Behrens et al., 2017; Garcia-Miranda et al., 2016)

610 using the primary and secondary antibodies detailed in Table S8.

\section{Co-localization and Expression Quantitation}

612 Cell Culture and Infection. HeLa cells cultured in DMEM in 8-well Ibidi plates were infected with HIV-1

613 attenuated virus (E-R-CFP), described above, by adding polybrene to each well at a final concentration

614 of $2 \mathrm{ug} / \mathrm{mL}$ followed by the virus inoculum. Media was exchanged with fresh media 24-hours post-

615 infection (h.p.i). The cells were fixed 48-hours h.p.i by washing with PBS, incubating with $3.7 \%$

616 formaldehyde for 10 minutes at room temperature, then washing three times with PBS. Cells were then

617 made permeable by incubating with $0.2 \%$ Triton $\mathrm{X}-100$ for 15 minutes at room temperature and

618 washing three times with PBS. Endogenous RNases were then deactivated by incubating with $0.1 \%$

619 DEPC in PBS for 15 minutes, removing the solution then incubating again with fresh $0.1 \%$ DEPC in

620 PBS for 15 minutes; the cells were then washed three times with PBS and stored at $4^{\circ} \mathrm{C}$. 
621 Immunofluorescence (IF) Labeling. All immunofluorescence steps were conducted at room

622 temperature. Blocking buffer was added to each well, incubated for 30-60 minutes, then removed. Cells

623 were then incubated with fresh blocking buffer containing the appropriate primary antibodies at

624 designated concentrations (Table S8) for 60 minutes followed by four, 5 minute, washes with blocking

625 buffer. Blocking buffer containing appropriate concentrations of the secondary antibodies and DAPI

626 stain (Table S8) were then incubated with the cells for 40 minutes followed by 4,5 minute, washes with

627 PBS. Finally, the cells were fixed with $3.7 \%$ formaldehyde for 10 minutes followed by 3 washes with

628 PBS.

629 Fluorescence In Situ Hybridization (FISH). The FISH protocol was conducted using Stellaris

630 designed hybridization probes (Table S10) and Stellaris FISH reagents. All FISH steps were conducted

631 in the dark. Cells were washed with FISH Wash Buffer A for 5 minutes at room temperature. FISH

632 Hybridization Buffer containing $12.5 \mathrm{nM}$ FISH probes was added to each well and incubated at $37^{\circ} \mathrm{C}$ for

6334 hours. The cells were then washed twice with FISH Wash Buffer A for 30 minutes at $37^{\circ} \mathrm{C}$ then

634 washed once with FISH Wash Buffer B for 5 minutes at room temperature.

635 Order of Protocols. The performance of each primary antibody was dependent on the order that the

636 FISH and IF protocols were performed. For some protein/antibody pairs (DNM2, HNRNPR, FAM120A,

637 MBOAT7, MOV10, RBM4, RBMX) the IF signal was superior if the IF was conducted prior to FISH. For

638 other antibodies (CSDE1, LRPPRC, TRIM56) the IF signal was superior if the IF was conducted after

639 FISH. For G3BP1 and IGF2BP3, either order was fine. The protocols for each procedure remained

640 consistent, the order in which they were done was only reversed.

641 HIV RNA, Gag, and Host Protein Single-Cell Imaging. Single-cell imaging experiments were

642 performed on a Nikon Ti-Eclipse inverted wide-field epifluorescence deconvolution microscope (Nikon

643 Corporation). Images were collected using an Orca-Flash 4.0 C11440 (Hamamatsu Photonics) camera

644 and Nikon NIS Elements software (v 4.20.03) using Nikon 60x (N.A. 1.40; Plan Apo) or 100X (N.A.

645 1.45; Plan Apo) objective lenses and the following excitation/emission filter set ranges (wavelengths in 
nanometers): 405/470 (DAPI), 430/470 (CFP), 490/525 (AlexaFluor488), 585/610 (CAL Fluor Red 590), 645/705 (AlexaFluor647). Images were generally acquired in z-stacks containing various numbers of

648 images along the z-axis of the cells. Images were processed and analyzed using FIJI/ImageJ2 (Rueden 649 et al., 2017). All z-frames within a z-stack were examined for instances of co-localization; however, the 650 fluorescence from only a single z-frame was used to produce co-localization images. For determining 651 HIV RNA, Gag, and host protein expression differences in cells, four z-frames were merged additively 652 for fluorescence quantitation of each component.

Quantitation of HIV RNA, Gag, and Host Protein Immunofluorescence. Fluorescence for each

654 channel (HIV-RNA, Gag protein, and each host protein) was quantified using FIJI/ImageJ2 (Rueden et al., 2017). Nuclear and total cellular fluorescence were measured by drawing perimeters around the nucleus (defined by DAPI staining) and the entire cell (defined by Gag protein fluorescence in late stage cells or autofluorescence in uninfected/early stage cells) then using FIJI quantitation tools to measure the fluorescence within each drawn perimeter. Cytoplasmic fluorescence was calculated by subtracting nuclear fluorescence from total cell fluorescence and the Nuc/Cyto ratio was calculated by dividing the nuclear fluorescence by the cytoplasmic fluorescence (Table S13). For determining correlation of host protein expression with HIV gRNA expression, cells with outlier values in total HIV gRNA fluorescence were excluded from the dataset. An outlier here is defined as a value that is more than 1.5 interquartile ranges (IQRs) below the $1^{\text {st }}$ quartile (Q1) or above the $3^{\text {rd }}$ quartile (Q3). IQR is defined as (Q3 - Q1); with Q3 and Q1 calculated using the quartile function in Excel (Table S13). The Pearson's R value was calculated, excluding outliers, to determine correlation of US HIV RNA and host protein fluorescence expression in the nucleus, cytoplasm, total cell, and for the Nuc/Cyto ratios using the CORREL function in Excel. $\mathrm{R}^{2}$ values were calculated using the chart tools in Excel (Table S13).

For determining host protein expression and distribution changes outliers were determined, as 
671 statistically significant differences in host protein expression a student's T-test, excluding outliers, was

672 used to determine a p-value. The percent change in each category was calculated using the mean

673 values for each category within Early and Late cells.

\section{QUANTIFICATION AND STATISTICAL ANALYSIS}

675 Statistical methods are described in the appropriate "Method Details" section or figure captions for all 676 data analyses.

\section{ACKNOWLEDGEMENTS:}

679 This study was supported by National Institutes of Health [R01Al110221, U54Al150470 to N.M.S., 680 R01CA193481 to L.M.S., T32CA009135 to E.L.E.III]; the Greater Milwaukee Foundation's Shaw 681 Scientist Program [to N.M.S.]; a UW-Madison UW2020 Infrastructure Award [to N.M.S]; two National 682 Science Foundation Graduate Research Fellowships [DGE-1256259 to J.T.B. and B.E.B.], an 683 OVCGRE Dissertation Completion Fellowship [to J.T.B.]; an Advance Opportunity Fellowship from the 684 UW-Madison SciMed/GRS program [to E.L.E.III]; Any opinions, findings, and conclusions or 685 recommendations expressed in this material are those of the authors and do not necessarily reflect the 686 views of the National Science Foundation.

AUTHOR CONTRIBUTIONS:

689 Conceptualization, N.M.S., L.M.S., and R.A.K.; Methodology, N.M.S., L.M.S., and R.A.K.; Formal 690 Analysis, R.A.K.; Investigation, R.A.K., E.L.E., J.T.B., M.S., and B.E.B.; Writing-Original Draft, R.A.K.; 691 Writing-Review \& Editing, L.M.S., N.M.S., R.A.K., E.L.E., J.T.B., and B.E.B.; Visualization, R.A.K.; 692 Supervision, L.M.S. and N.M.S.; Funding Acquisition, L.M.S. and N.M.S.

\section{DECLARATION of INTERESTS:}

695 The authors declare no competing interests. 


\section{REFERENCES}

697

698

699

700

701

702

703

704

705

706

707

708

709

710

711

712

713

714

715

716

717

718

719

720

721

722

723

724

725

726

727

728

729

730

Adachi, A., Gendelman, H.E., Koenig, S., Folks, T., Willey, R., Rabson, A., and Martin, M.A. (1986). Production of acquired immunodeficiency syndrome-associated retrovirus in human and nonhuman cells transfected with an infectious molecular clone. J Virol 59, 284-291.

Bai, Y., Tambe, A., Zhou, K., and Doudna, J.A. (2014). RNA-guided assembly of Rev-RRE nuclear export complexes. Elife 3, e03656.

Becker, J.T., and Sherer, N.M. (2017). Subcellular Localization of HIV-1 gag-pol mRNAs Regulates Sites of Virion Assembly. J Virol 91.

Behrens, R.T., Aligeti, M., Pocock, G.M., Higgins, C.A., and Sherer, N.M. (2017). Nuclear Export Signal Masking Regulates HIV-1 Rev Trafficking and Viral RNA Nuclear Export. J Virol 91.

Berkowitz, R.D., Luban, J., and Goff, S.P. (1993). Specific binding of human immunodeficiency virus type 1 gag polyprotein and nucleocapsid protein to viral RNAs detected by RNA mobility shift assays. J Virol 67, 7190-7200.

Bolinger, C., and Boris-Lawrie, K. (2009). Mechanisms employed by retroviruses to exploit host factors for translational control of a complicated proteome. Retrovirology 6,8 .

Breuza, L., Poux, S., Estreicher, A., Famiglietti, M.L., Magrane, M., Tognolli, M., Bridge, A., Baratin, D., Redaschi, N., and UniProt, C. (2016). The UniProtKB guide to the human proteome. Database (Oxford) 2016.

Briese, M., Saal-Bauernschubert, L., Ji, C., Moradi, M., Ghanawi, H., Uhl, M., Appenzeller, S., Backofen, R., and Sendtner, M. (2018). hnRNP $R$ and its main interactor, the noncoding RNA 7SK, coregulate the axonal transcriptome of motoneurons. Proc Natl Acad Sci U S A 115, E2859-E2868.

Coffin, J.M., Hughes, S.H., and Varmus, H.E. (1997). The Interactions of Retroviruses and their Hosts. In Retroviruses, J.M. Coffin, S.H. Hughes, and H.E. Varmus, eds. (Cold Spring Harbor (NY)).

Cox, J., and Mann, M. (2008). MaxQuant enables high peptide identification rates, individualized p.p.b.-range mass accuracies and proteome-wide protein quantification. Nat Biotechnol 26, 1367-1372.

Cox, J., Neuhauser, N., Michalski, A., Scheltema, R.A., Olsen, J.V., and Mann, M. (2011). Andromeda: a peptide search engine integrated into the MaxQuant environment. J Proteome Res 10, 1794-1805.

Cullen, B.R. (1991). Regulation of HIV-1 gene expression. FASEB J 5, 2361-2368.

Daugherty, M.D., D'Orso, I., and Frankel, A.D. (2008). A solution to limited genomic capacity: using adaptable binding surfaces to assemble the functional HIV Rev oligomer on RNA. Mol Cell 31, 824-834.

Daugherty, M.D., Liu, B., and Frankel, A.D. (2010). Structural basis for cooperative RNA binding and export complex assembly by HIV Rev. Nat Struct Mol Biol 17, 1337-1342.

de Hoon, M.J., Imoto, S., Nolan, J., and Miyano, S. (2004). Open source clustering software. Bioinformatics 20, 1453-1454.

DiMattia, M.A., Watts, N.R., Cheng, N., Huang, R., Heymann, J.B., Grimes, J.M., Wingfield, P.T., Stuart, D.I., and Steven, A.C. (2016). The Structure of HIV-1 Rev Filaments Suggests a Bilateral Model for Rev-RRE Assembly. Structure 24, 1068-1080. 
DiMattia, M.A., Watts, N.R., Stahl, S.J., Rader, C., Wingfield, P.T., Stuart, D.I., Steven, A.C., and Grimes, J.M. (2010). Implications of the HIV-1 Rev dimer structure at 3.2 A resolution for multimeric binding to the Rev response element. Proc Natl Acad Sci U S A 107, 5810-5814.

Eckenfelder, A., Segeral, E., Pinzon, N., Ulveling, D., Amadori, C., Charpentier, M., Nidelet, S., Concordet, J.P., Zagury, J.F., Paillart, J.C., et al. (2017). Argonaute proteins regulate HIV-1 multiply spliced RNA and viral production in a Dicer independent manner. Nucleic Acids Res 45, 4158-4173.

Emery, A., Zhou, S., Pollom, E., and Swanstrom, R. (2017). Characterizing HIV-1 Splicing by Using NextGeneration Sequencing. J Virol 91.

Erde, J., Loo, R.R., and Loo, J.A. (2014). Enhanced FASP (eFASP) to increase proteome coverage and sample recovery for quantitative proteomic experiments. J Proteome Res 13, 1885-1895.

Fang, X., Wang, J., O'Carroll, I.P., Mitchell, M., Zuo, X., Wang, Y., Yu, P., Liu, Y., Rausch, J.W., Dyba, M.A., et al. (2013). An unusual topological structure of the HIV-1 Rev response element. Cell 155, 594-605.

Freed, E.O., and Mouland, A.J. (2006). The cell biology of HIV-1 and other retroviruses. Retrovirology 3, 77.

Garcia-Miranda, P., Becker, J.T., Benner, B.E., Blume, A., Sherer, N.M., and Butcher, S.E. (2016). Stability of HIV Frameshift Site RNA Correlates with Frameshift Efficiency and Decreased Virus Infectivity. J Virol 90, 6906-6917.

Hadian, K., Vincendeau, M., Mausbacher, N., Nagel, D., Hauck, S.M., Ueffing, M., Loyter, A., Werner, T., Wolff, H., and Brack-Werner, R. (2009). Identification of a heterogeneous nuclear ribonucleoprotein-recognition region in the HIV Rev protein. J Biol Chem 284, 33384-33391.

Harvey, J.J., Lewsey, M.G., Patel, K., Westwood, J., Heimstadt, S., Carr, J.P., and Baulcombe, D.C. (2011). An antiviral defense role of AGO2 in plants. PLoS One 6, e14639.

Hendrix, J., Baumgartel, V., Schrimpf, W., Ivanchenko, S., Digman, M.A., Gratton, E., Krausslich, H.G., Muller, B., and Lamb, D.C. (2015). Live-cell observation of cytosolic HIV-1 assembly onset reveals RNA-interacting Gag oligomers. J Cell Biol 210, 629-646.

Hirata, Y., Yamamori, N., Kono, N., Lee, H.C., Inoue, T., and Arai, H. (2013). Identification of small subunit of serine palmitoyltransferase a as a lysophosphatidylinositol acyltransferase 1-interacting protein. Genes Cells 18, 397-409.

Holmes, M., Zhang, F., and Bieniasz, P.D. (2015). Single-Cell and Single-Cycle Analysis of HIV-1 Replication. PLoS Pathog 11, e1004961.

Jin, D., and Musier-Forsyth, K. (2019). Role of host tRNAs and aminoacyl-tRNA synthetases in retroviral replication. J Biol Chem 294, 5352-5364.

Jonson, L., Vikesaa, J., Krogh, A., Nielsen, L.K., Hansen, T., Borup, R., Johnsen, A.H., Christiansen, J., and Nielsen, F.C. (2007). Molecular composition of IMP1 ribonucleoprotein granules. Mol Cell Proteomics 6, 798-811.

Jung, Y.M., Yu, K.L., Park, S.H., Lee, S.D., Kim, M.J., and You, J.C. (2018). Investigation of function and regulation of the YB-1 cellular factor in HIV replication. BMB Rep 51, 290-295.

Karn, J., and Stoltzfus, C.M. (2012). Transcriptional and posttranscriptional regulation of HIV-1 gene expression. Cold Spring Harb Perspect Med 2, a006916.

Kelly, T.J., Suzuki, H.I., Zamudio, J.R., Suzuki, M., and Sharp, P.A. (2019). Sequestration of microRNA-mediated target repression by the Ago2-associated RNA-binding protein FAM120A. RNA 25, 1291-1297. 
Knoener, R.A., Becker, J.T., Scalf, M., Sherer, N.M., and Smith, L.M. (2017). Elucidating the in vivo interactome of HIV-1 RNA by hybridization capture and mass spectrometry. Sci Rep 7, 16965.

Kula, A., Guerra, J., Knezevich, A., Kleva, D., Myers, M.P., and Marcello, A. (2011). Characterization of the HIV-1 RNA associated proteome identifies Matrin 3 as a nuclear cofactor of Rev function. Retrovirology 8, 60.

Lee, H.C., Inoue, T., Imae, R., Kono, N., Shirae, S., Matsuda, S., Gengyo-Ando, K., Mitani, S., and Arai, H. (2008). Caenorhabditis elegans mboa-7, a member of the MBOAT family, is required for selective incorporation of polyunsaturated fatty acids into phosphatidylinositol. Mol Biol Cell 19, 1174-1184.

Lee, H.C., Inoue, T., Sasaki, J., Kubo, T., Matsuda, S., Nakasaki, Y., Hattori, M., Tanaka, F., Udagawa, O., Kono, N., et al. (2012). LPIAT1 regulates arachidonic acid content in phosphatidylinositol and is required for cortical lamination in mice. Mol Biol Cell 23, 4689-4700.

Lever, A., Gottlinger, H., Haseltine, W., and Sodroski, J. (1989). Identification of a sequence required for efficient packaging of human immunodeficiency virus type 1 RNA into virions. J Virol 63, 4085-4087.

Luban, J., and Goff, S.P. (1994). Mutational analysis of cis-acting packaging signals in human immunodeficiency virus type 1 RNA. J Virol 68, 3784-3793.

Mahiet, C., and Swanson, C.M. (2016). Control of HIV-1 gene expression by SR proteins. Biochem Soc Trans 44, 1417-1425.

Marchand, V., Santerre, M., Aigueperse, C., Fouillen, L., Saliou, J.M., Van Dorsselaer, A., Sanglier-Cianferani, S., Branlant, C., and Motorin, Y. (2011). Identification of protein partners of the human immunodeficiency virus 1 tat/rev exon 3 leads to the discovery of a new HIV-1 splicing regulator, protein hnRNP K. RNA Biol 8, 325-342.

Mbonye, U., and Karn, J. (2014). Transcriptional control of HIV latency: cellular signaling pathways, epigenetics, happenstance and the hope for a cure. Virology 454-455, 328-339.

McLaren, M., Marsh, K., and Cochrane, A. (2008). Modulating HIV-1 RNA processing and utilization. Front Biosci 13, 5693-5707.

Meng, B., and Lever, A.M. (2013). Wrapping up the bad news: HIV assembly and release. Retrovirology 10, 5.

Mergener, K., Facke, M., Welker, R., Brinkmann, V., Gelderblom, H.R., and Krausslich, H.G. (1992). Analysis of HIV particle formation using transient expression of subviral constructs in mammalian cells. Virology 186, 25-39.

Mi, H., Huang, X., Muruganujan, A., Tang, H., Mills, C., Kang, D., and Thomas, P.D. (2017). PANTHER version 11: expanded annotation data from Gene Ontology and Reactome pathways, and data analysis tool enhancements. Nucleic Acids Res 45, D183-D189.

Mili, S., and Pinol-Roma, S. (2003). LRP130, a pentatricopeptide motif protein with a noncanonical RNA-binding domain, is bound in vivo to mitochondrial and nuclear RNAs. Mol Cell Biol 23, 4972-4982.

Mu, X., Li, W., Wang, X., and Gao, G. (2013). YB-1 stabilizes HIV-1 genomic RNA and enhances viral production. Protein Cell 4, 591-597.

Ocwieja, K.E., Sherrill-Mix, S., Mukherjee, R., Custers-Allen, R., David, P., Brown, M., Wang, S., Link, D.R., Olson, J., Travers, K., et al. (2012). Dynamic regulation of HIV-1 mRNA populations analyzed by single-molecule enrichment and long-read sequencing. Nucleic Acids Res 40, 10345-10355.

Oughtred, R., Stark, C., Breitkreutz, B.J., Rust, J., Boucher, L., Chang, C., Kolas, N., O'Donnell, L., Leung, G., McAdam, R., et al. (2019). The BioGRID interaction database: 2019 update. Nucleic Acids Res 47, D529-D541. 
Pollard, V.W., and Malim, M.H. (1998). The HIV-1 Rev protein. Annu Rev Microbiol 52, 491-532.

Puray-Chavez, M., Tedbury, P.R., Huber, A.D., Ukah, O.B., Yapo, V., Liu, D., Ji, J., Wolf, J.J., Engelman, A.N., and Sarafianos, S.G. (2017). Multiplex single-cell visualization of nucleic acids and protein during HIV infection. Nat Commun 8, 1882.

Purcell, D.F., and Martin, M.A. (1993). Alternative splicing of human immunodeficiency virus type 1 mRNA modulates viral protein expression, replication, and infectivity. J Virol 67, 6365-6378.

Reches, A., Nachmani, D., Berhani, O., Duev-Cohen, A., Shreibman, D., Ophir, Y., Seliger, B., and Mandelboim, O. (2016). HNRNPR Regulates the Expression of Classical and Nonclassical MHC Class I Proteins. J Immunol 196, 4967-4976.

Rueden, C.T., Schindelin, J., Hiner, M.C., DeZonia, B.E., Walter, A.E., Arena, E.T., and Eliceiri, K.W. (2017). ImageJ2: ImageJ for the next generation of scientific image data. BMC Bioinformatics 18, 529.

Ruzzenente, B., Metodiev, M.D., Wredenberg, A., Bratic, A., Park, C.B., Camara, Y., Milenkovic, D., Zickermann, V., Wibom, R., Hultenby, K., et al. (2012). LRPPRC is necessary for polyadenylation and coordination of translation of mitochondrial mRNAs. EMBO J 31, 443-456.

Saldanha, A.J. (2004). Java Treeview--extensible visualization of microarray data. Bioinformatics 20, 3246-3248.

Schweitzer, C.J., Matthews, J.M., Madson, C.J., Donnellan, M.R., Cerny, R.L., and Belshan, M. (2012). Knockdown of the cellular protein LRPPRC attenuates HIV-1 infection. PLoS One 7, e40537.

Sertznig, H., Hillebrand, F., Erkelenz, S., Schaal, H., and Widera, M. (2018). Behind the scenes of HIV-1 replication: Alternative splicing as the dependency factor on the quiet. Virology 516, 176-188.

Singh, D., Boeras, I., Singh, G., and Boris-Lawrie, K. (2016). Isolation of Cognate Cellular and Viral Ribonucleoprotein Complexes of HIV-1 RNA Applicable to Proteomic Discovery and Molecular Investigations. Methods Mol Biol 1354, 133-146.

Spiniello, M., Knoener, R.A., Steinbrink, M.I., Yang, B., Cesnik, A.J., Buxton, K.E., Scalf, M., Jarrard, D.F., and Smith, L.M. (2018). HyPR-MS for Multiplexed Discovery of MALAT1, NEAT1, and NORAD IncRNA Protein Interactomes. J Proteome Res 17, 3022-3038.

Spiniello, M., Steinbrink, M.I., Cesnik, A.J., Miller, R.M., Scalf, M., Shortreed, M.R., and Smith, L.M. (2019). Comprehensive in vivo identification of the c-Myc mRNA protein interactome using HyPR-MS. RNA 25, 1337-1352.

Stoltzfus, C.M. (2009). Chapter 1. Regulation of HIV-1 alternative RNA splicing and its role in virus replication. Adv Virus Res 74, 1-40.

Swanson, C.M., and Malim, M.H. (2006). Retrovirus RNA trafficking: from chromatin to invasive genomes. Traffic 7, 1440-1450.

Tyanova, S., Temu, T., Sinitcyn, P., Carlson, A., Hein, M.Y., Geiger, T., Mann, M., and Cox, J. (2016). The Perseus computational platform for comprehensive analysis of (prote)omics data. Nat Methods 13, 731-740.

Vega, Y., Delgado, E., de la Barrera, J., Carrera, C., Zaballos, A., Cuesta, I., Marino, A., Ocampo, A., Miralles, C., Perez-Castro, S., et al. (2016). Sequence Analysis of In Vivo-Expressed HIV-1 Spliced RNAs Reveals the Usage of New and Unusual Splice Sites by Viruses of Different Subtypes. PLoS One 11, e0158525.

Volpon, L., Culjkovic-Kraljacic, B., Sohn, H.S., Blanchet-Cohen, A., Osborne, M.J., and Borden, K.L.B. (2017). A biochemical framework for elF4E-dependent mRNA export and nuclear recycling of the export machinery. RNA 23, 927-937. 
bioRxiv preprint doi: https://doi.org/10.1101/2020.09.15.298190; this version posted September 16, 2020. The copyright holder for this preprint (which was not certified by peer review) is the author/funder, who has granted bioRxiv a license to display the preprint in perpetuity. It is made available under aCC-BY 4.0 International license.

845 Weinberger, L.S., Burnett, J.C., Toettcher, J.E., Arkin, A.P., and Schaffer, D.V. (2005). Stochastic gene expression 846 in a lentiviral positive-feedback loop: HIV-1 Tat fluctuations drive phenotypic diversity. Cell 122, 169-182.

847 Zhou, Y., Rong, L., Lu, J., Pan, Q., and Liang, C. (2008). Insulin-like growth factor II mRNA binding protein 1 848 associates with Gag protein of human immunodeficiency virus type 1, and its overexpression affects virus assembly. 849 J Virol 82, 5683-5692. 
bioRxiv preprint doi-Nttps://doi.org/10.1101/2020.09.15.298190; this version posted September 16, 2020. The copyright holder for this preprint (which was not ceriffied by ded review) is the authotrfunder, who has gptrated bioRxiv a license to display the preprint in perpetuity. It is made Genome $5^{\prime}$ ravailable underaCC-BY 4.0 international license.

\section{Protein Products}

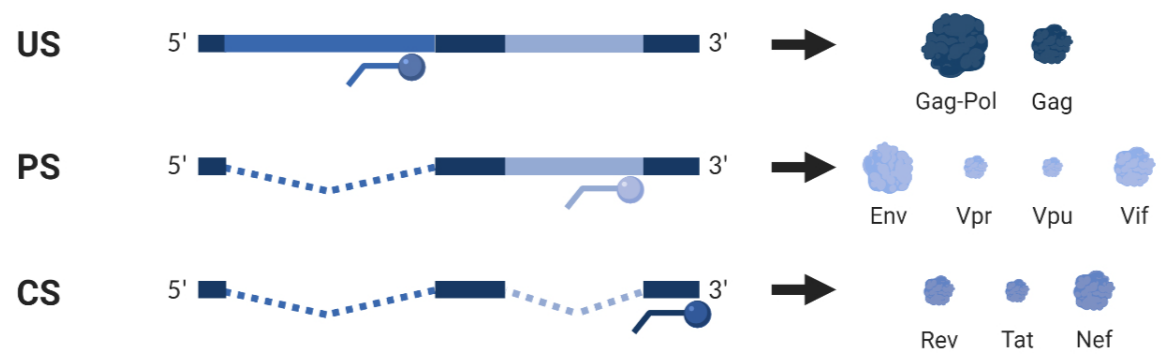

\section{Capture Oligonucleotide \\ (CO) Legend \\ Intron 1-CO Intron 2-CO 3'Exon-CO}

B

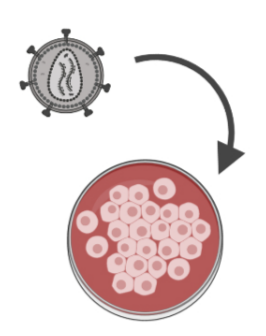

HIV Infect

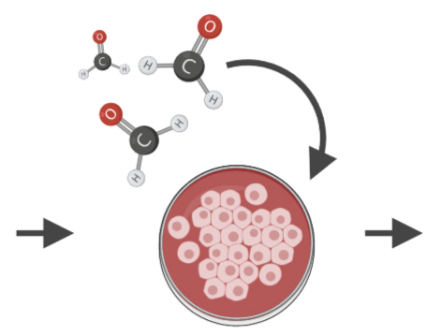

Formaldehyde Crosslink

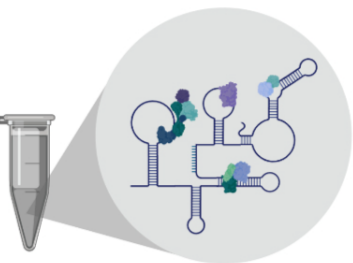

Lyse and Solubilize

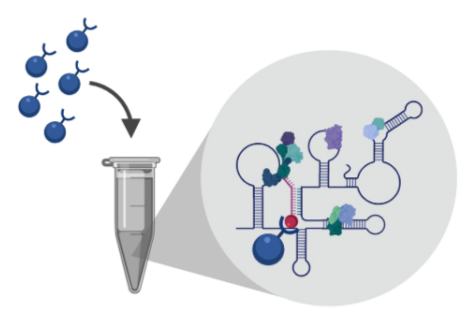

Capture with Streptavidin-Coated Magnetic Beads

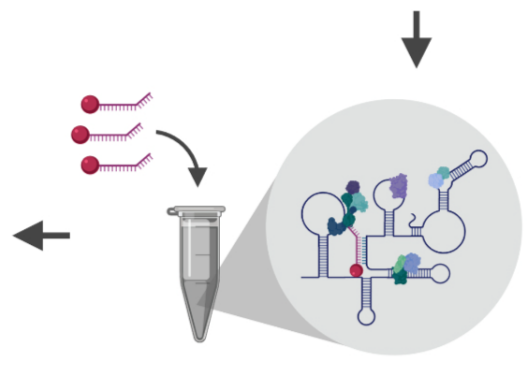

Hybridization of CO to HIV RNA

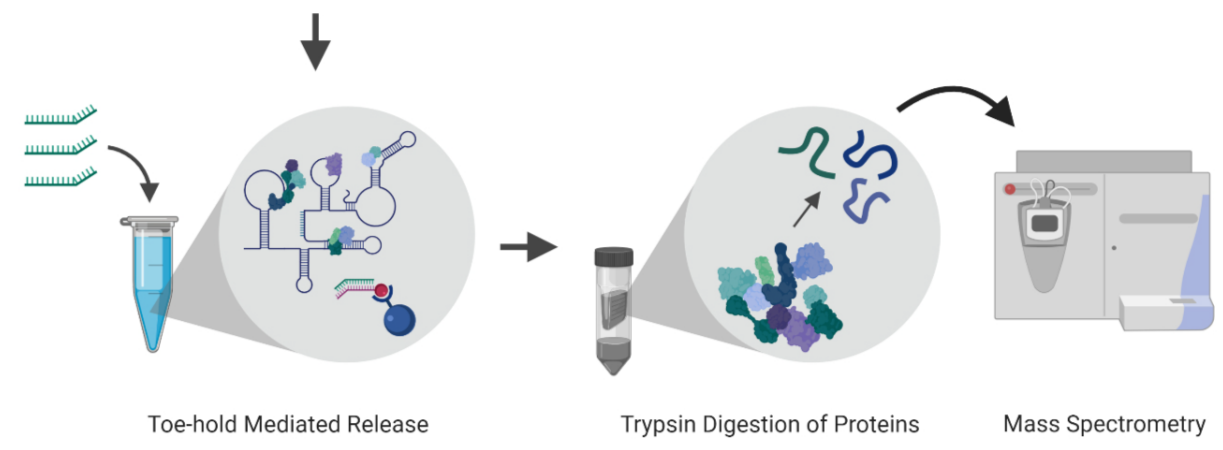

C

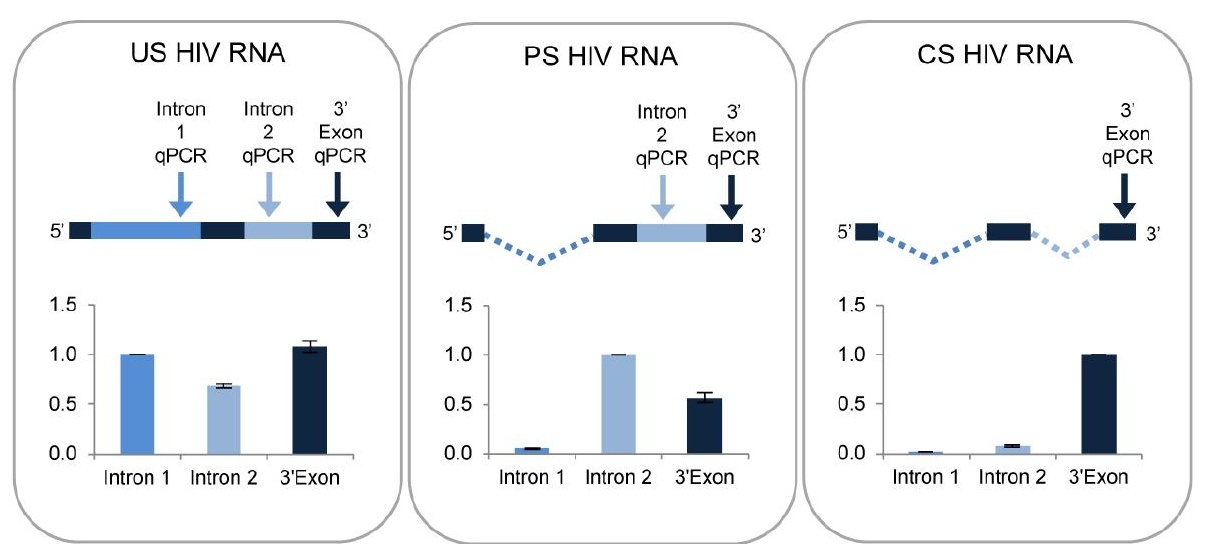


bioRxiv preprint doi: https://doi.org/10.1101/2020.09.15.298190; this version posted September 16, 2020. The copyright holder for this preprint (which was not certified by peer review) is the author/funder, who has granted bioRxiv a license to display the preprint in perpetuity. It is made available under aCC-BY 4.0 International license.

A

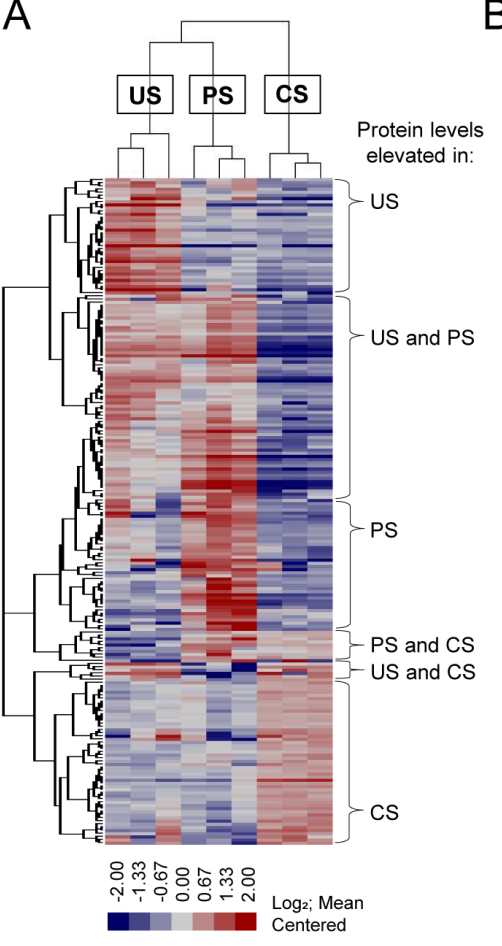

B

\begin{tabular}{|c|c|c|c|c|c|c|}
\hline \multirow{2}{*}{$\begin{array}{l}\text { Biological Process or Cellular } \\
\text { Component }\end{array}$} & \multicolumn{2}{|c|}{ US } & \multicolumn{2}{|c|}{ PS } & \multicolumn{2}{|c|}{ cs } \\
\hline & $\begin{array}{c}\text { protein } \\
\#\end{array}$ & p-value & $\begin{array}{c}\text { protein } \\
\#\end{array}$ & p-value & $\begin{array}{c}\text { protein } \\
\#\end{array}$ & $\mathrm{p}$-value \\
\hline Carboxylic acid metabolic process & 26 & $1 \times 10^{-13}$ & $\mathrm{NE}$ & NE & $\mathrm{NE}$ & $\mathrm{NE}$ \\
\hline Coenzyme metabolic process & 14 & $4 \times 10^{-10}$ & $\mathrm{NE}$ & $\mathrm{NE}$ & $\mathrm{NE}$ & NE \\
\hline Mitochondrial nucleiod & 8 & $1 \times 10^{-10}$ & $\mathrm{NE}$ & NE & $\mathrm{NE}$ & $\mathrm{NE}$ \\
\hline Regulation of mRNA stability & 9 & $9 \times 10^{-9}$ & 9 & $7 \times 10^{-9}$ & $\mathrm{NE}$ & $\mathrm{NE}$ \\
\hline mRNA splicing; via spliceosome & 9 & $1 \times 10^{-5}$ & 9 & $9 \times 10^{-6}$ & NE & NE \\
\hline Regulation of mRNA splicing & 5 & $1 \times 10^{-4}$ & 7 & $5 \times 10^{-7}$ & NE & NE \\
\hline Positive regulation of mRNA splicing & $\mathrm{NE}$ & $\mathrm{NE}$ & 3 & $2 \times 10^{-4}$ & $\mathrm{NE}$ & NE \\
\hline Negative regulation of mRNA splicing & 3 & $2 \times 10^{-4}$ & $N E$ & NE & NE & NE \\
\hline Chromosome condensation & $\mathrm{NE}$ & NE & 6 & $6 \times 10^{-8}$ & NE & NE \\
\hline Histone trimethylation & $\mathrm{NE}$ & NE & 3 & $8 \times 10^{-6}$ & NE & $\mathrm{NE}$ \\
\hline Nuclear Body & $\mathrm{NE}$ & $\mathrm{NE}$ & 13 & $7 \times 10^{-7}$ & $\mathrm{NE}$ & NE \\
\hline Post-transcriptional regulation of gene expression & 15 & $7 \times 10^{-9}$ & 14 & $4 \times 10^{-8}$ & 8 & $2 \times 10^{-4}$ \\
\hline Regulation of translation & 12 & $1 \times 10^{-7}$ & 12 & $7 \times 10^{-8}$ & 7 & $2 \times 10^{-4}$ \\
\hline Negative regulation of translation & 9 & $2 \times 10^{-8}$ & 9 & $1 \times 10^{-8}$ & $\mathrm{NE}$ & NE \\
\hline Translation & 12 & $4 \times 10^{-7}$ & NE & $\mathrm{NE}$ & 18 & $1 \times 10^{-15}$ \\
\hline Translation initiation & NE & NE & $\mathrm{NE}$ & NE & 12 & $2 \times 10^{-13}$ \\
\hline Mitochondrial translation & 7 & $2 \times 10^{-6}$ & NE & NE & NE & NE \\
\hline Cotranslational protein targeting to membrane & NE & NE & NE & NE & 10 & $4 \times 10^{-12}$ \\
\hline tRNA aminoacylation for protein translation & $\mathrm{NE}$ & NE & $\mathrm{NE}$ & NE & 4 & $3 \times 10^{-5}$ \\
\hline
\end{tabular}

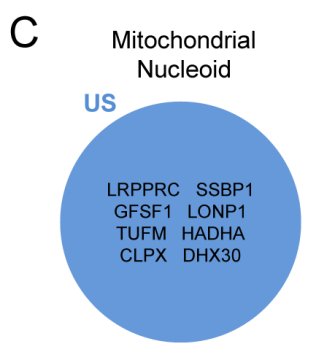

Regulation of mRNA stability

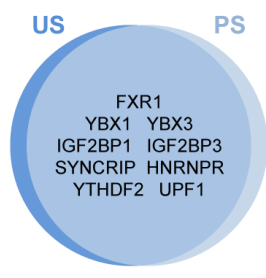

Regulation of translation

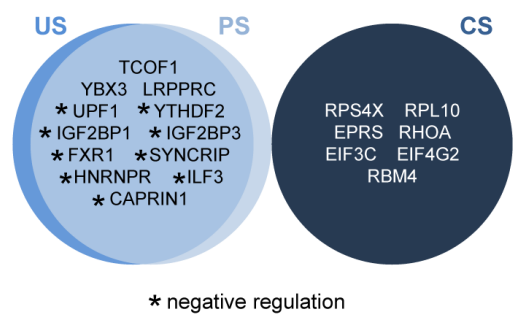

* negative regulation
mRNA splicing; via spliceosome

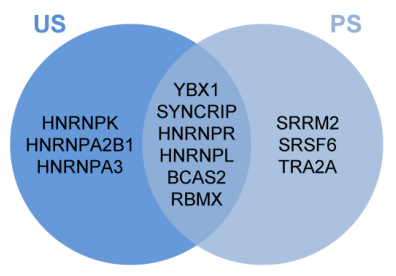

Nuclear Bodies

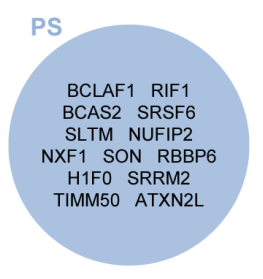

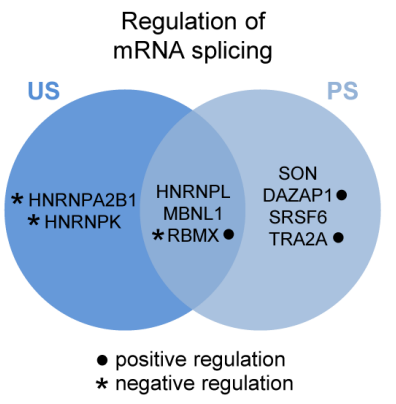

Translation
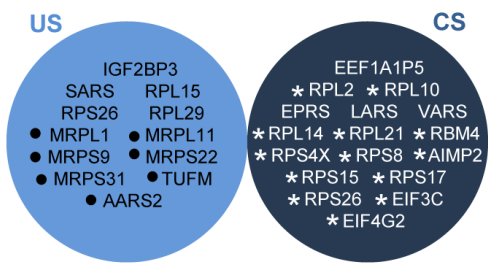

- mitochondrial translation * translation initiation 
bioRxiv preprint doi: https://doi.org/10.1101/2020.09.15.298190; this version posted September 16, 2020. The copyright holder for this preprint (which was not certified by peer review) is the author/funder, who has granted bioRxiv a license to display the preprint in perpetuity. It is made

A available under aCC-BY 4.0 International license.

B

HIV Splice Variant

US Gag-CFP

PS

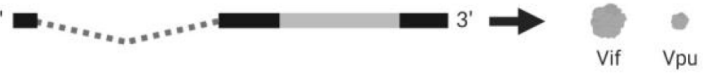

CS

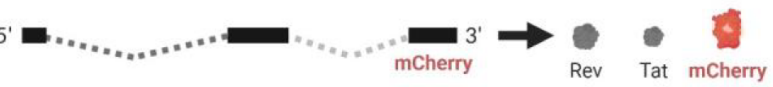

C

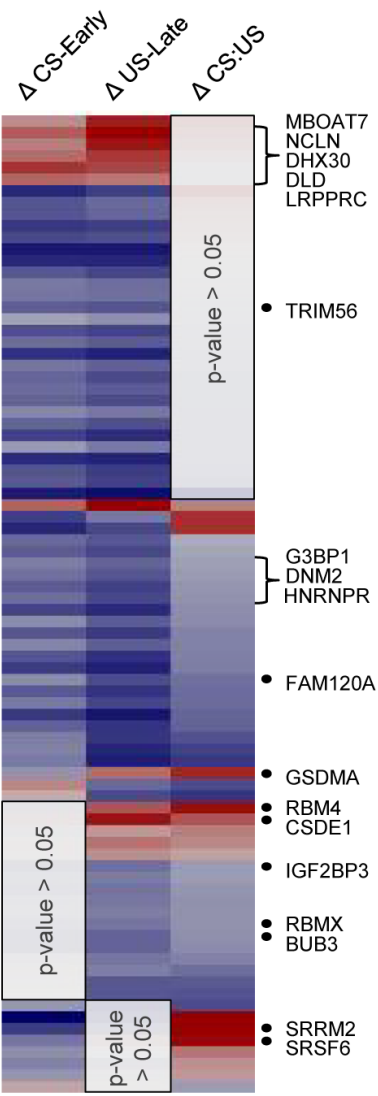

우ㅇㅜㅜ웅용ㅇ \% change in expression

Protein Products

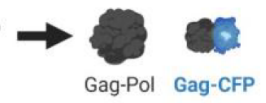

D

\begin{tabular}{|c|c|c|c|c|c|}
\hline \multirow{2}{*}{\multicolumn{2}{|c|}{ Protein }} & \multirow[b]{2}{*}{$\begin{array}{l}\text { HIV splice } \\
\text { variant }\end{array}$} & \multicolumn{2}{|c|}{$\begin{array}{c}\text { Effect of siRNA } \\
\text { knockdown }\end{array}$} & \multirow[b]{2}{*}{ General protein function } \\
\hline & & & $\begin{array}{l}\text { Early } \\
\text { (CS) }\end{array}$ & $\begin{array}{l}\text { Late } \\
\text { (US) }\end{array}$ & \\
\hline \multirow{5}{*}{ 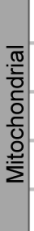 } & LRPPRC & US, PS & Inc & Inc & Mitochondrial and nuclear; potential role in mRNA nuclear export \\
\hline & DHX30 & US, PS & Inc & Inc & Mitochondrial; RNA helicase \\
\hline & MBOAT7 & US, PS & Inc & Inc & Localizes to ER and mitochondrial associated membranes (MAMs) \\
\hline & GSDMA & us & Dec & Inc & Mitochondrial lipid binding; apoptotic process \\
\hline & DLD & cs & Inc & Inc & Mitochondrial and nuclear; lipoamide dehydrogenase \\
\hline \multirow{3}{*}{ 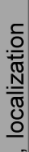 } & FAM120A & US, PS & Dec & Dec & mRNA transport \\
\hline & HNRNPR & US, PS & Dec & Dec & mRNA processing \\
\hline & IGF2BP3 & US, PS & NC & Dec & Regulation of mRNA stability and translation \\
\hline \multirow{2}{*}{$\frac{\frac{3}{\overline{0}}}{\frac{\pi}{\omega 0}}$} & G3BP1 & US, PS & Dec & Dec & Helicase; stress granule assembly \\
\hline & RBMX & US, PS & NC & Dec & mRNA splicing \\
\hline \multirow{4}{*}{ 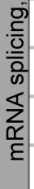 } & CSDE1 & US, PS & NC & Inc & Regulation of mRNA stability \\
\hline & SRSF6 & PS & Dec & NC & mRNA splicing \\
\hline & SRRM2 & PS & Dec & NC & mRNA splicing \\
\hline & RBM4 & cs & NC & Inc & Regulation of mRNA splicing and translation \\
\hline \multirow{4}{*}{ 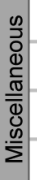 } & TRIM56 & us & Dec & Dec & E3 ubiquitin - protein ligase; innate antiviral immunity \\
\hline & BUB3 & PS & NC & Dec & Mitotic spindle assembly checkpoint \\
\hline & DNM2 & cS & Dec & Dec & Microtubule - associated; vesicular trafficking \\
\hline & NCLN & cs & Inc & Inc & Protein stabilization \\
\hline
\end{tabular}
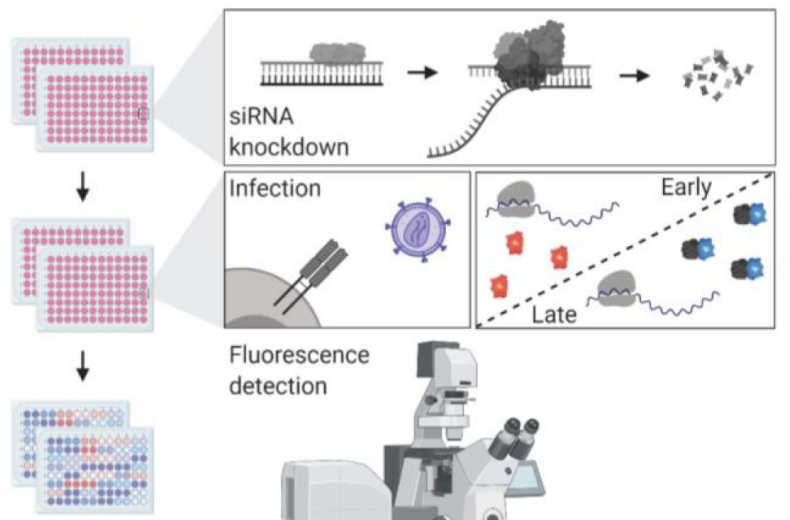

Fluorescence detection

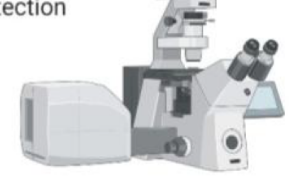


bigRxiverepito doi: https://doi
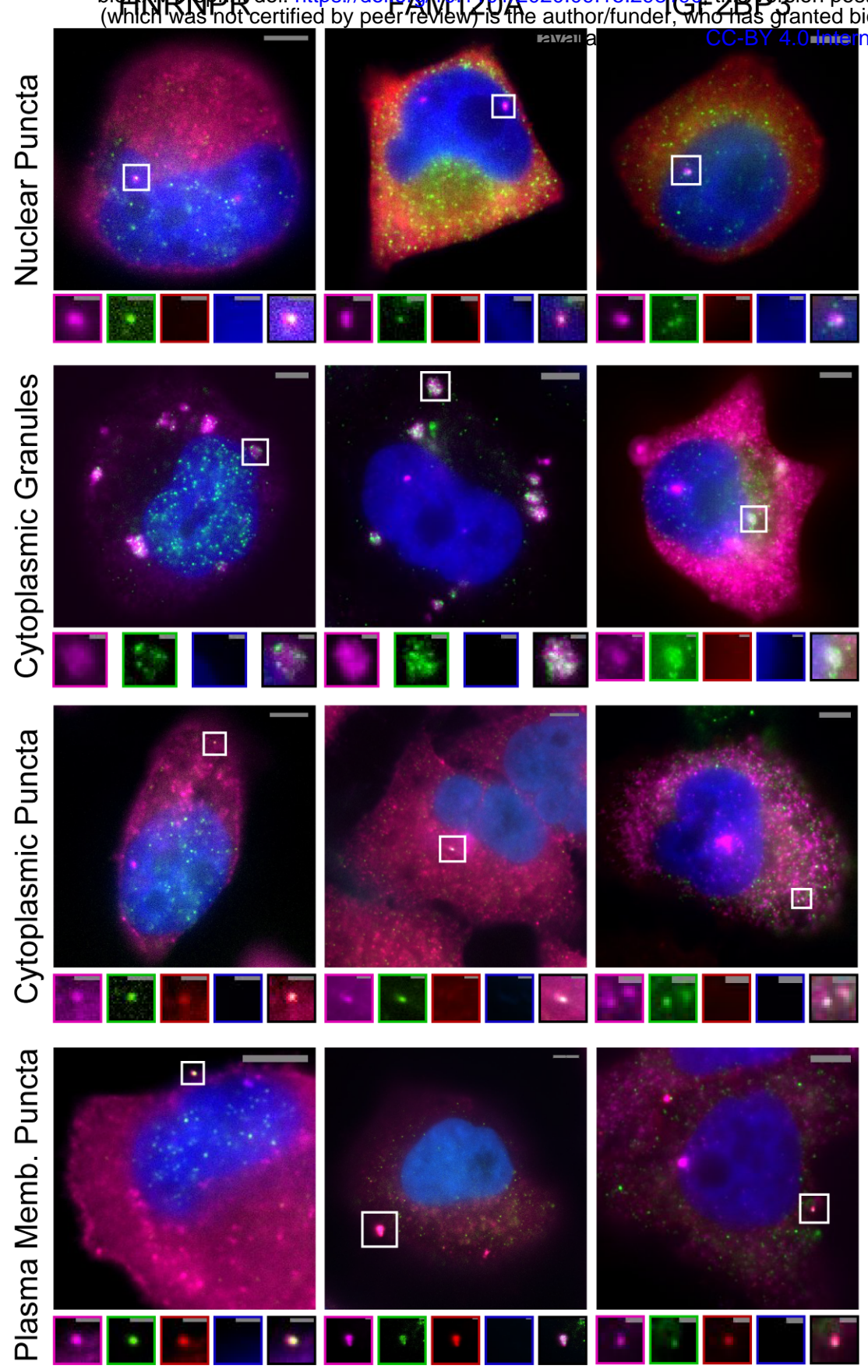

B

C
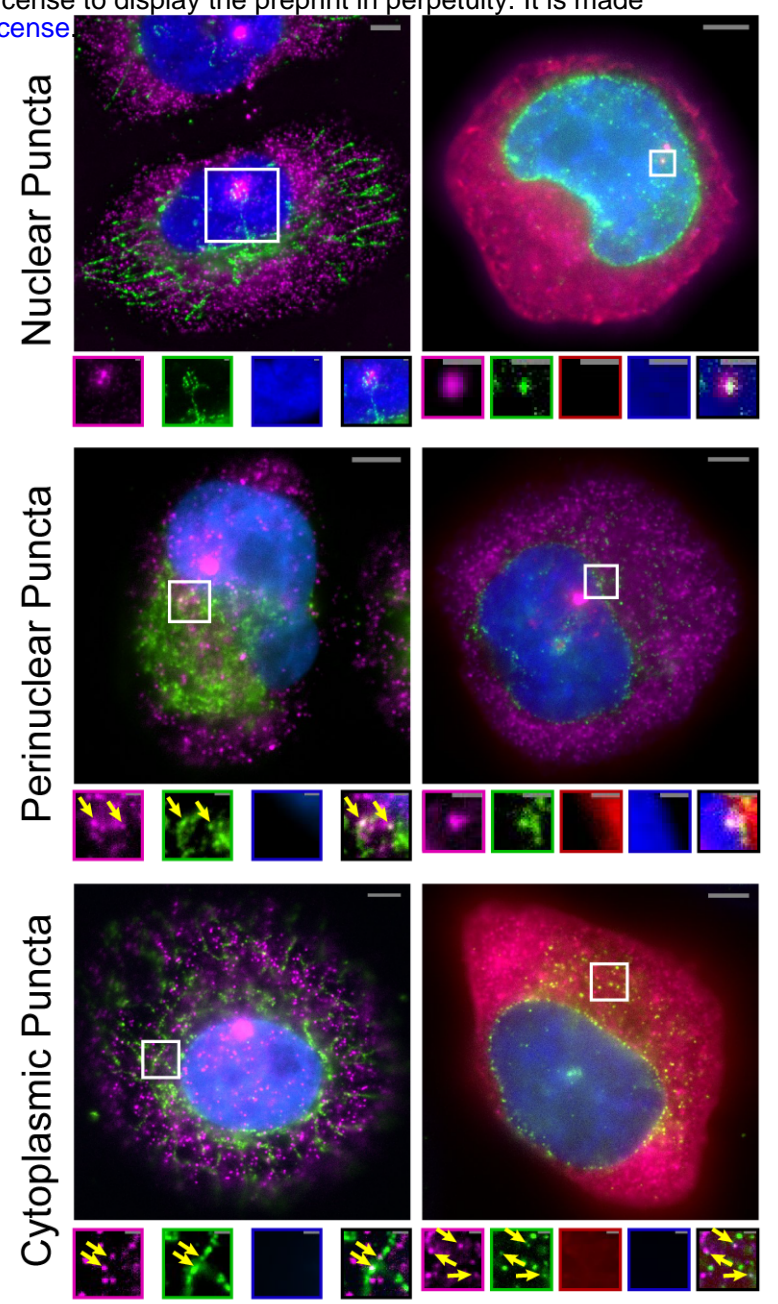

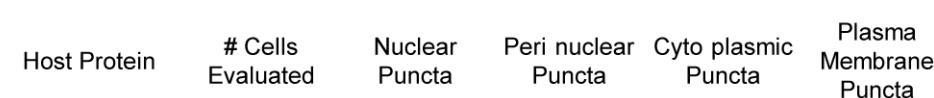

\begin{tabular}{|c|c|c|c|c|c|c|}
\hline \multirow{7}{*}{ 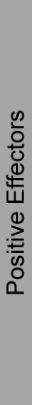 } & HNRNPR & 41 & $80 \%$ & $41 \%$ & $90 \%$ & $68 \%$ \\
\hline & FAM120A & 38 & $8 \%$ & $5 \%$ & $97 \%$ & $83 \%$ \\
\hline & IGF2BP3 & 45 & $4 \%$ & $0 \%$ & $98 \%$ & $68 \%$ \\
\hline & MOV10 & 45 & $0 \%$ & $20 \%$ & $84 \%$ & $83 \%$ \\
\hline & RBMX & 17 & $82 \%$ & $41 \%$ & $76 \%$ & $50 \%$ \\
\hline & DNM2 & 29 & $7 \%$ & $0 \%$ & $100 \%$ & $100 \%$ \\
\hline & TRIM56 & 49 & $0 \%$ & $8 \%$ & $71 \%$ & $31 \%$ \\
\hline \multirow{4}{*}{ 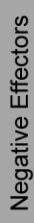 } & MBOAT7 & 47 & $57 \%$ & $91 \%$ & $91 \%$ & $0 \%$ \\
\hline & LRPPRC & 39 & $28 \%$ & $54 \%$ & $79 \%$ & $0 \%$ \\
\hline & RBM4 & 23 & $96 \%$ & $0 \%$ & $74 \%$ & $100 \%$ \\
\hline & CSDE1 & 41 & $7 \%$ & $29 \%$ & $93 \%$ & $80 \%$ \\
\hline
\end{tabular}

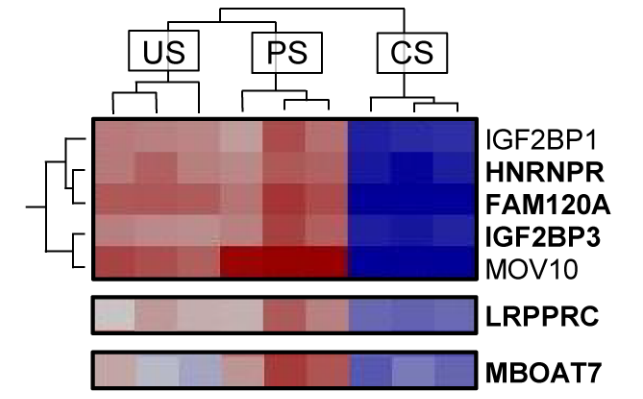

$\log _{2}$; mean

centered

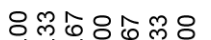

NiণO

D

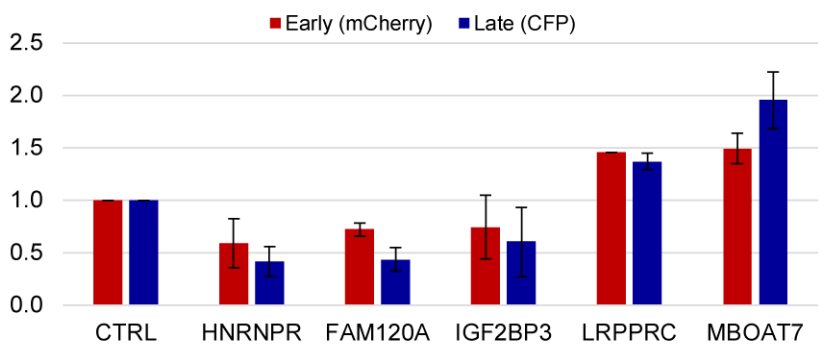



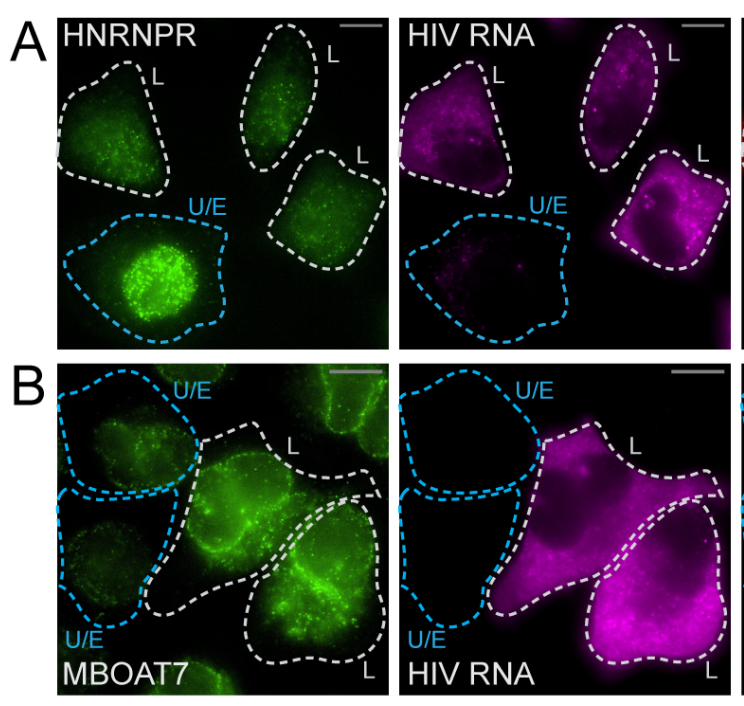

\section{Expression Changes}

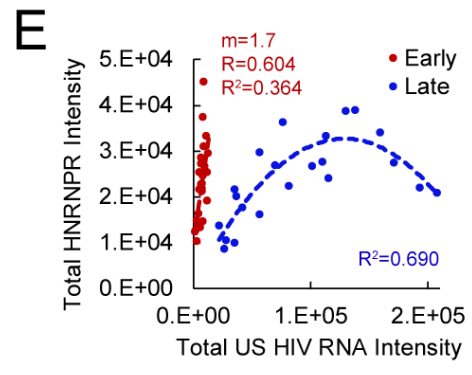

G

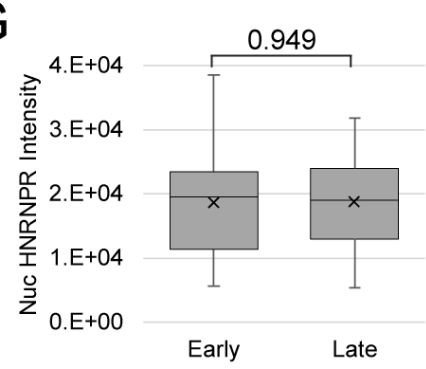

$F$
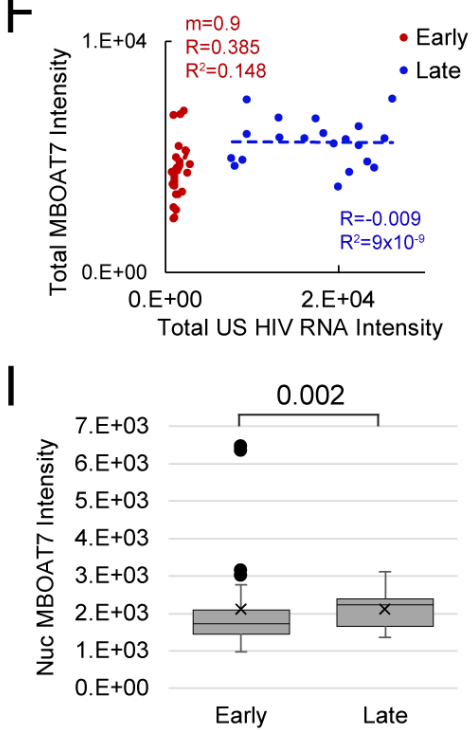

$\mathrm{H}$

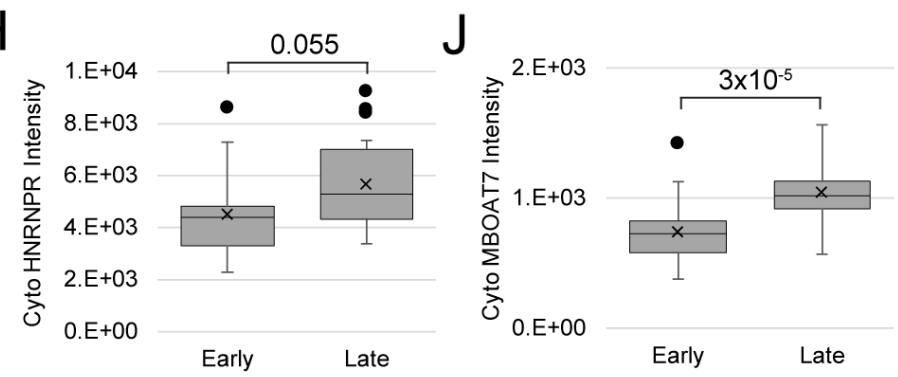

K

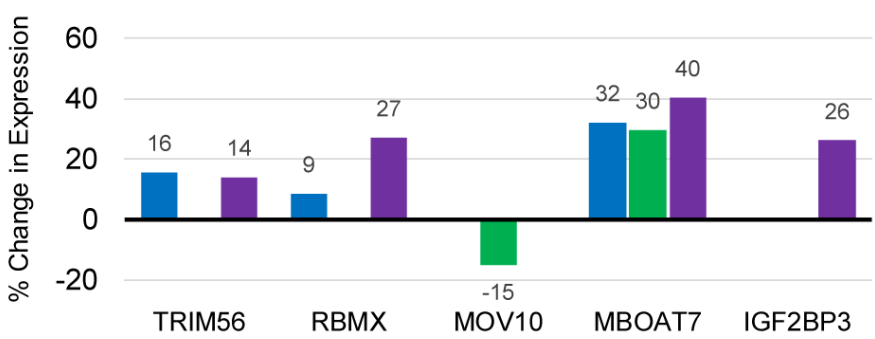

$\square$ Total $\square$ Nuc $\square$ Cyto
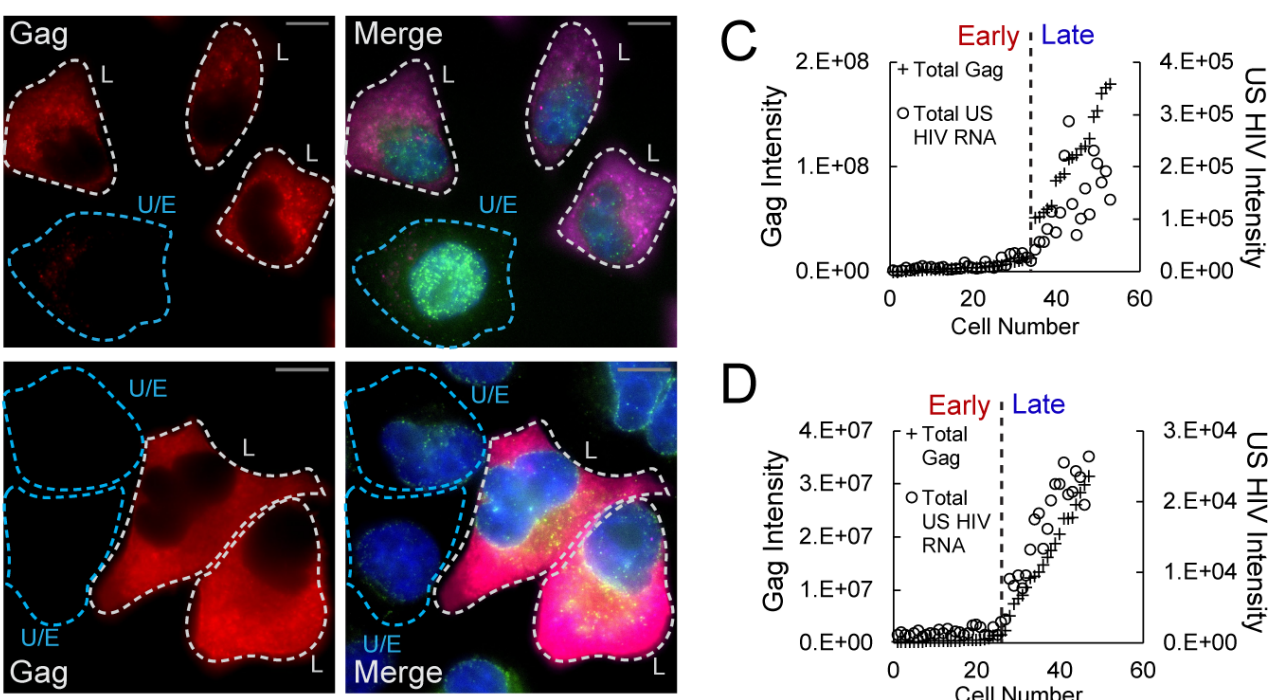

D

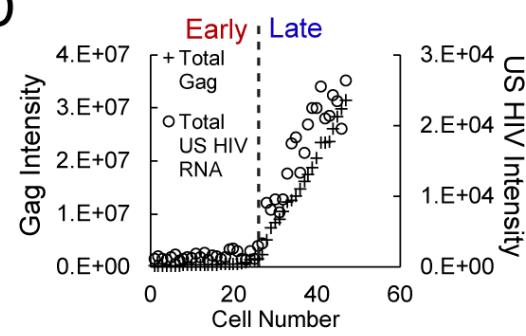

Subcellular Distribution Changes

$\mathrm{L}$

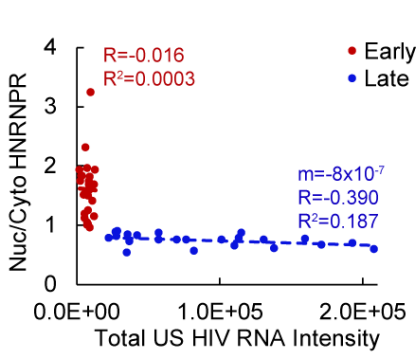

$\mathrm{M}$

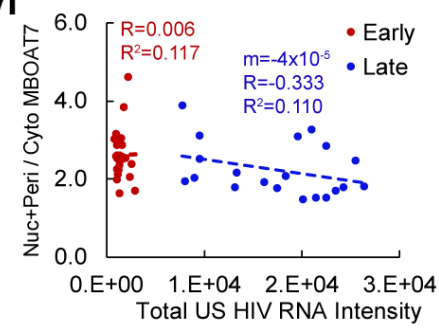

$\mathrm{N}$
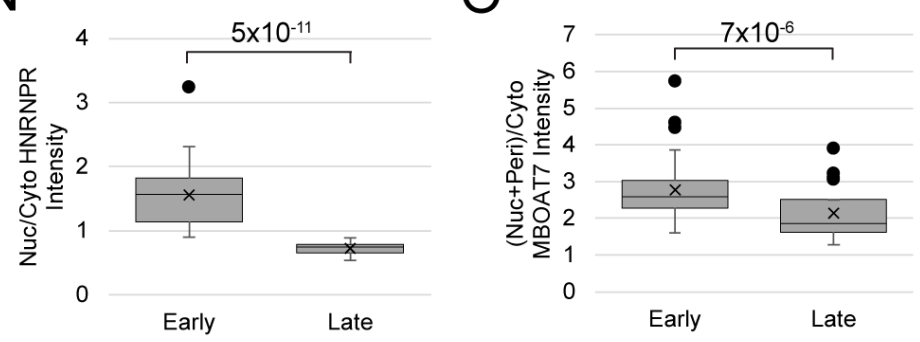

$\mathrm{P}$

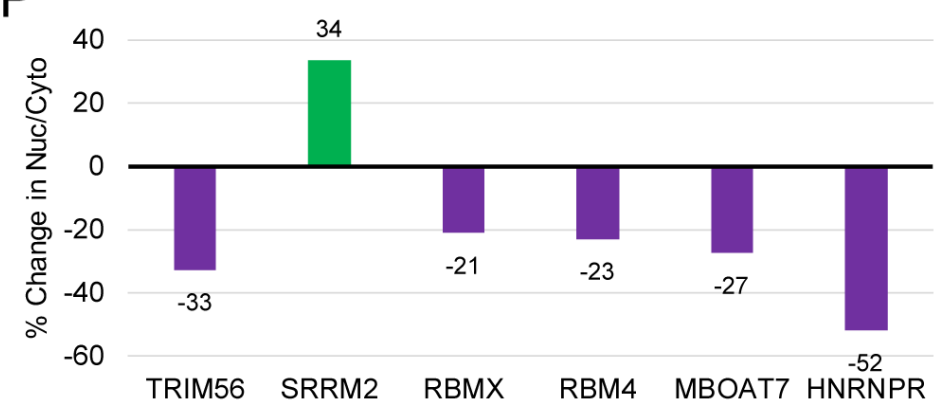


bioRxiv preprint doi: https://doi.org/10.1101/2020.09.15.298190; this version posted September 16, 2020. The copyright holder for this preprint (which was not certified by peer review) is the author/funder, who has granted bioRxiv a license to display the preprint in perpetuity. It is made available under aCC-BY 4.0 International license.

Host protein co-localization with US HIV RNA
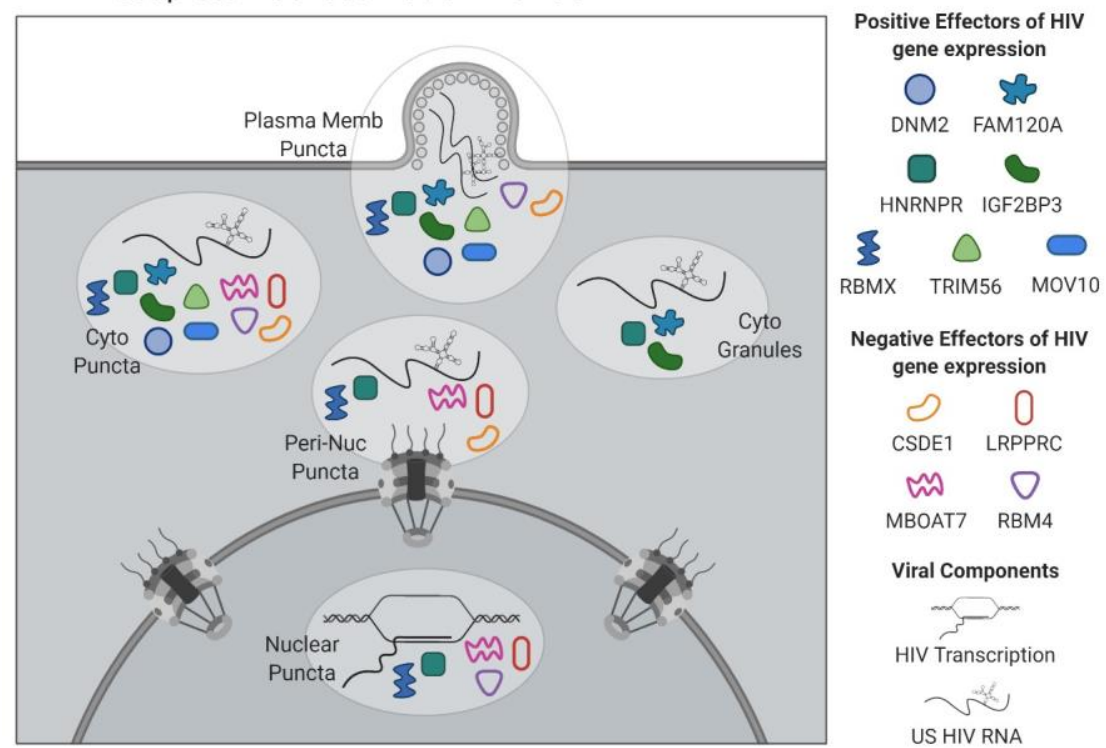

B

Host protein expression and subcellular distribution
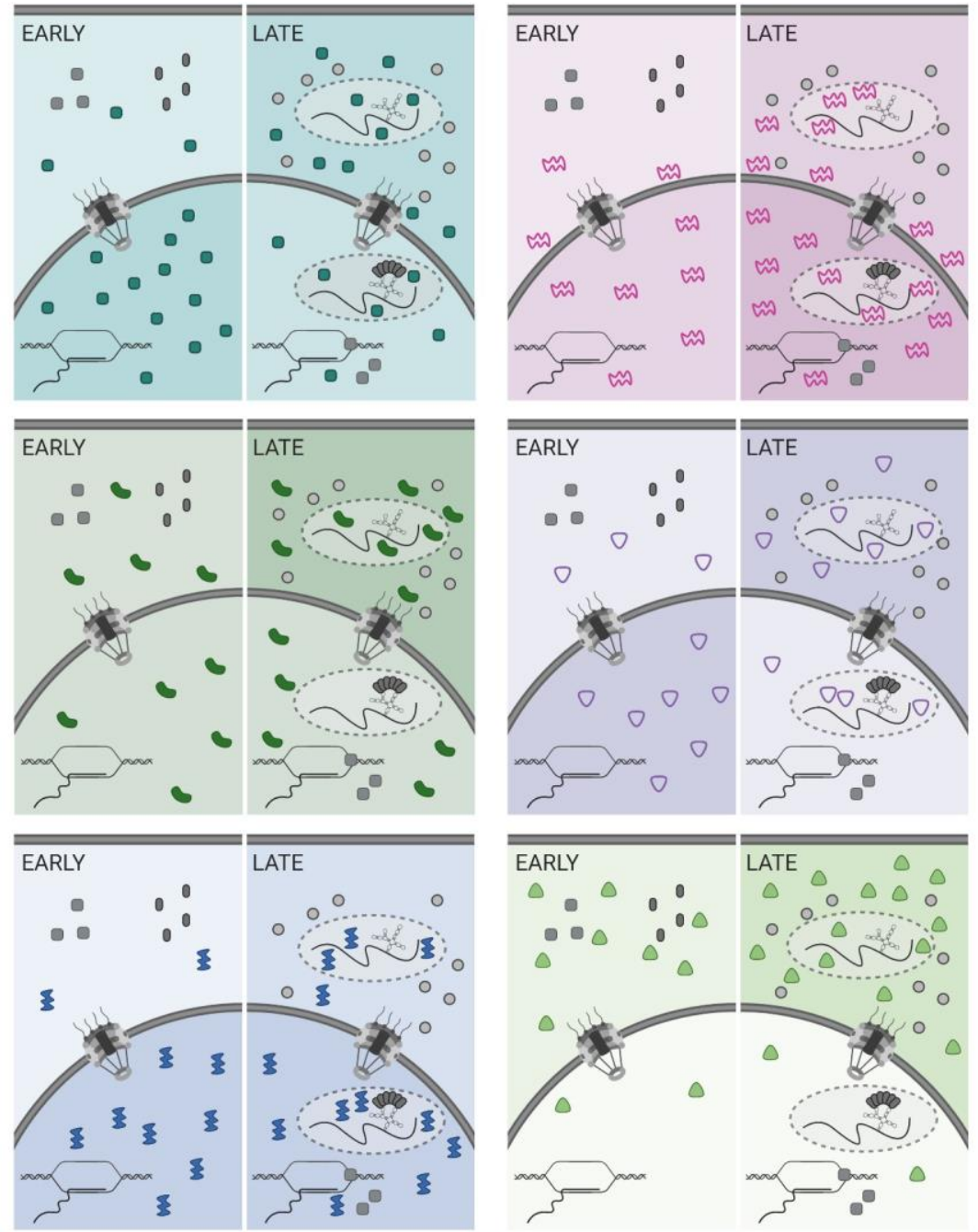

Positive Effectors of HIV gene expression

$\bigcirc_{\text {HNRNPR IGF2BP3 }}$

$\$ 0$

RBMX TRIM56
Negative Effectors of HIV gene expression w MBOAT7 RBM4

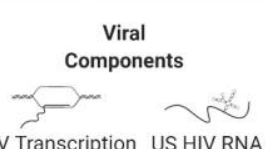

HIV Transcription US HIV RNA 

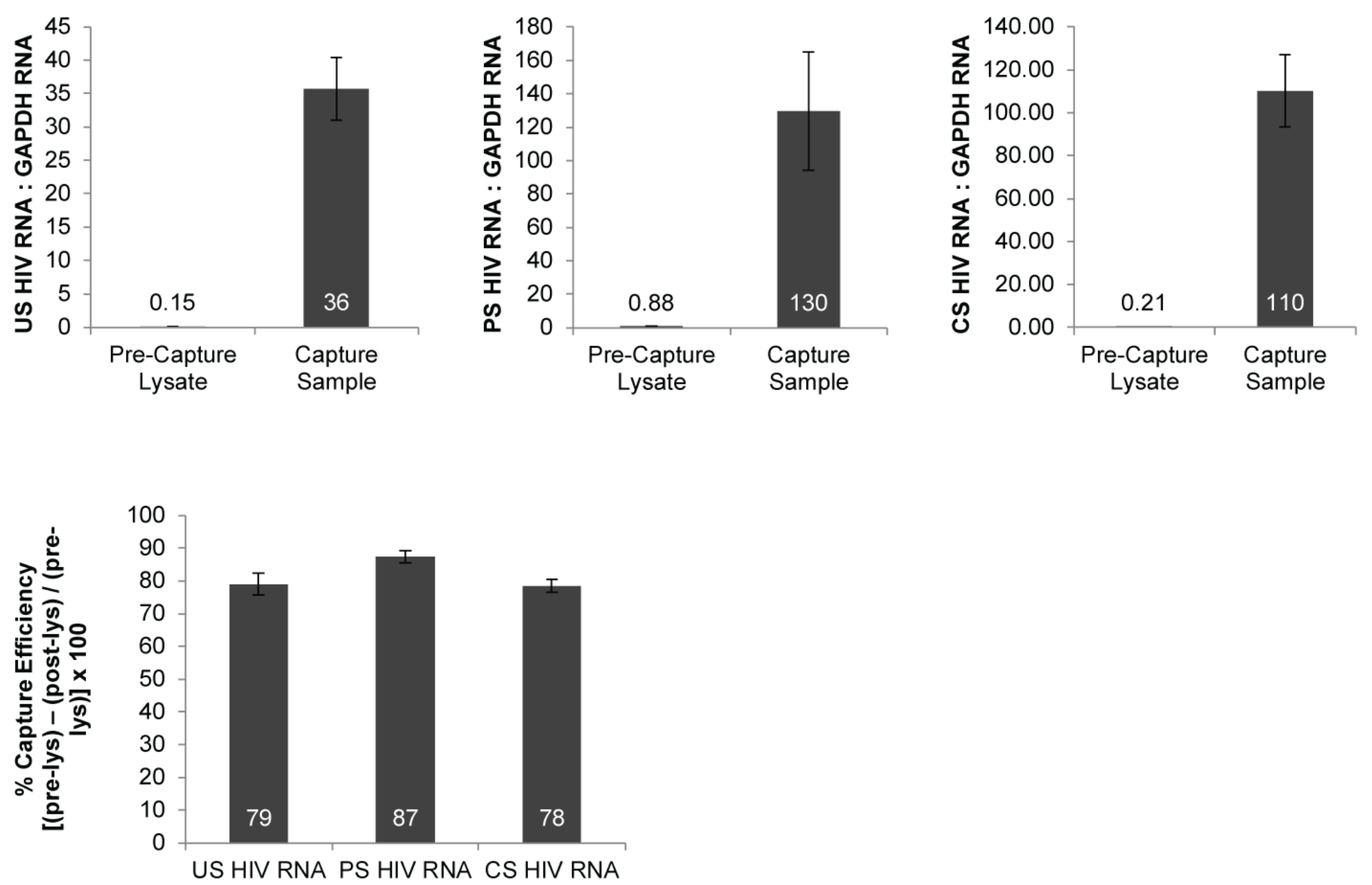
bioRxiv preprint doi: https://doi.org/10.1101/2020.09.15.298190; this version posted September 16, 2020. The copyright holder for this preprint

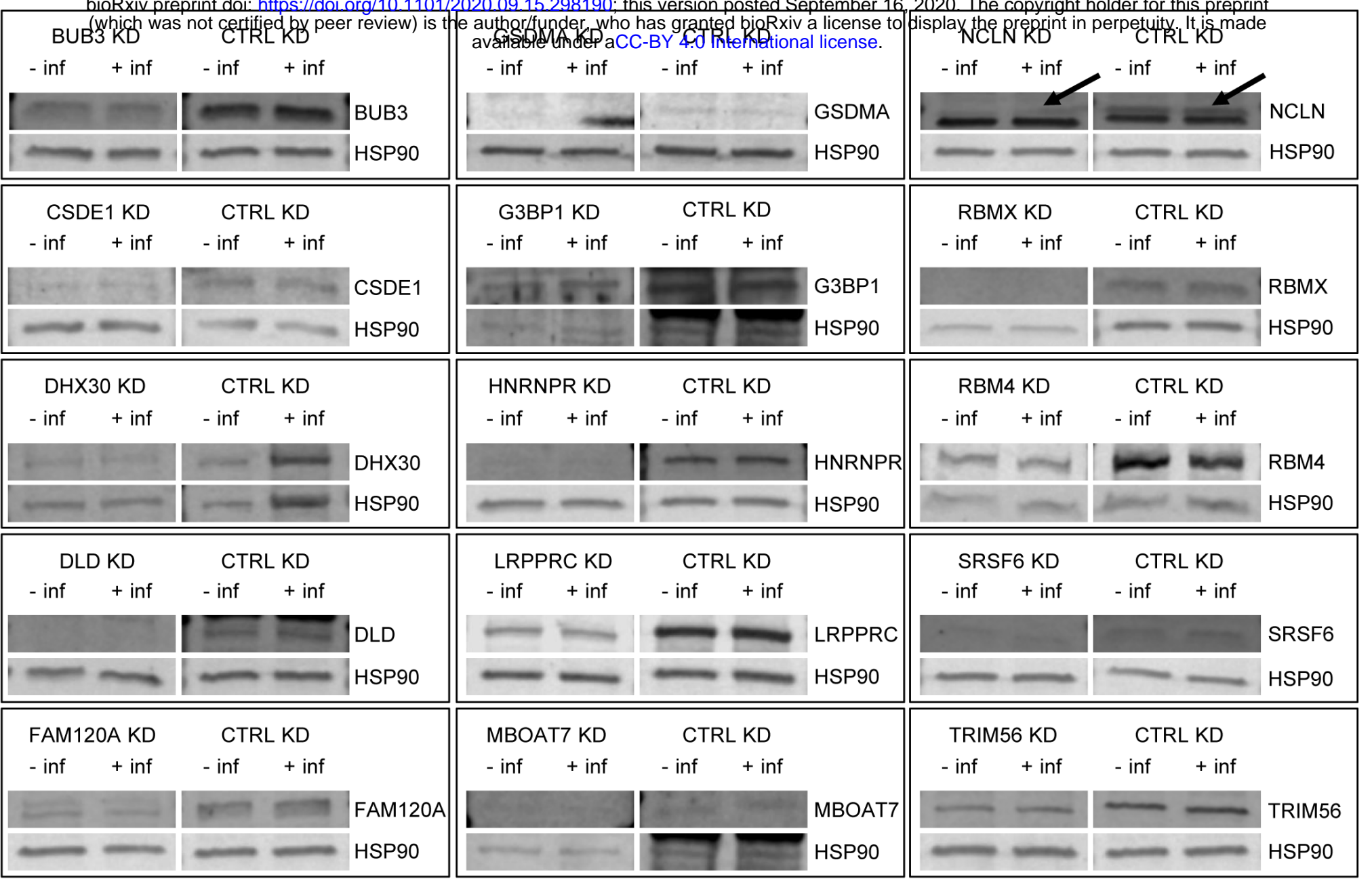




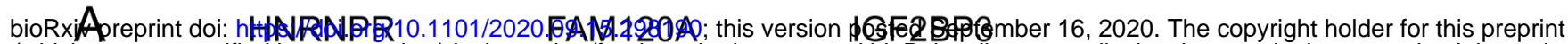
(which was notcertified hy neer review) is the authorffunder who has aranted hioBviva license to display the preprint in perpetuity. It is made
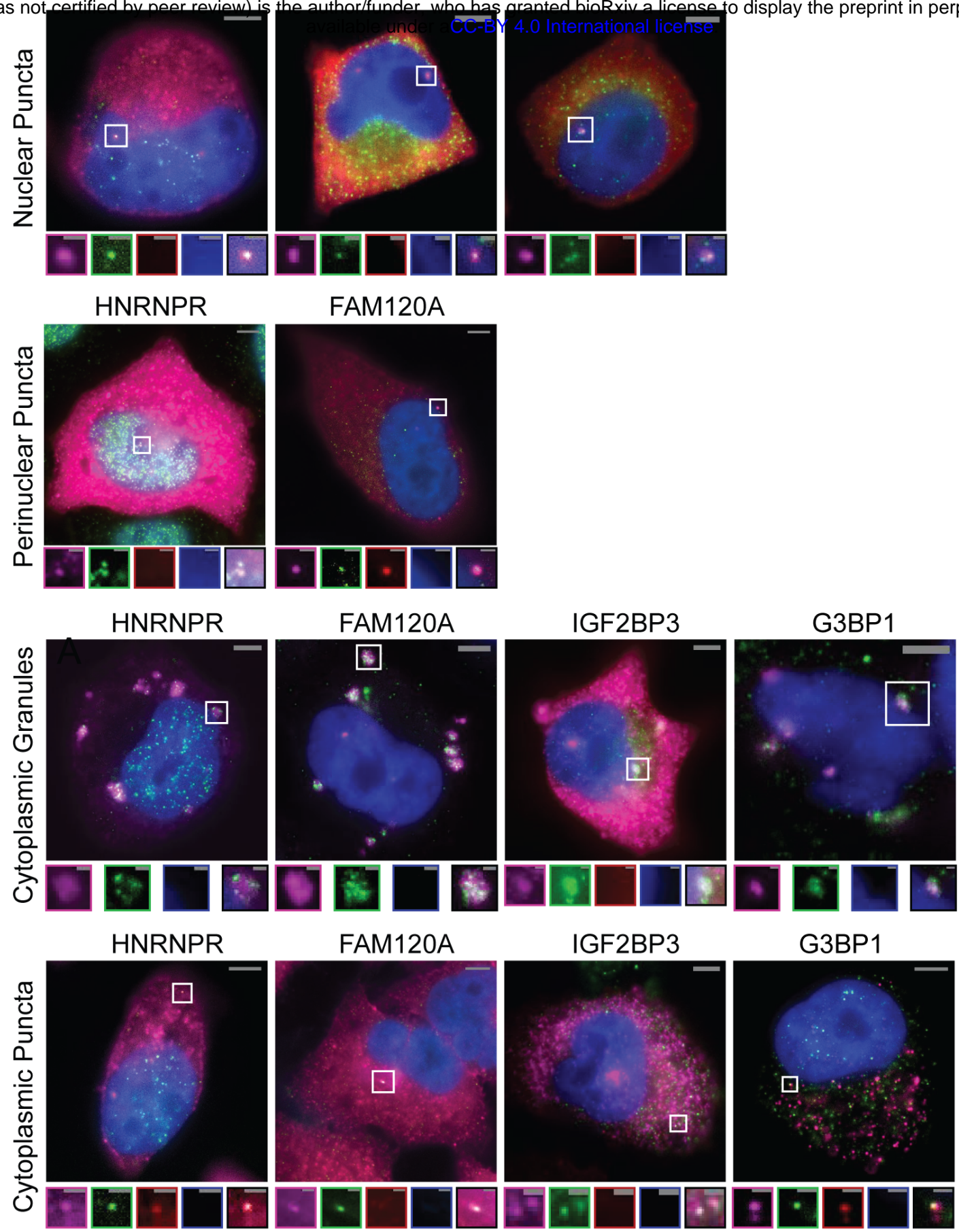

G3BP1

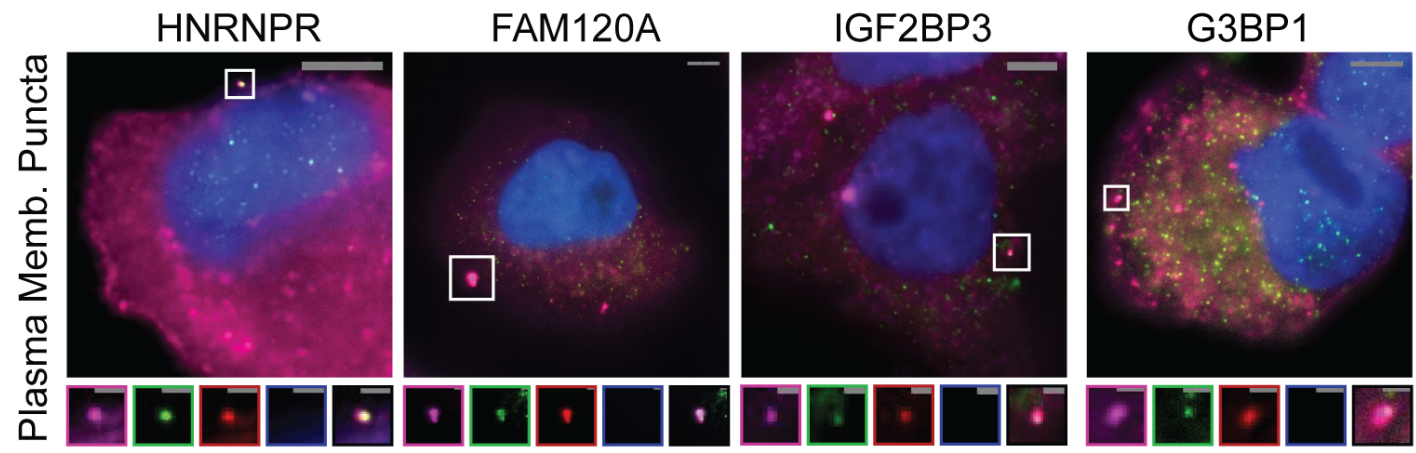

HIV RNA

Host Protein

Gag Protein

DAPI

Merge 


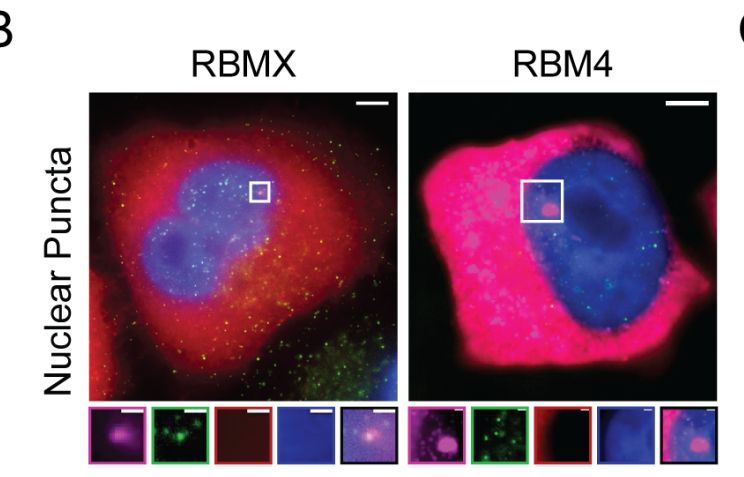

C
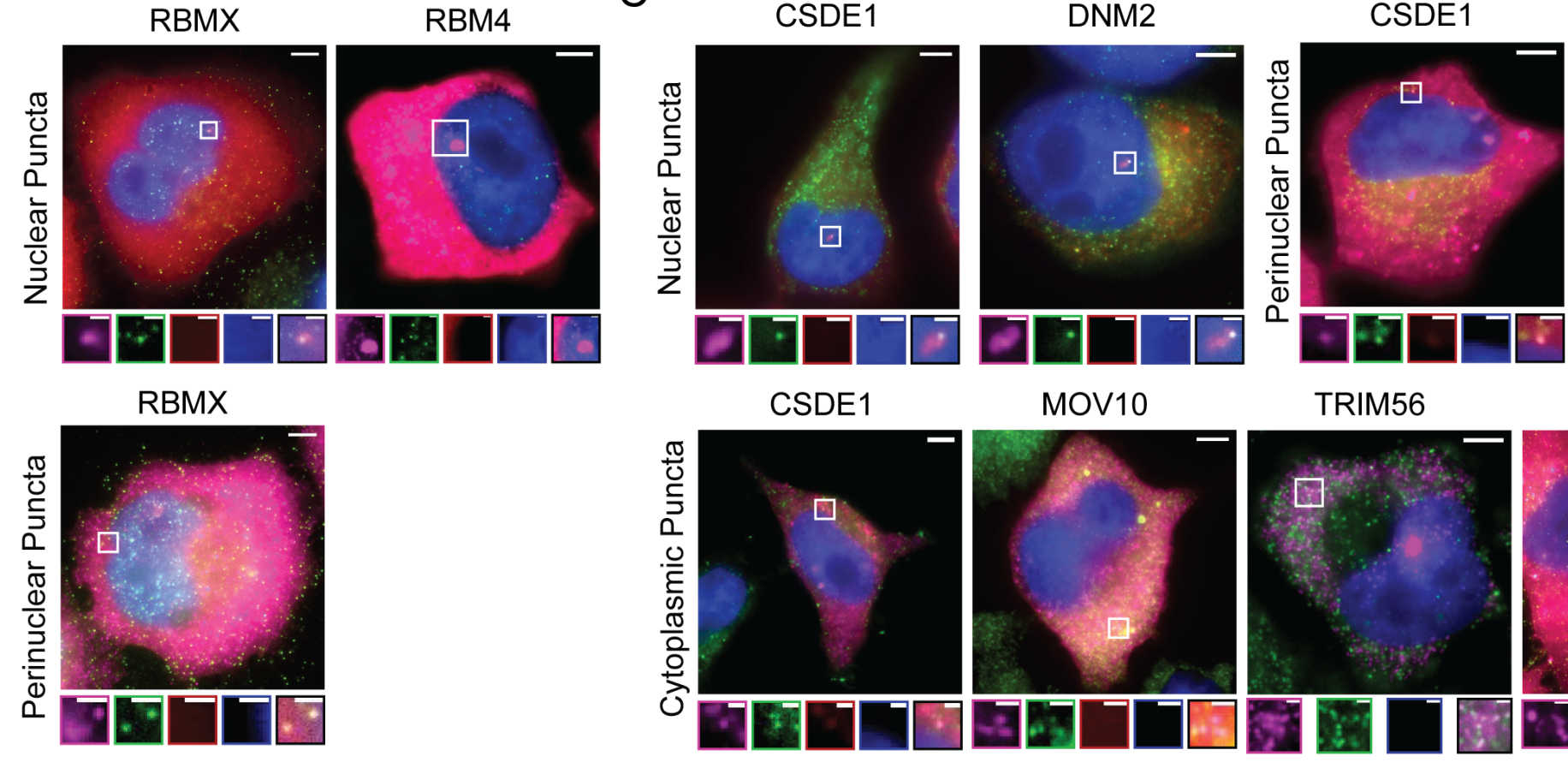

\section{DNM2}
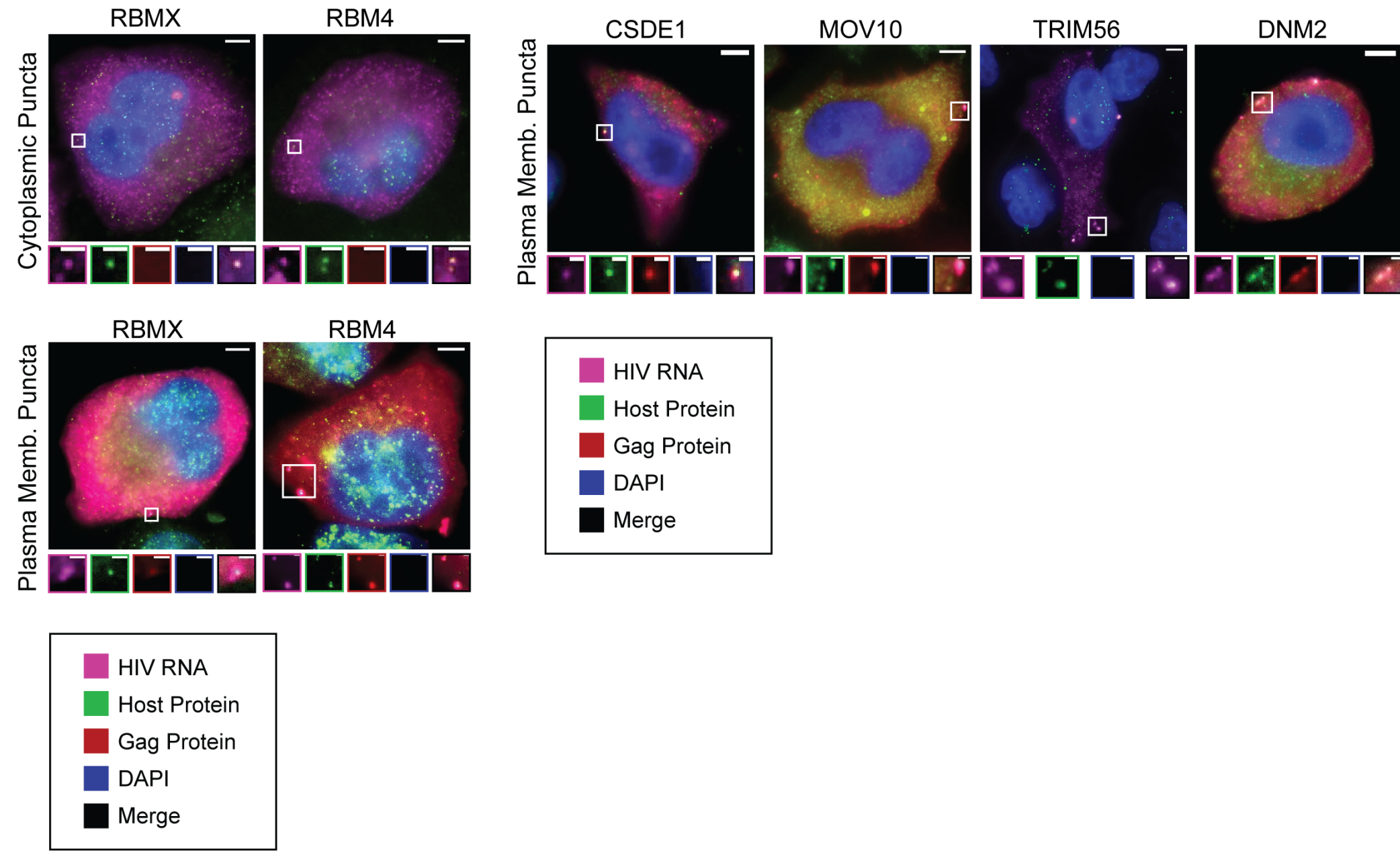


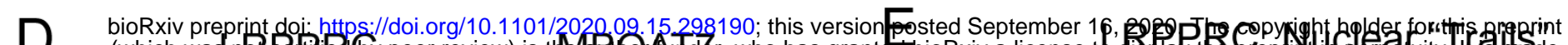

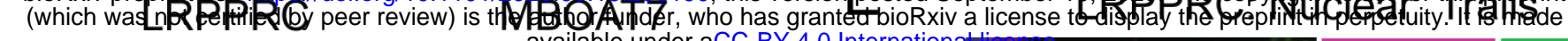
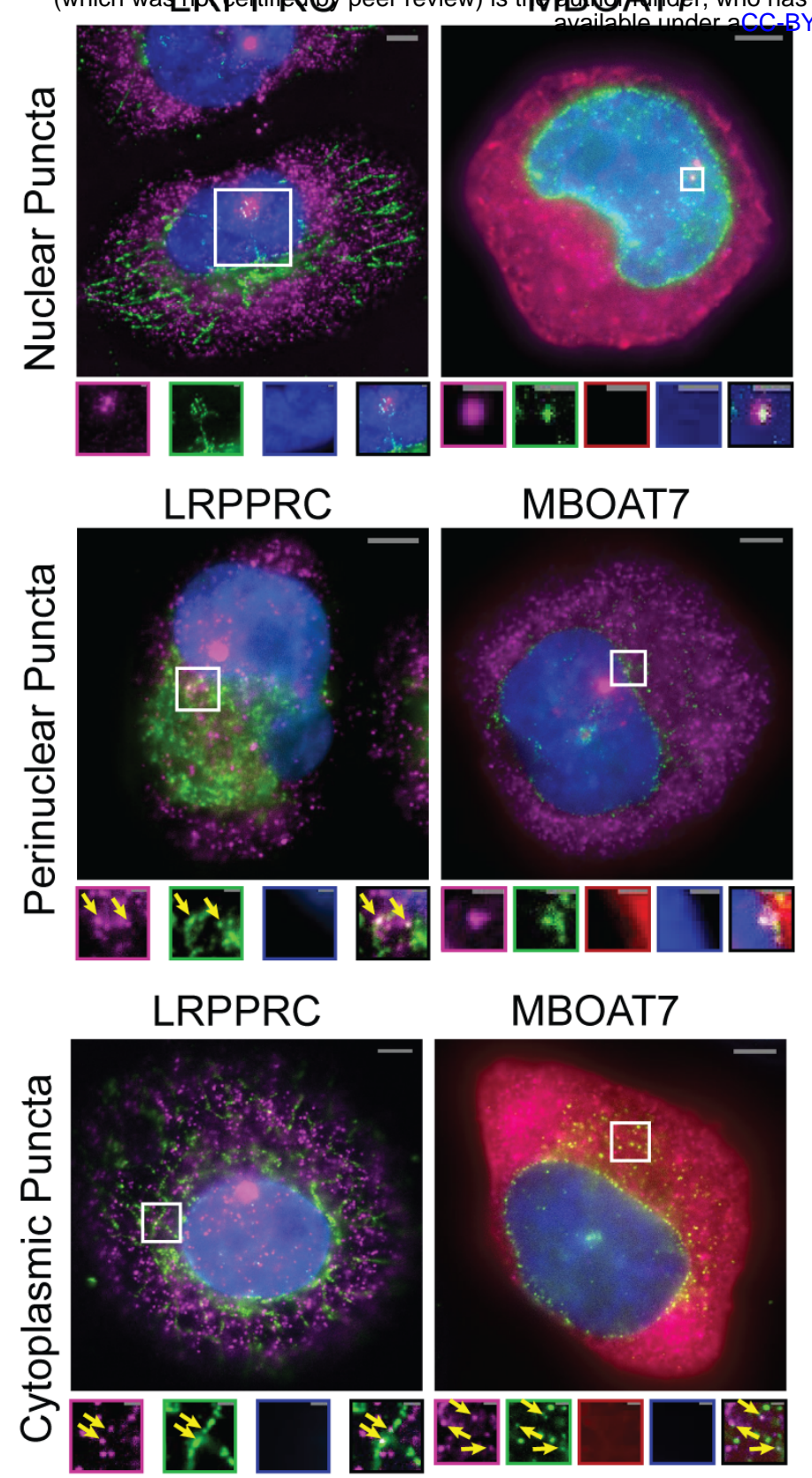

F
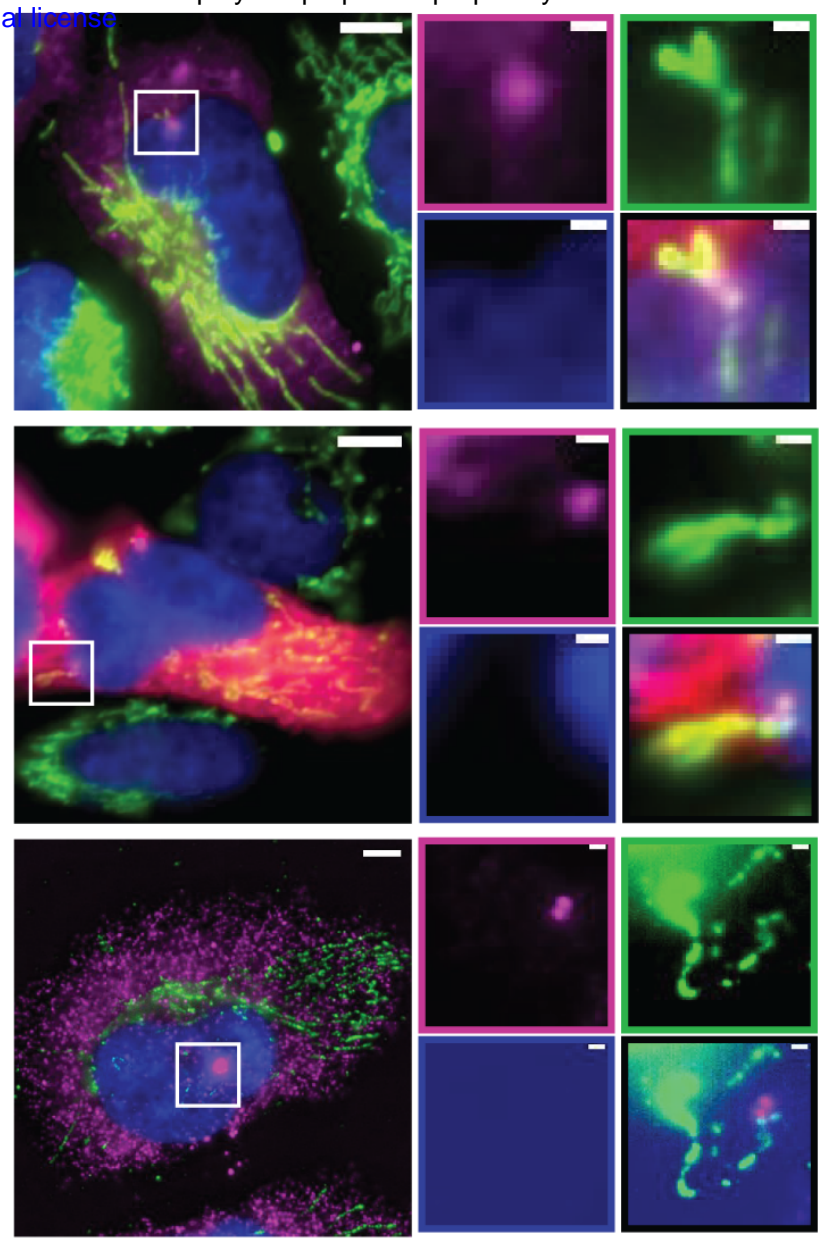

\begin{tabular}{|l|}
\hline HIV RNA \\
Host Protein \\
Gag Protein \\
DAPI \\
Merge
\end{tabular}

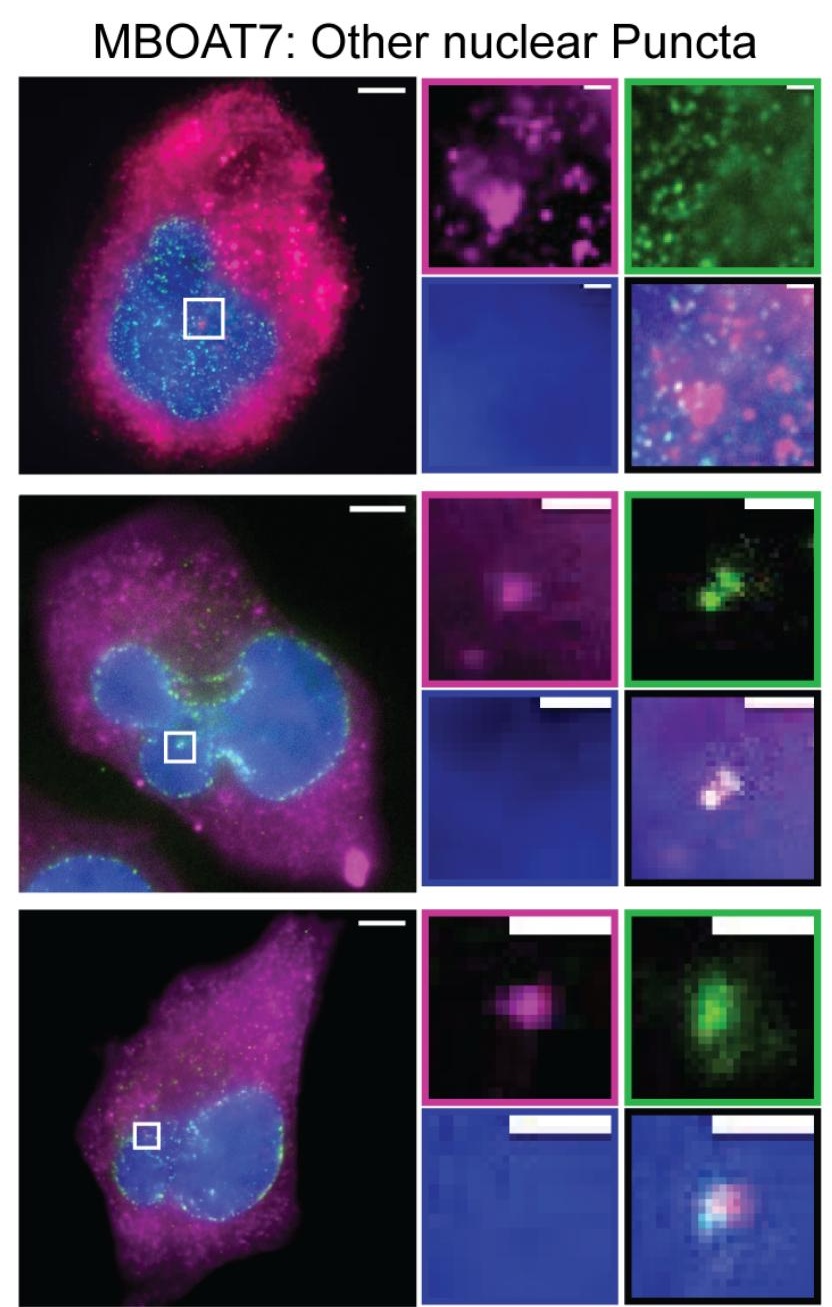




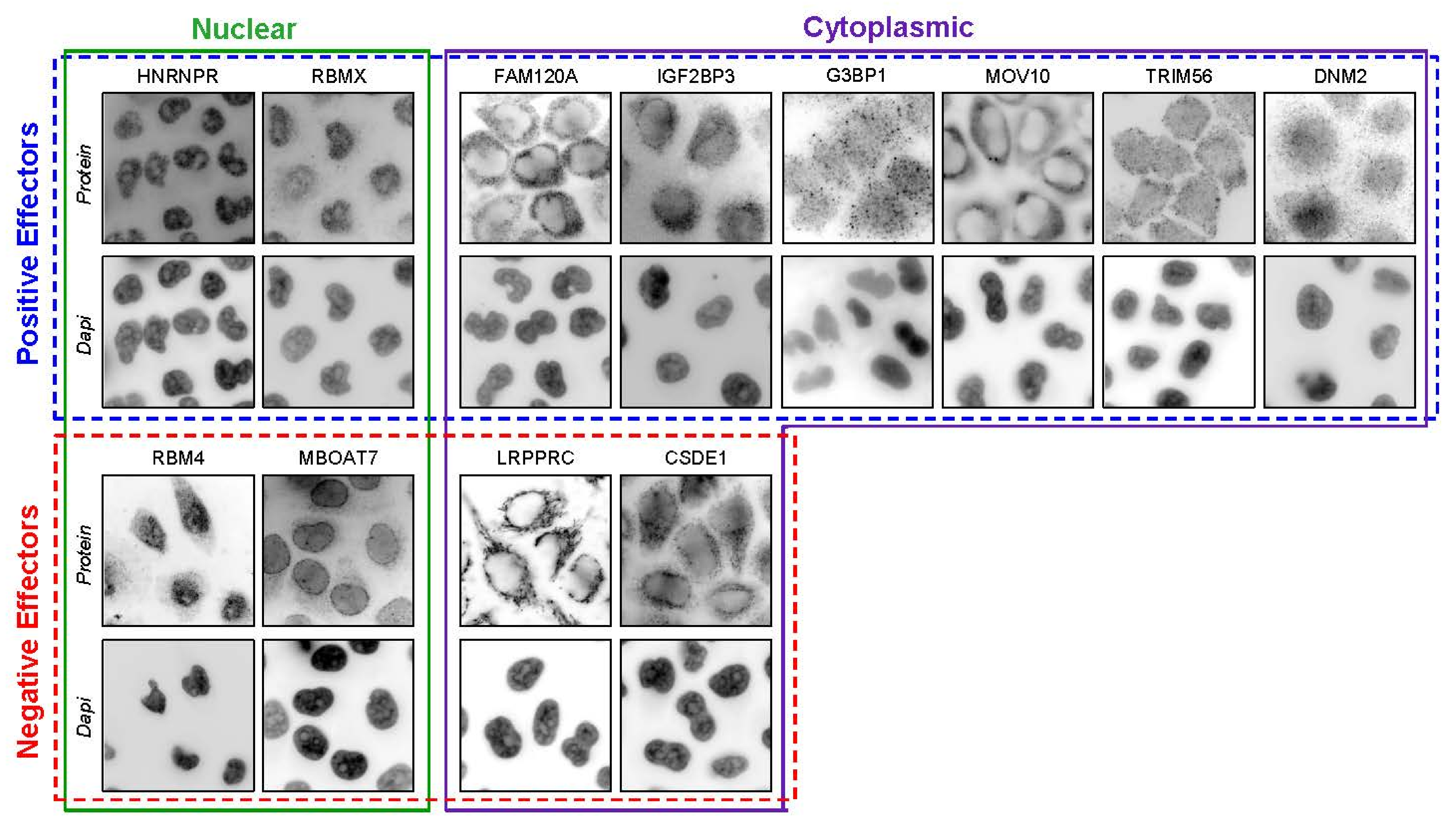



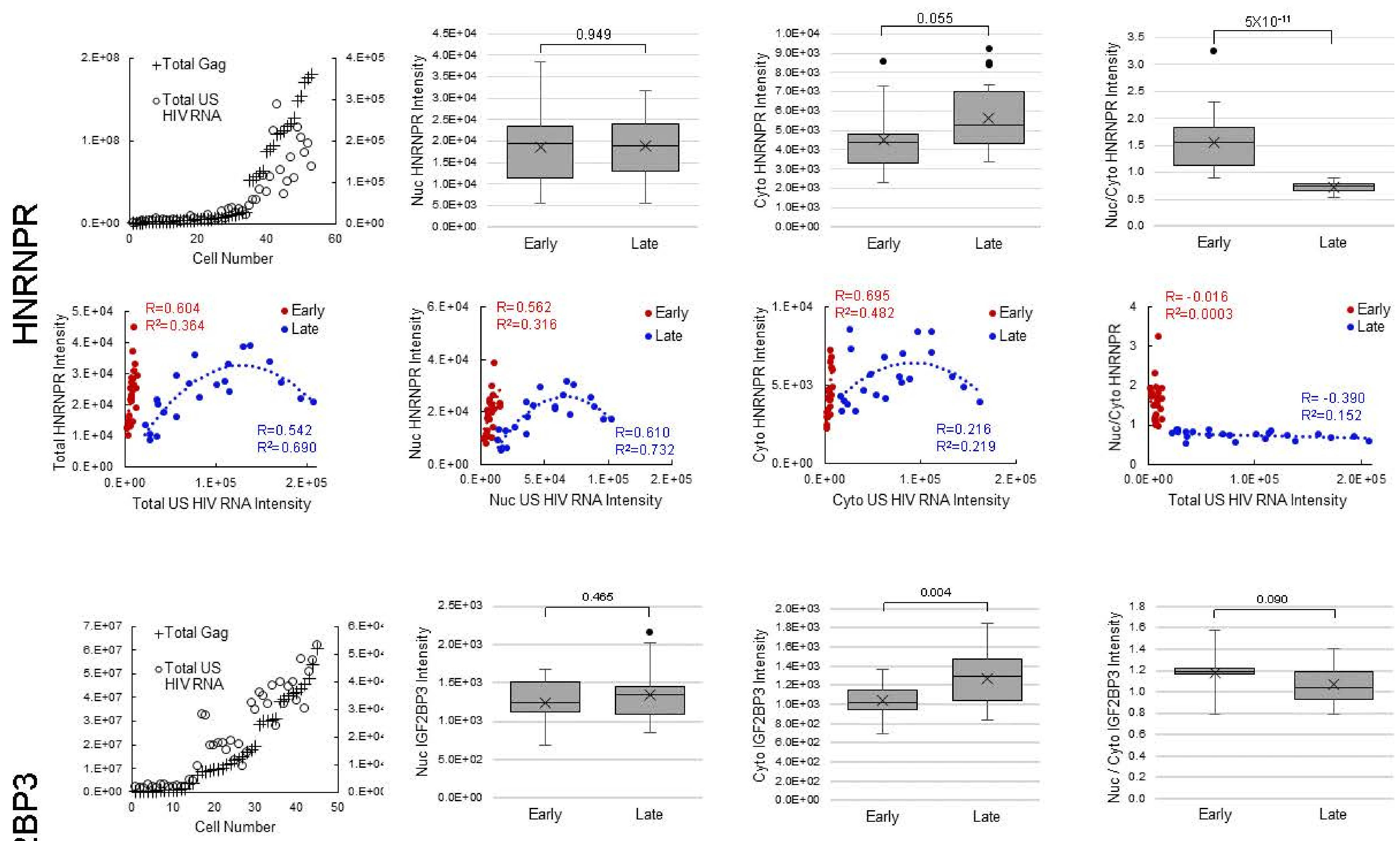

는
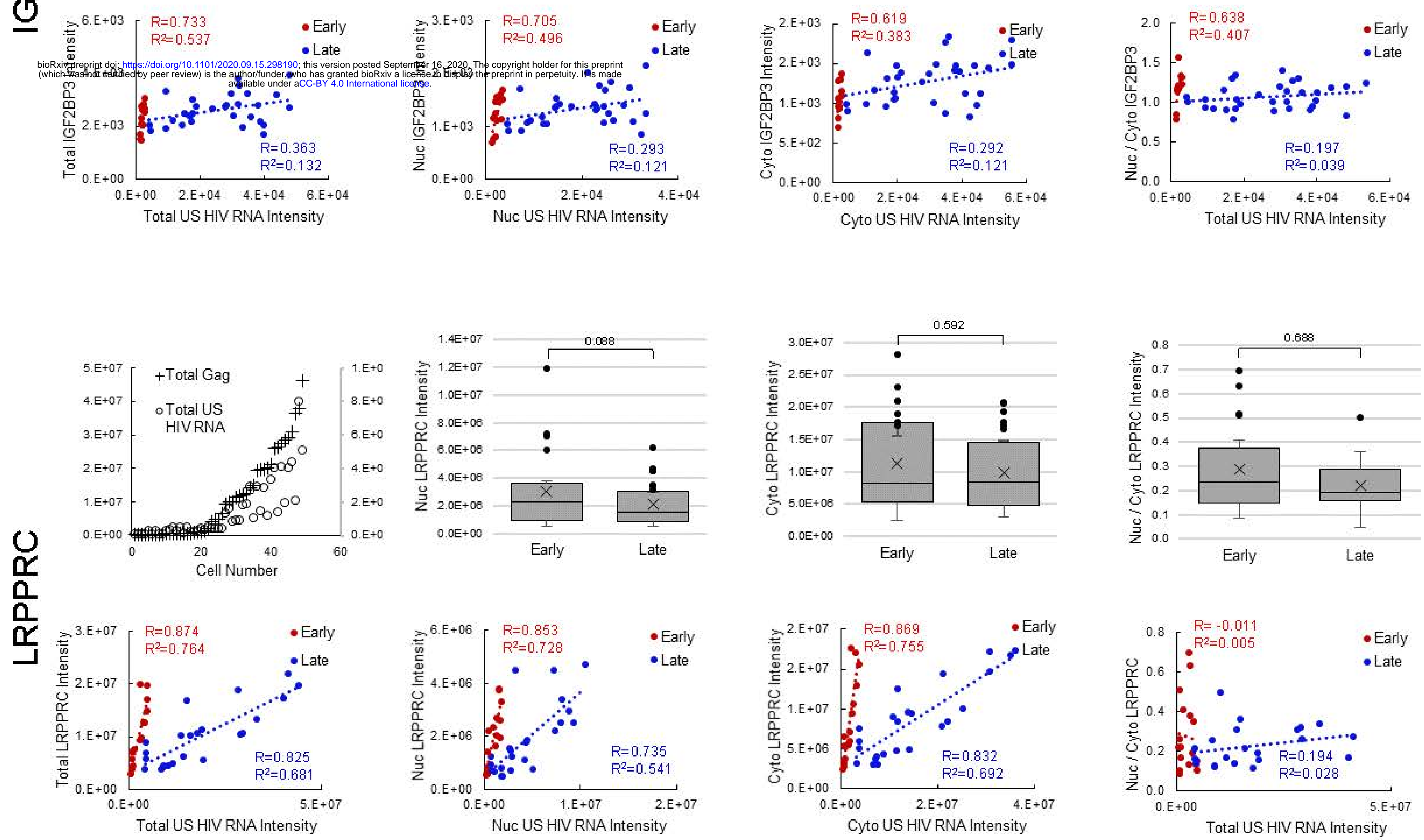

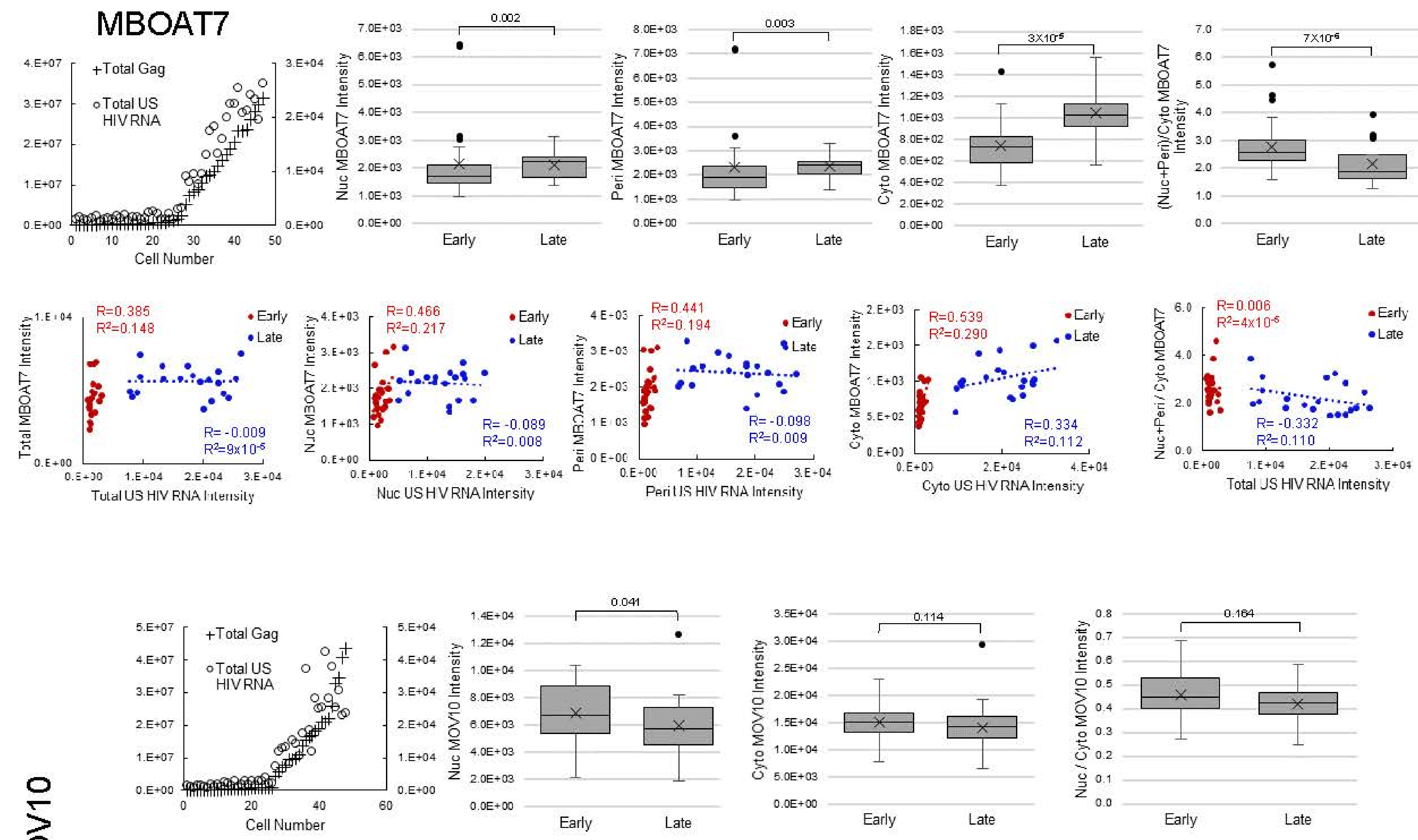

乏
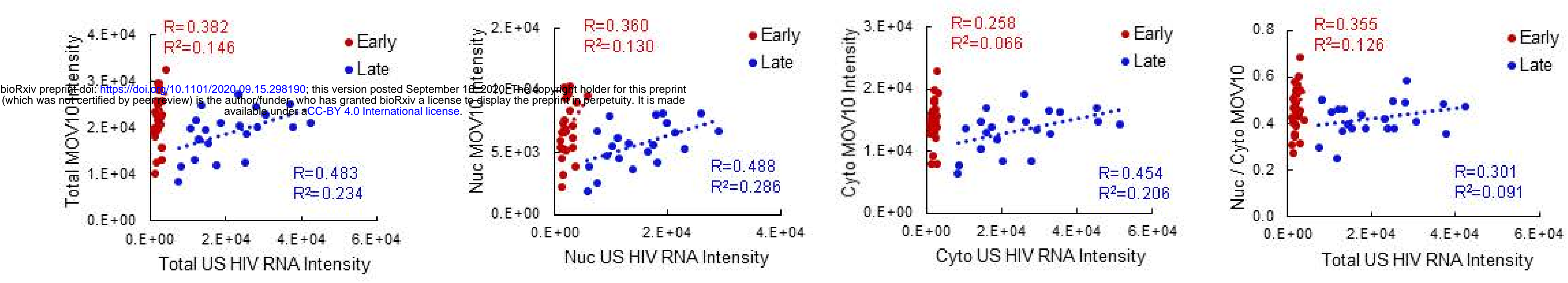

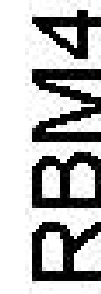
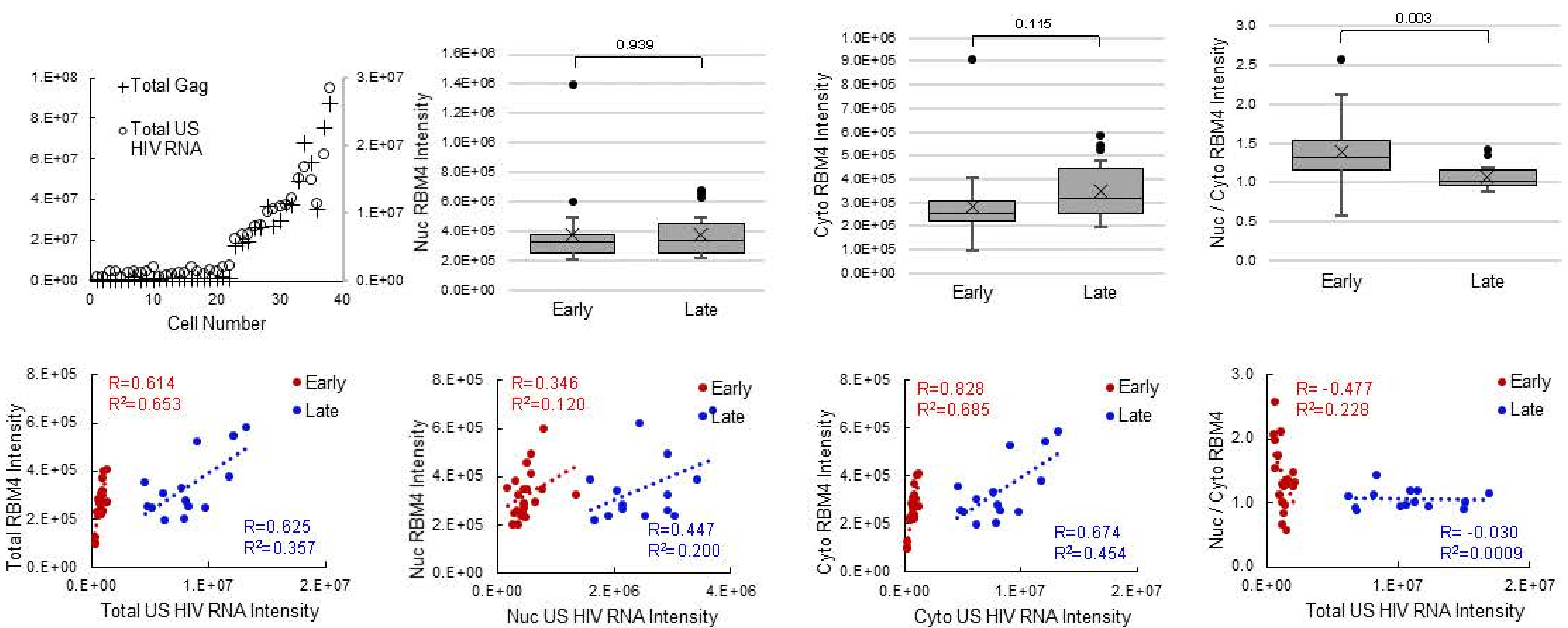

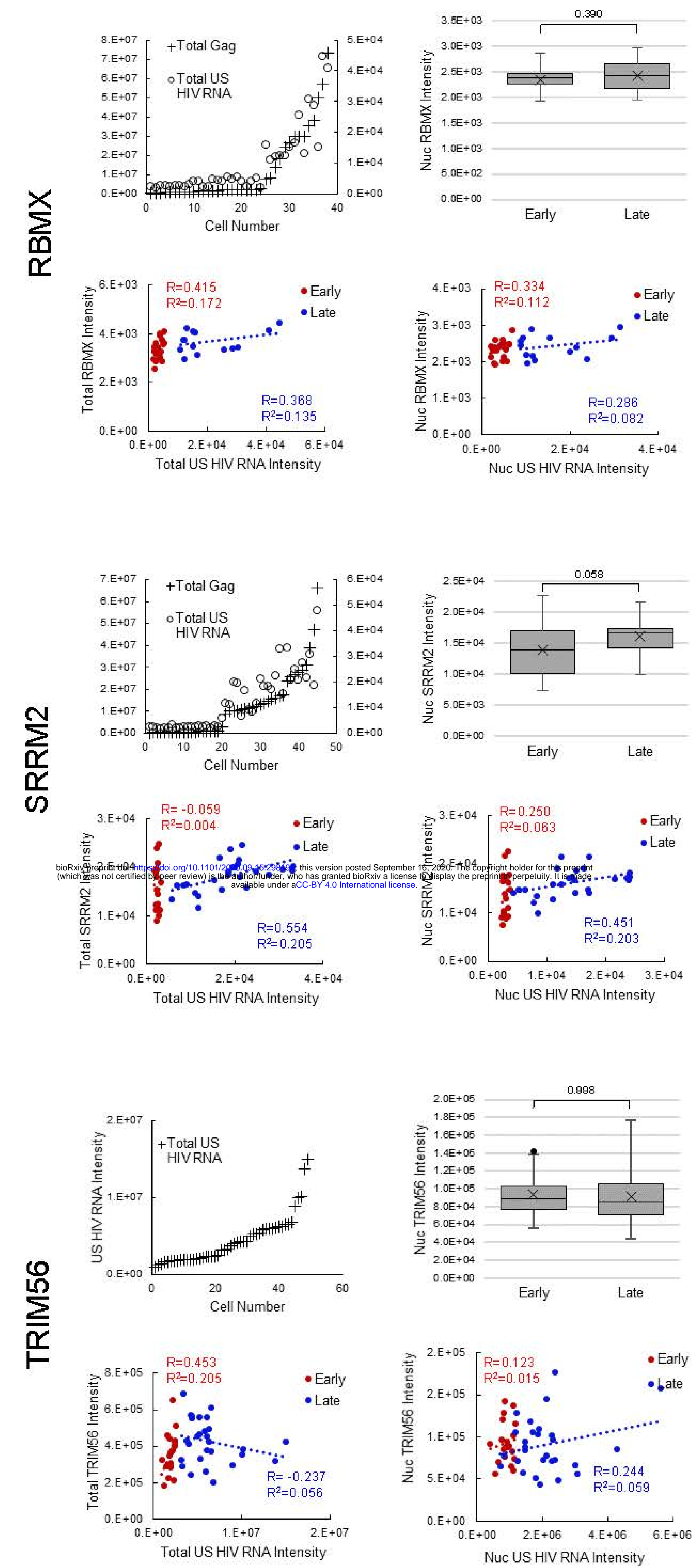
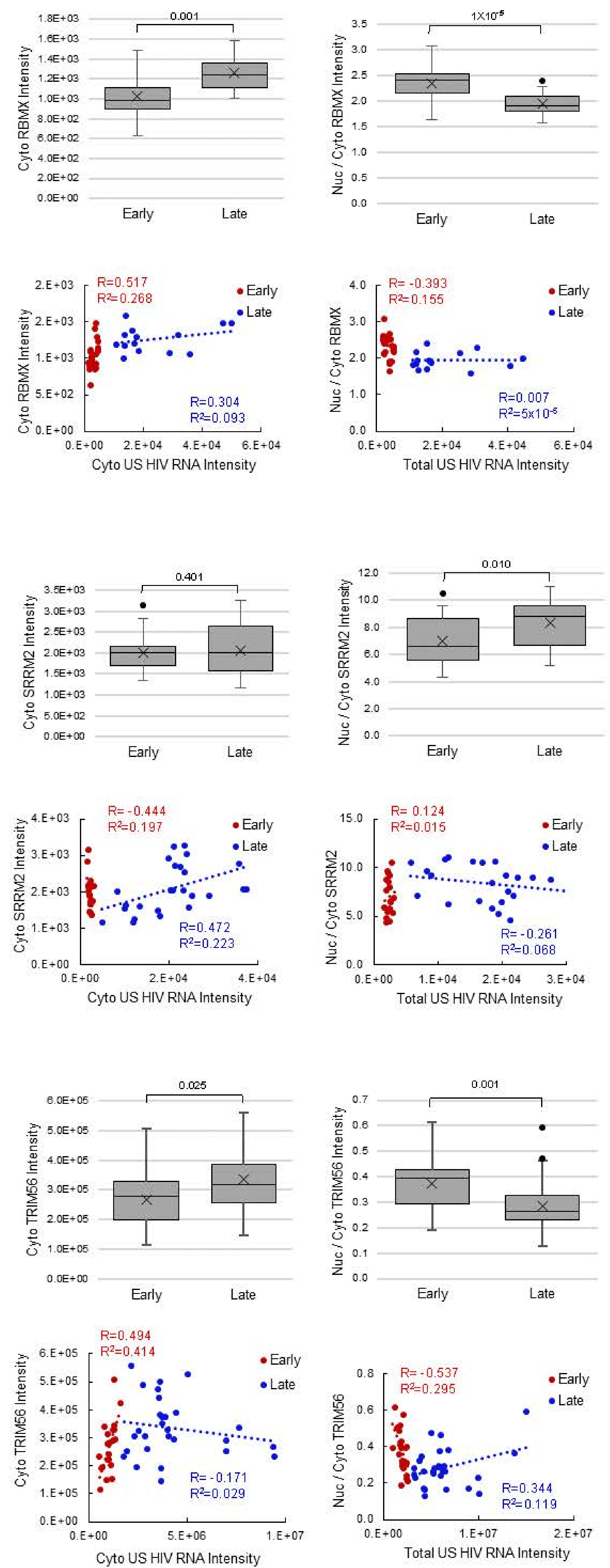


\section{Host Protein and HIV US RNA Expression Correlation; Early Cells}

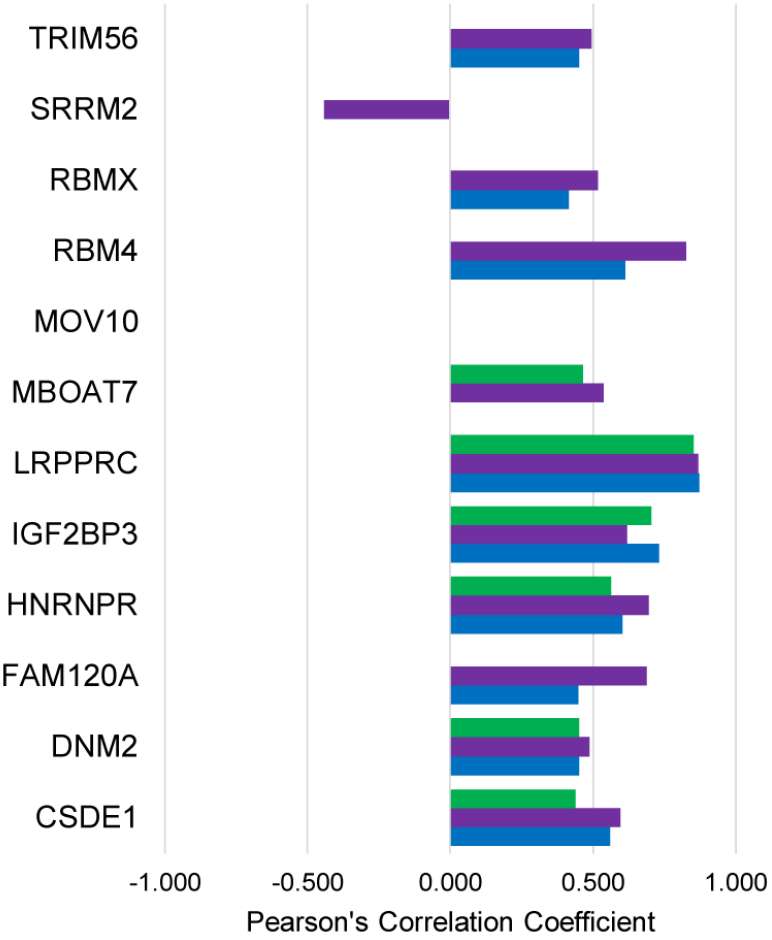

\section{Host Protein and HIV US RNA Expression Correlation; Late Cells}
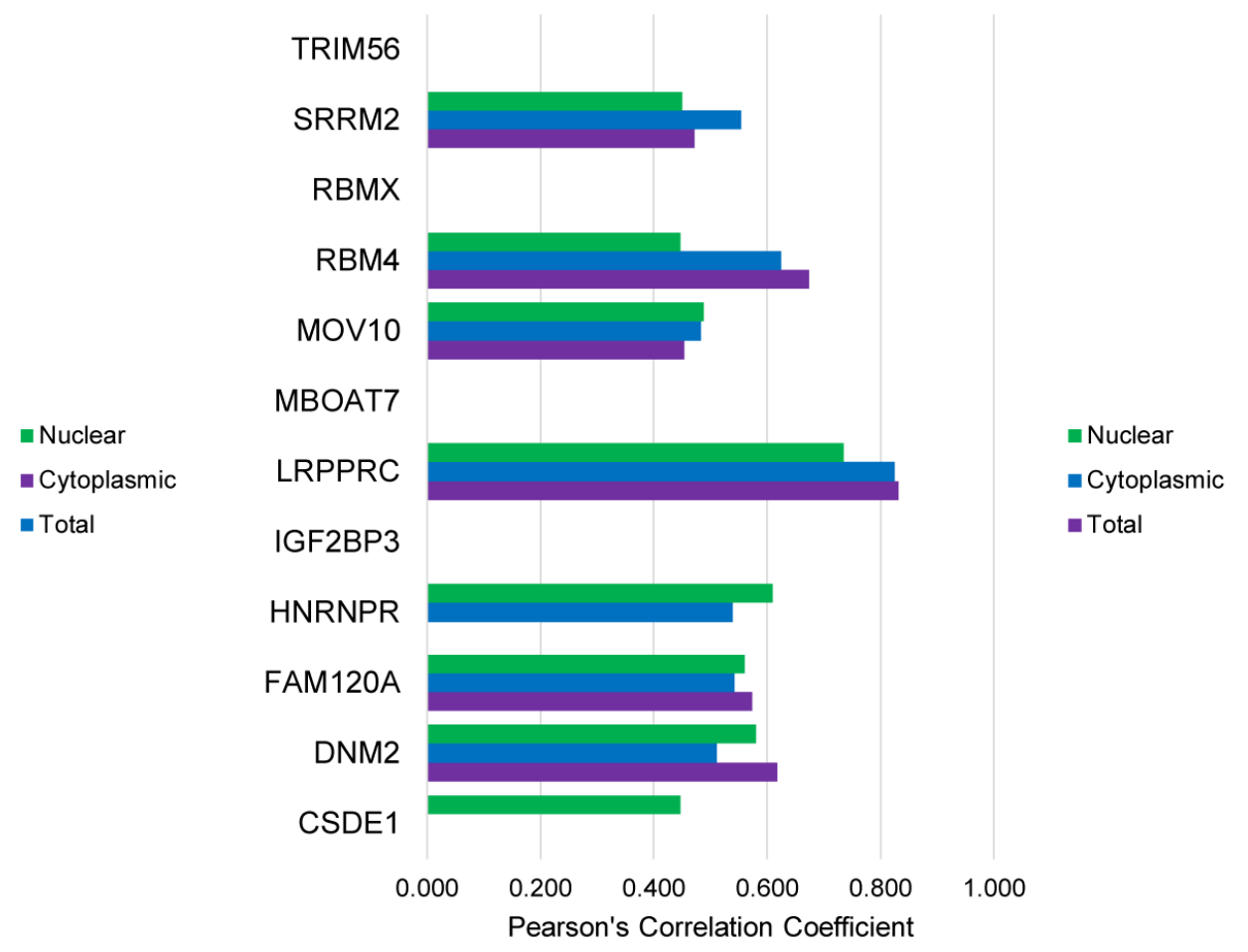

\section{Nuc/Cyto Host Protein and HIV US RNA Expression Correlation}

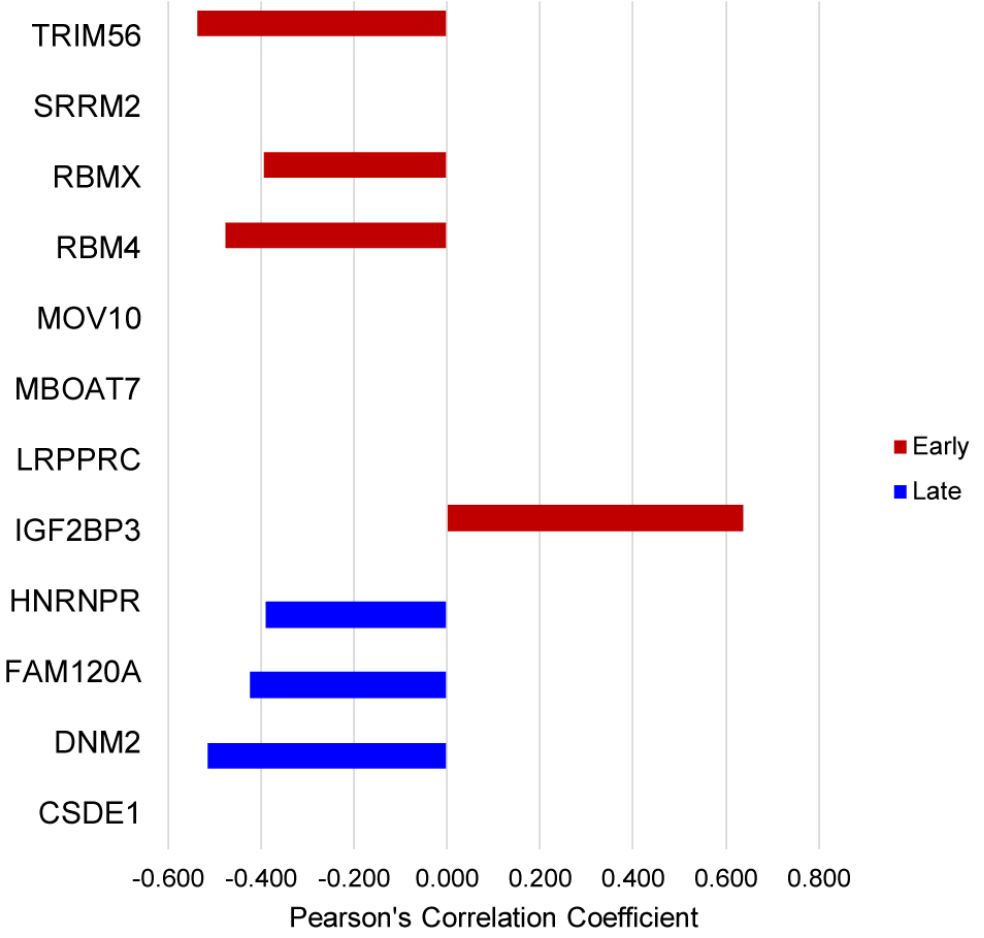




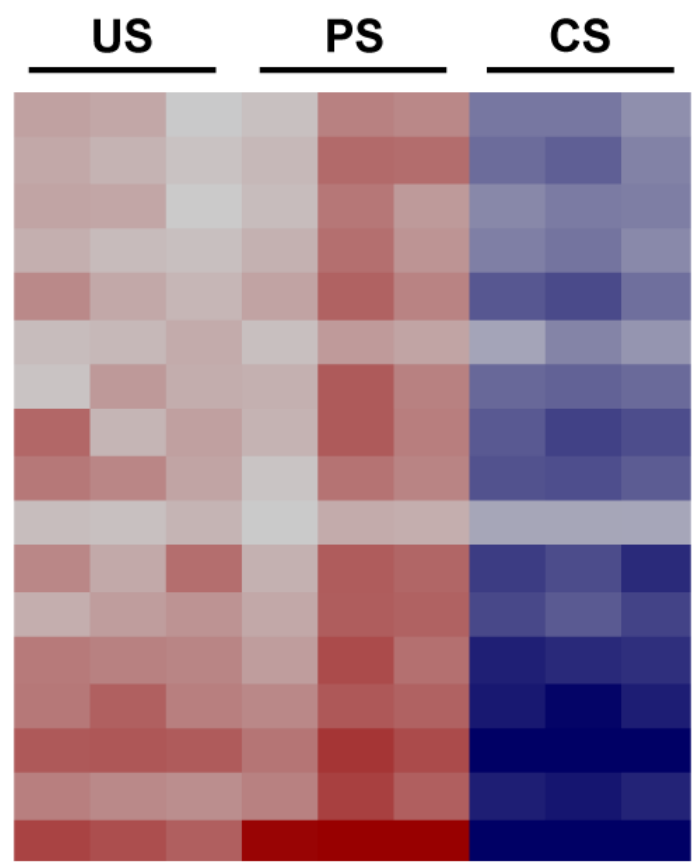

- Splicing Protein

- Stress Granule Protein

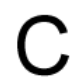

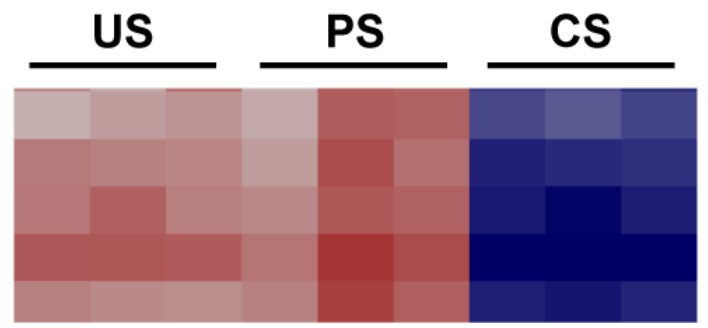

YBX1

IGF2BP1 HNRNPR

FAM120A

IGF2BP3

$\log _{2}$; mean centered

○ ํํㅇํํ요 i 